Rodrigo Braga Pinheiro

Um estudo sobre técnicas de renderização do fenômeno de dispersão atmosférica

Dissertação de Mestrado

Dissertação apresentada como requisito parcial para obtenção do grau de Mestre pelo Programa de Pós-graduação em Informática do Departamento de Informática da PUC-Rio.

Orientador: Prof. Alberto Barbosa Raposo

Rio de Janeiro Março de 2014 
Rodrigo Braga Pinheiro

\section{Um estudo sobre técnicas de renderização do fenômeno de dispersão atmosférica}

Dissertação apresentada como requisito parcial para obtenção do grau de Mestre pelo Programa de Pós-graduação em Informática do Departamento de Informática do Centro Técnico Científico da PUC-Rio. Aprovada pela Comissão Examinadora abaixo assinada.

Prof. Alberto Barbosa Raposo

Orientador

Departamento de Informática - PUC-Rio

Prof. Bruno Feijó Departamento de Informática - PUC-Rio

Prof. Waldemar Celes Filho Departamento de Informática - PUC-Rio

Prof. José Eugênio Leal Coordenador Setorial do Centro Técnico Científico - PUC-Rio 
Todos os direitos reservados. É proibida a reprodução total ou parcial do trabalho sem a autorização da universidade, do autor e do orientador.

Rodrigo Braga Pinheiro

Graduou-se em Engenharia da Computação na Pontifícia Universidade Católica do Rio de Janeiro em 2011.

Ficha Catalográfica

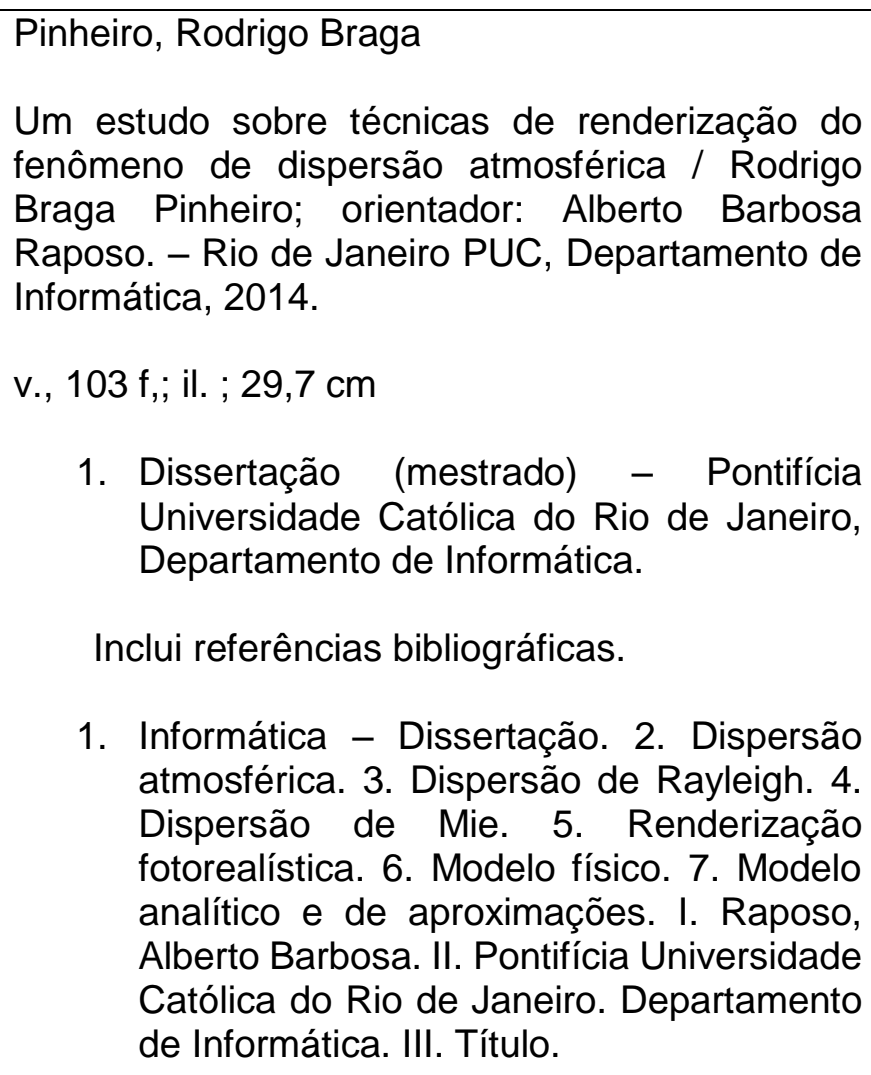

1. Dissertação (mestrado) - Pontifícia Universidade Católica do Rio de Janeiro, Departamento de Informática.

Inclui referências bibliográficas.

1. Informática - Dissertação. 2. Dispersão atmosférica. 3. Dispersão de Rayleigh. 4. Dispersão de Mie. 5. Renderização fotorealística. 6. Modelo físico. 7. Modelo analítico e de aproximações. I. Raposo, Alberto Barbosa. II. Pontifícia Universidade Católica do Rio de Janeiro. Departamento de Informática. III. Título.

CDD: 004 


\section{Agradecimentos}

À Deus e a todos, por terem me dado forças para vencer mais uma etapa da minha vida.

À minha família e meus amigos, por acreditarem, apoiarem as minhas decisões e por estarem comigo em todos os momentos.

À minha namorada, pelo apoio e, principalmente, pela paciência que teve durante todo esse processo.

Ao meu orientador, pelos conselhos e ensinamentos.

À CAPES, pelo financiamento e ajuda com o investimento em minha educação e qualificação. Ao Instituto Tecgraf e a Petrobras, por permitirem a execução desse estudo em um de seus projetos. 


\section{Resumo}

Pinheiro, Rodrigo Braga; Raposo, Alberto Barbosa. Um estudo sobre técnicas de renderização do fenômeno de dispersão atmosférica. Rio de Janeiro, 2014. 103p. Dissertação de Mestrado - Departamento de Informática, Pontifícia Universidade Católica do Rio de Janeiro.

Um dos grandes desafios da computação gráfica é conseguir representar ambientes virtuais que assemelham-se aos ambientes reais observados pelos seres humanos em seu diaa-dia. A fim de alcançar essa representação, diversos estudos foram realizados na área de renderização fotorealística e, principalmente, na que diz respeito à modelagem física e representação de fenômenos naturais. Esse estudo propõe explicar e analisar técnicas que representam o fenômeno de dispersão atmosférica; responsável por definir a cor da atmosfera/céu. Para alcançar esse objetivo, serão apresentadas duas técnicas: uma técnica baseada em um modelo físico e outra baseada em um modelo analítico e de aproximações. Esse estudo apresenta os detalhes de cada uma das técnicas e apresenta um comparativo para auxiliar na escolha da técnica de acordo com a necessidade e os requisitos da aplicação que irá representar o fenômeno de dispersão atmosférica.

\section{Palavras-chave}

Dispersão atmosférica; Dispersão de Rayleigh; Dispersão de Mie; Renderização fotorealística; Modelo físico; Modelo analítico e de aproximações 


\section{Abstract}

Pinheiro, Rodrigo Braga; Raposo, Alberto Barbosa (Advisor). A study about rendering techniques of the atmospheric scattering phenomenon. Rio de Janeiro, 2014. 103p. MSc. Dissertation - Departamento de Informática, Pontifícia Universidade Católica do Rio de Janeiro.

One of the greatest challenges of computer graphics is to represent virtual environments that resemble real environments observed by humans in their day-to-day. In order to achieve this representation, several studies have been conducted in the area of photorealistic rendering, and especially in regards to physical modelling and representation of natural phenomena. This study aims to explain and analyze techniques that represent the phenomenon of atmospheric scattering; responsible for setting the color of atmosphere/sky. To achieve this goal, two techniques are presented: one based on a physical model and the other based on an analytical model and approximations. This study presents the details of each technique and a comparative to help in choosing the technique according to the need and requirements of the application that will represent the phenomenon of atmospheric scattering.

\section{Keywords}

Atmospheric scattering; Rayleigh scattering; Mie scattering; Photorealistic rendering; Physical model; Analytical model and approximations 


\section{Sumário}

1 Introdução $\quad 13$

1.1 Motivação 14

$\begin{array}{lll}1.2 & \text { Proposta } & 15\end{array}$

2 Princípios da dispersão atmosférica $\quad 17$

$\begin{array}{lll}2.1 \text { Óptica } & 17\end{array}$

2.2 Matéria, Radiação e Onda eletromagnética 17

$\begin{array}{lll}2.3 \text { Atmosfera } & 18\end{array}$

2.4 Interações radiação-matéria 20

2.5 Polarização 21

2.6 Dispersão da luz 22

2.7 Regimes atmosféricos $\quad 23$

2.8 Profundidade óptica e Transmitância 26

2.9 Irradiância e Radiância 27

2.10 Dispersão atmosférica $\quad 27$

2.11 Efeitos da dispersão atmosférica 28

$3 \quad$ Trabalhos Relacionados 33

$4 \quad$ Modelo matemático da dispersão atmosférica 38

$\begin{array}{lll}4.1 & \text { Densidade atmosférica } & 38\end{array}$

$\begin{array}{lll}4.2 & \text { Polarização } & 40\end{array}$

4.3 Dispersão da luz 41

$\begin{array}{lll}4.4 & \text { Regimes atmosféricos } & 44\end{array}$

4.5 Profundidade óptica e Transmitância 51

4.6 Irradiância e Radiância 53

$\begin{array}{lll}4.7 & \text { Dispersão atmosférica } & 55\end{array}$

5 Estudo das técnicas $\quad 56$

$\begin{array}{ll}5.1 & \text { Bruneton e Neyret } \\ 5.2 & 58\end{array}$

5.2 Schuler 64

6 Resultados $\quad 76$

6.1 Hardware e tecnologia utilizada 76

6.2 Captura do tempo $\quad 77$

6.3 Principais parâmetros utilizados durante a etapa de desenvolvimento 78

6.4 Técnica: Bruneton e Neyret, dispersão simples e regime atmosférico de Rayleigh $\quad 78$

6.5 Técnica: Bruneton e Neyret "simplificada", dispersão simples e regime atmosférico de Rayleigh 79

6.6 Técnica: Schuler, com dispersão simples e regime atmosférico de Rayleigh 82

6.7 Discussão do resultado 85

7 Conclusão e trabalhos futuros $\quad 91$

$\begin{array}{lll}7.1 \text { Conclusão } & 91\end{array}$ 
7.2 Trabalhos futuros

Referências Bibliográficas

Apêndices 


\section{Lista de figuras}

2.1 A onda se propaga ao longo do eixo horizontal com comprimento de onda lambda (ao centro). O campo elétrico, o campo magnético e o vetor de onda são representados, respectivamente, em azul, vermelho e preto (à direita).

2.2 Espectro de luz

2.3 Composição atmosférica

2.4 Representação da densidade atmosférica

2.5 Interações entre a radiação solar e as matérias que compõem a atmosfera

2.6 Visão frontal e lateral da luz não-polarizada 21

2.7 Visão frontal e lateral da luz polarizada linearmente 21

2.8 Processo de polarização 22

2.9 Etapas que ocorrem durante a colisão entre a luz e a matéria 23

2.10 Adpatação do efeito de emissão para o efeito de dispersão 23

2.11 Resultado da análise dos regimes de dispersão 25

2.12 Profundidade óptica e Transmitância 26

2.13 Irradiância e Radiância $\quad 27$

2.14 Sensibilidade dos cones do olho humano ao comprimento de onda 29

2.15 Cor do céu limpo durante o dia 30

2.16 Cor do céu ao amanhecer/entardecer $\quad 31$

2.17 Cor do céu considerando Rayleigh e Mie 32

2.18 Perspectiva aérea $\quad 32$

3.1 Obras de artes que mostram a percepção do céu 33

3.2 Resultado obtido por Nishita em $1993 \quad 35$

3.3 Infográfico contendo a evolução das técnicas 37

4.1 Visão geral da interação entre os vetores de campo elétrico e o dipolo elétrico oscilante

4.2 Representação da função de fase e da luz dispersada segundo o regime de Rayleigh

4.3 Diferença entre a partícula no regime de Rayleigh (esquerda) e no regime de Mie (direita)

4.4 Dispersão da luz no regime de Mie $\quad 51$

4.5 Transmitância 53

4.6 Radiância na superfície do planeta 53

4.7 Radiância em um ponto qualquer do meio material 54

4.8 Modelo de dispersão simples $\quad 55$

5.1 Aproximação da radiância em uma única dispersão 56

5.2 Radiância em múltiplas dispersões $\quad 57$

5.3 Sistema de coordenadas astronômico 57

5.4 Cosseno do ângulo de zenith 58 
5.5 Esquemático das etapas de renderização proposta por Bruneton e Neyret para dispersão simples considerando apenas o regime de Rayleigh

5.6 Esquemático das etapas de renderização proposta nesse estudo para dispersão simples considerando apenas o regime de Rayleigh

5.7 Limites da altitude e do cosseno do ângulo de incidência do Sol

5.8 Pontos de interseção e menor distância entre o observador e o ponto de interseção

5.9 Cálculo da profundidade óptica 62

5.10 Resultado da transmitância 63

5.11 Resultado da dispersão considerando apenas o regime de Rayleigh 64

5.12 Função de Chapman 66

5.13 Representação gráfica da função de Chapman extraída do livro GPU Pro 3 [37]

5.14 Massa de ar ao longo de um caminho

5.15 Modificação da função de Chapman para tratar o problema de precisão numérica

5.16 Modificação da função de Chapman para tratar caminhos com distâncias aproximadas

5.17 Esquemático das etapas de renderização da proposta de Schuler $\quad 74$

6.1 Consumo de memória em Kilobytes

6.2 Tempo de execução em microsegundos $\quad 79$

6.3 Consumo de memória em Kilobytes 80

6.4 Tempo de execução em microsegundos $\quad 81$

6.5 Atmosfera observada do espaço (mais distante da superfície do planeta)

6.6 Atmosfera observado do espaço (mais próximo da superfície do planeta)

6.7 Ponto de vista (ao entrar/dentro) da atmosfera 81

6.8 Pôr-do-Sol $\quad 82$

6.9 Contorno da atmosfera vista da parte oculta do planeta $\quad 82$

6.10 Tempo de execução em microsegundos 83

6.11 Atmosfera observada do espaço (mais distante da superfície do planeta)

6.12 Atmosfera observado do espaço (mais próximo da superfície do planeta)

6.13 Ponto de vista (ao entrar/dentro) da atmosfera 84

6.14 Pôr-do-Sol $\quad 84$

6.15 Contorno da atmosfera vista da parte oculta do planeta 84

6.16 Consumo de memória (de cada técnica) em Kilobytes 85

6.17 Tempo de pré-processamento (de cada técnica) em microsegundos 86

6.18 Tempo de renderização (de cada técnica) em microsegundos 86

6.19 Atmosfera observada do espaço (mais distante da superfície do planeta)

6.20 Atmosfera observada do espaço (mais distante da superfície do planeta)

6.21 Atmosfera observada do espaço (mais próximo da superfície do planeta) 
Um estudo sobre técnicas de renderização do fenômeno de dispersão atmosférica

6.22 Ponto de vista ao entrar na atmosfera $\quad 88$

6.23 Ponto de vista dentro da atmosfera 88

6.24 Pôr-do-Sol 88

6.25 Pôr-do-Sol $\quad 89$

6.26 Contorno da atmosfera vista da parte oculta do planeta $\quad 89$ 


\section{Introdução}

Um dos grandes desafios da computação gráfica é conseguir representar ambientes virtuais que assemelham-se aos ambientes reais observados pelos seres humanos em seu dia-a-dia. A fim de conseguir alcançar essa representação, diversos estudos foram realizados na área de renderização fotorealística e, principalmente, na que diz respeito à modelagem física e a representação de fenômenos naturais.

Os fenômenos físicos-naturais são observados de diversas formas e em diversas situações, como por exemplo: a gravidade, o movimento das ondas em alto-mar e próximas do litoral, a forma de erosão de acordo com o tipo de solo, etc. Neste estudo, estamos interessados na representação do fenômeno de dispersão atmosférica.

O fenômeno de dispersão atmosférica é responsável por determinar a "cor da atmosfera". A atmosfera, no caso da Terra, é composta por diversas camadas de gases que são retidas devido à força gravitacional do planeta. Em algumas dessas camadas são encontradas moléculas de gases $\left(\mathrm{N}_{2}, \mathrm{O}_{2}\right.$, $\mathrm{CO}_{2}$, etc), partículas de aerosol (poeira, poluição, cristais de gelo, etc) entre outras diversas partículas. Logo, quando um feixe de luz penetra a atmosfera é intuitivo pensar que ocorrerão interações entre os feixes e as partículas suspensas na atmosfera. Essas interações irão alterar a direção desses feixes de luz e, consequentemente, a percepção da cor da atmosfera e da luz que a atravessa.

Neste estudo serão apresentadas duas técnicas diferentes para representar o fenômeno de dispersão atmosférica. Ambas as técnicas são baseadas em GPU ${ }^{1}$; no entanto, uma delas é baseada em um modelo físico (mais custoso, porém mais realístico) enquanto a outra é baseada em um modelo analítico e de aproximações matemáticas (menos custoso, porém menos realístico).

No segundo capítulo desta dissertação são apresentados os princípios físicos envolvidos na representação do fenômeno de dispersão. No terceiro capítulo são apresentados os trabalhos relacionados a esse tema. No quarto capítulo são apresentadas as equações matemáticas que definem os princípios físicos da dispersão atmosférica. No quinto capítulo são estudadas as duas técnicas de renderização do fenômeno de dispersão. No sexto capítulo são

${ }^{1}$ Graphics Processing Unit 
apresentados os resultados obtidos nesse estudo. No sétimo capítulo são apresentadas as conclusões e os trabalhos futuros.

Os capítulos desta dissertação foram dispostos com o propósito de manter a leitura e a apresentação dos conceitos de forma incremental objetivando uma das principais contribuições desta dissertação que é dar ao leitor uma referência compacta e complementar aos artigos que tratam sobre a renderização do fenômeno de dispersão atmosférica. Nesta dissertação são agrupados os principais conceitos relativos ao tema que, originalmente, estão fragmentados em diversos outros artigos. A dissertação também apresenta outras contribuições como, por exemplo, a influência dos regimes atmosféricos no cálculo e na qualidade da renderização além de fornecer um comparativo entre duas técnicas de renderização diferentes possibilitado que o leitor conclua qual linha de desenvolvimento é mais apropriada para sua aplicação.

\section{1}

\section{Motivação}

Uma das grandes áreas de pesquisa envolvendo a computação gráfica é a área de realidade virtual. O principal objetivo da realidade virtual é desenvolver ambientes 3D e imersivos onde os usuários consigam reviver, dentro do ambiente virtual, as experiências que eles estão acostumados a viver no seu dia-a-dia. No entanto, para que essa experiência ocorra, é necessário induzir diversos estímulos e possibilitar a percepção do espaço virtual no qual o usuário está inserido a fim de enganar o cérebro humano fazendo-o acreditar que é uma situação real.

Esses ambientes imersivos podem ser colaborativos (CAVE ${ }^{2}$, RAVE $^{3}$, etc), multi sensório-motor (estereoscopia, áudio 3D, etc), individuais (HMD ${ }^{4}$, etc) ou até mesmo uma combinação entre eles [63]. No entanto, é indispensável para qualquer um desses ambientes atender aos seguintes requisitos: utilizar controladores precisos e com rápida resposta para processar, em tempo-real, as interações do usuário; ter uma forma natural e intuitiva de manipular os elementos do ambiente e é necessário representar de forma mais realística possível os fenômenos físicos naturais observados pelo ser humano.

Tendo em vista esses requisitos para a criação de uma aplicação (minimamente satisfatória) de realidade virtual, percebeu-se a possibilidade de criar um estudo sobre técnicas de renderização do fenômeno de dispersão atmosférica. A representação da dispersão atmosférica é muito importante para

\footnotetext{
${ }^{2}$ Cave Automatic Virtual Environment

${ }^{3}$ Remote Access Virtual Environment

${ }^{4}$ Head-Mounted Display
} 
aplicações que possuem foco na visualização planetária, ou seja, na visualização do planeta a partir de um ponto de vista no espaço e para aplicações que possuem foco na visualização de ambientes abertos onde a iluminação é basicamente proveniente do Sol/Céu.

\section{2}

\section{Proposta}

Transformar este estudo em um referência unificada e compacta com diversas informações e conceitos sobre o fenômeno de dispersão atmosférica além, de explicar e analisar duas técnicas diferentes de renderização possibilitando que o leitor tenha maiores detalhes sobre as linhas de desenvolvimento e qual delas é a mais adequada para sua aplicação.

A primeira técnica foi desenvolvida por Bruneton e Neyret [32] e foca na modelagem física do fenômeno, ou seja, em uma representação mais fiel do que acontece no mundo real, porém mais custosa computacionalmente. Embora o artigo de Elek et al. [36] seja mais atual do que a técnica de Bruneton e Neyret, em termos de renderização da dispersão atmosférica, ele propõe apenas uma melhoria pontual em umas das equações que definem o fenômeno. O principal foco artigo do Elek et al. é tratar o relacionamento do fenômeno de dispersão atmosférica com o meio, ou seja, como o fenômeno de dispersão interage com outros elementos que compõe a cena (como, por exemplo, oceano). Como o foco desse estudo envolve apenas o fenômeno de dispersão atmosférica, optouse pela técnica de Bruneton e Neyret que foca apenas no fenômeno de dispersão atmosférica, além de ser mais reconhecida academicamente.

A segunda técnica foi desenvolvida por Schuler [61] e foca em um modelo analítico e com aproximações, ou seja, abre-se mão da fidelidade com a realidade a fim de melhorar a performance e a rapidez da renderização.

\subsection{1}

\section{Entendimento}

Existem dois grandes tópicos a serem entendidos nesse tema, são eles: compreensão do fenômeno físico e renderização.

- Compreensão do fenômeno físico

A compreensão do fenômeno físico é, sem dúvida, o maior problema para os desenvolvedores que estão pretendendo implementar a técnica de dispersão atmosférica. Nos artigos pesquisados, não existe nenhum paralelo - por mais simples que seja - entre o universo entendido pelas pessoas com base física/matemática e o universo entendido pelas pessoas com base de 
programação. Essa afirmação ficou evidente após pesquisar diversos projetos de terceiros que implementavam a técnica de dispersão atmosférica. Grande parte desses trabalhos simplesmente replicam o código disponibilizado por Bruneton e Neyret, ou seja, não há entendimento do fenômeno, nem do seu porquê e nem mesmo de como se deu o processo de implementação.

- Renderização

Pelo fato das duas técnicas serem completamente diferentes é preciso explicar o processo de renderização separadamente. A técnica de Bruneton e Neyret utiliza diversos shaders, possui etapas em pré-processamento, cria e reutiliza texturas $2 \mathrm{D}$ e 3D, enquanto a técnica de Schuler utiliza somente um único shader, não possui pré-processamento e apenas consulta texturas 2D.

Diante dessas observações, está sendo proposto - como parte desse estudo - a explicação mais detalhada do fenômeno de dispersão atmosférica e das duas técnicas de renderização. Com isso, o entendimento do que está sendo representado por cada técnica tende a se tornar mais claro e, consequentemente, mais fácil de se alterar e de se criar novas propostas.

\section{2 .2}

\section{Análise}

Outro ponto importante a ser considerado é a análise/avaliação das técnicas. Esse estudo está propondo apresentar um comparativo entre diversos fatores que podem definir a escolha entre uma técnica ou outra dependendo da necessidade de quem irá implementá-la. Alguns fatores são:

- Consumo de memória

- Tempo total de execução

- Qualidade visual

- Simplificações e limitações 


\section{2 \\ Princípios da dispersão atmosférica}

Neste capítulo serão apresentados todos os princípios físicos necessários para a compreensão do fenômeno de dispersão atmosférica.

\section{1}

\section{Óptica}

Óptica é o ramo da física que estuda os fenômenos luminosos, bem como suas propriedades. A Óptica é dividida em:

- Física - Estuda a compreensão da natureza física da luz e fenômenos como interferência, polarização, difração, dispersão entre outros.

- Geométrica - Estuda os fenômenos luminosos baseados em leis empíricas (experimentais), que são explicados sem que haja necessidade de se conhecer a natureza física da luz. A óptica geométrica usa, como ferramenta de estudo, a geometria.

Neste estudo, será considerado somente a Óptica Física.

\section{2}

\section{Matéria, Radiação e Onda eletromagnética}

Matéria (ou material) é o termo genérico utilizado para representar qualquer elemento físico que possua massa.

Radiação é o termo genérico utilizado para representar qualquer forma de energia que se propaga através do vácuo ou através de um meio material com uma determinada velocidade.

Onda eletromagnética é o termo genérico utilizado para representar a combinação dos campos magnético e elétrico que oscilam perpendicularmente um em relação ao outro e se propagam na mesma direção da energia. Toda onda eletromagnética possui três grandezas físicas básicas: amplitude (ou intensidade), comprimento de onda (ou frequência) e polarização ${ }^{1}$. A Figura 2.1 ilustra uma onda eletromagnética linearmente polarizada produzida por um dipolo elétrico oscilante ${ }^{2}$.

Outro termo bastante utilizado na literatura é luz. A luz pode ser entendida como uma radiação sob a forma de onda eletromagnética.

\footnotetext{
${ }^{1}$ A polarização será abordada na seção 2.5

${ }^{2} \mathrm{O}$ dipolo elétrico oscilante será abordado na seção 2.6
} 


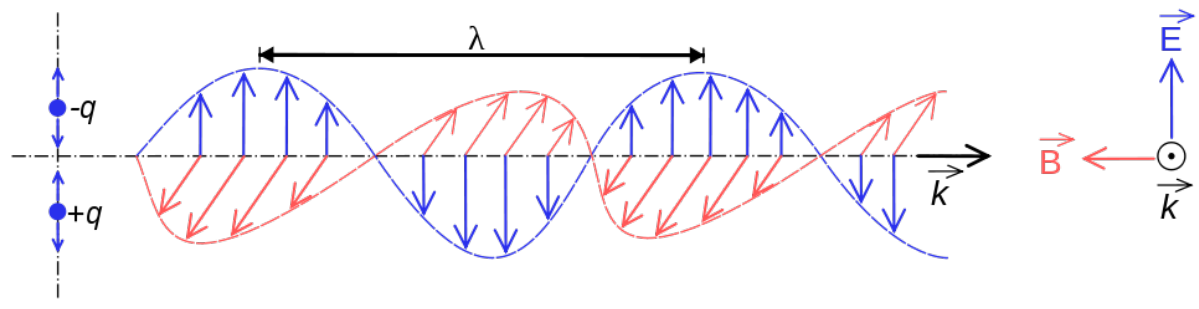

Figura 2.1: A onda se propaga ao longo do eixo horizontal com comprimento de onda lambda (ao centro). O campo elétrico, o campo magnético e o vetor de onda são representados, respectivamente, em azul, vermelho e preto (à direita).

Neste estudo, o principal interesse é na radiação solar sob a forma de onda eletromagnética, ou seja, na luz solar. Por definição, a luz solar é uma radiação eletromagnética emitida pelo Sol que se propaga pelo vácuo a uma velocidade de, aproximadamente, 300.000 quilômetros por segundo. Essa radiação é composta por diversas ondas eletromagnéticas com propriedades diferentes e, consequentemente, com comprimentos de onda também diferentes.

Neste estudo, será considerado apenas um determinado intervalo de comprimentos de onda: o intervalo de luz visível ao olho humano. Esse intervalo está definido, aproximadamente, entre 380 nanometros e 740 nanometros; ou seja, entre o espectro de luz ultravioleta e o de luz infravermelha (ambas invisíveis ao olho humano).

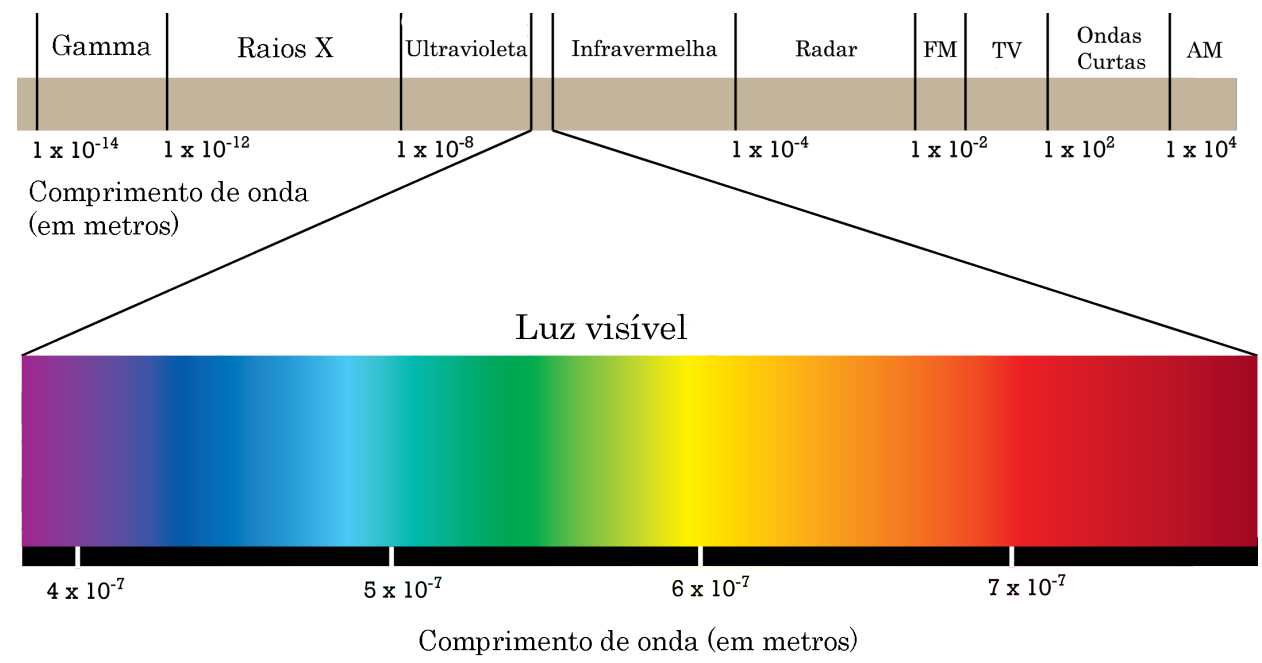

Figura 2.2: Espectro de luz

\section{3}

\section{Atmosfera}

A atmosfera é definida como uma camada de gases que envolve a Terra ou outro planeta. Porém, essa definição é bastante genérica e não leva em 
consideração outras diversas matérias que estão presentes na atmosfera e que contribuem para o fenômeno de dispersão atmosférica. Para representar a composição da atmosfera com mais fidelidade é preciso considerar que existem, além dos gases, matérias maiores como, por exemplo: aerossol, poeira, neblina, partículas sólidas, entre outros.

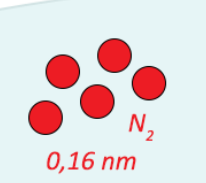

atmosfera

planeta

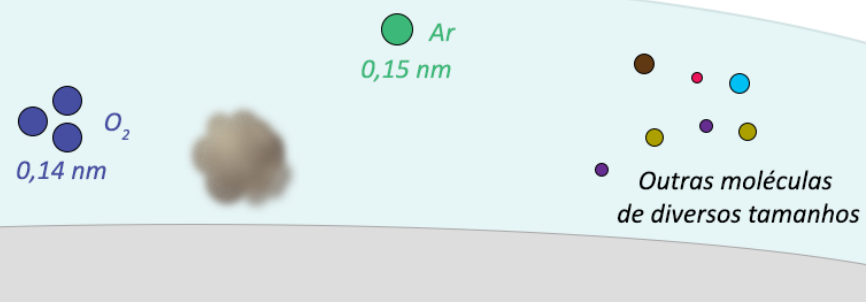

Figura 2.3: Composição atmosférica

Os gases e as outras matérias que compõem a atmosfera estão mais concentrados quando estão próximos da superfície do planeta. Consequentemente, quanto mais próximo da superfície do planeta maior é a pressão e a densidade da atmosfera. Por outro lado, quanto mais afastado da superfície do planeta menor é a pressão e a densidade da atmosfera tornandoa mais rarefeita. A Figura 2.4 ilustra a densidade atmosférica variando em relação a altura.

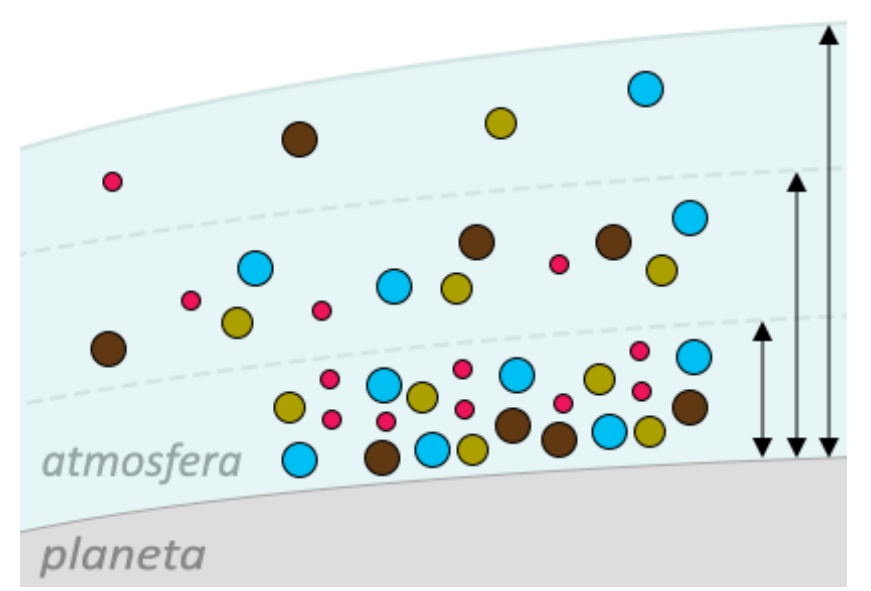

Figura 2.4: Representação da densidade atmosférica

A definição matemática da densidade atmosférica será apresentada na seção 4.1. 


\section{4}

\section{Interações radiação-matéria}

Interações radiação-matéria são todos os efeitos físicos que ocorem quando a radiação colide com algum tipo de matéria. Esse efeitos podem ser, basicamente, de três naturezas diferentes: emissão, absorção ou dispersão [51]. A Figura $2.5^{3}$ ilustra as três naturezas dos efeitos de interação entre radiação e matéria.

A emissão é o efeito que ocorre quando o matéria colidida passar a emitir radiação. Essa radiação pode ser de diversos tipos: alfa, beta, gamma, térmica, etc. No entanto, esse tipo de interação é mais estudada em outros campos da Física como termodinâmica e quântica. Como esse estudo envolve o campo da óptica, o efeito de emissão não será considerado.

A absorção é o efeito que ocorre quando a matéria colidida absorve parte da energia da radiação incidente. Dependendo do tipo de matéria, essa energia absorvida pode ser transformada em outro tipo de energia.

A dispersão é o efeito que ocorre quando a matéria colidida redireciona (espalha) a radiação incidente em diversas direções. Esse espalhamento varia em função de diversos fatores como, por exemplo: a proporção entre o tamanho do raio da matéria e o comprimento de onda, a polarizabilidade, o ângulo de fase, etc.

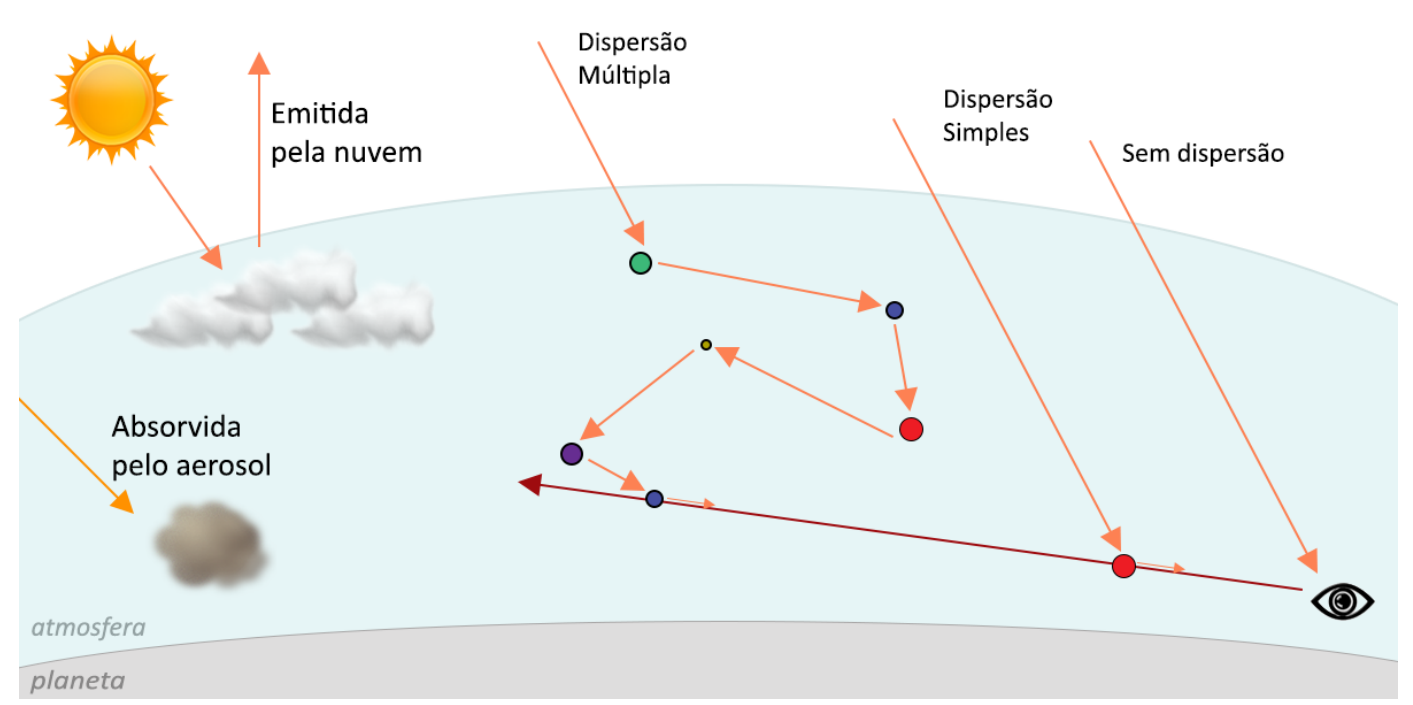

Figura 2.5: Interações entre a radiação solar e as matérias que compõem a atmosfera

Outro termo bastante utilizado na literatura é extinção. Geralmente, o efeito de dispersão e o de absorção acontecem em conjunto e esses efeitos

${ }^{3} \mathrm{~A}$ dispersão simples e múltipla serão especificadas com maiores detalhes na seção 2.10 
reduzem (atenuam) a quantidade de energia da radiação. Logo, o termo extinção é utilizado para representar a quantidade de energia extinta durante o processo de absorção e dispersão como um todo.

\section{5}

\section{Polarização}

Para entender o processo de polarização, é preciso conhecer os conceitos de luz não-polarizada e luz polarizada.

A luz não-polarizada é composta por ondas eletromagnéticas que oscilam em infinitos planos seguindo a direção de propagação da luz. A Figura 2.6 ilustra a luz não-polarizada.

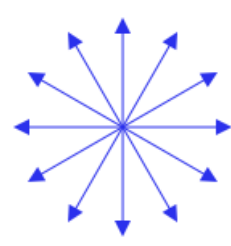

Visão frontal

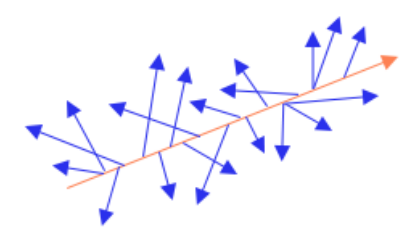

Visão lateral

Figura 2.6: Visão frontal e lateral da luz não-polarizada

A luz polarizada é composta por ondas eletromagnéticas que oscilam em relação à um plano de referência seguindo a direção de propagação da luz. Essa luz pode assumir três formas diferentes:

- Luz linearmente polarizada - Composta por ondas eletromagnéticas que oscilam perpendicularmente ou paralelamente ao plano de referência. A Figura 2.7 ilustra esse tipo de polarização.
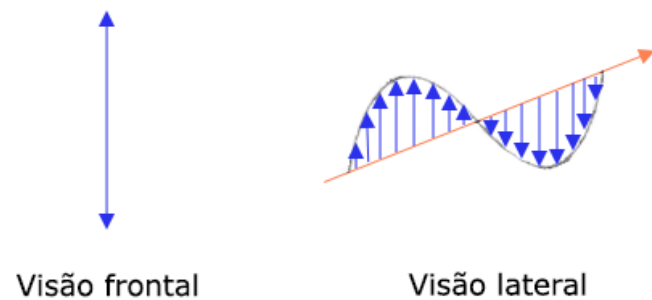

Figura 2.7: Visão frontal e lateral da luz polarizada linearmente

- Luz circulamente polarizada - Composta por ondas eletromagnéticas que oscilam perpendicularmente e paralelamente ao plano de referência. Essas ondas eletromagnéticas possuem a mesma amplitude porém apresentam uma diferença de fase de $90^{\circ}$. 
- Luz elipticamente polarizada - Composta por ondas eletromagnéticas que oscilam perpendicularmente e paralelamente ao plano de referência. Essas ondas eletromagnéticas possuem amplitudes diferentes e qualquer diferença de fase que não seja um ângulo múltiplo de $90^{\circ}$.

Uma vez definidos os conceitos de luz não-polarizada e luz polarizada pode-se definir o conceito de polarização. A polarização é o termo genérico utilizado para representar o processo que transforma uma luz não-polarizada em uma luz polarizada. A polarização pode ocorrer através do uso de polarizadores ou a partir de fenômenos físicos que geram luzes polarizadas como, por exemplo, a reflexão, a refração e dispersão. Neste estudo, o principal interesse está relacionado ao processo de polarização por dispersão [23] [11] devido ao dipolo elétrico oscilante ${ }^{4}$.

A Figura 2.8 ilustra os conceitos de luz não-polarizada, luz polarizada, plano de referência e dispersão resumindo o que acontece no processo de polarização.

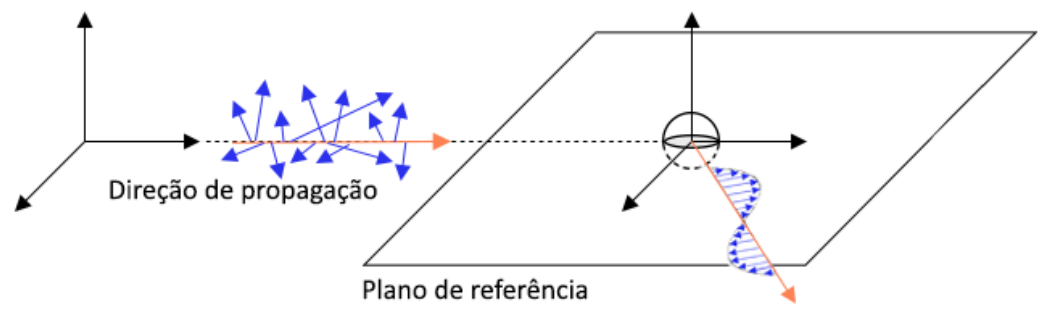

Figura 2.8: Processo de polarização

A definição matemática da polarização será apresentada na seção 4.2.

\section{6}

\section{Dispersão da luz}

Para entender o processo de dispersão da luz, é preciso analisar o que ocorre no momento da colisão entre a luz e a matéria. A colisão entre a luz e a matéria faz com que as órbitas de elétrons das moléculas dentro do matéria sofram uma perturbação com a mesma frequência da luz, ou seja, os elétrons começam a oscilar na mesma frequência de onda da luz. A perturbação (ou oscilação) dos elétrons resulta na separação (e aproximação) das cargas elétricas dentro da matéria. Essa separação (e aproximação) polariza a matéria e gera o chamado dipolo elétrico oscilante, conforme ilustrado na Figura 2.9. O dipolo elétrico oscilante é responsável por emitir novas ondas em outras direções porém, sob a forma de ondas polarizadas. [70] [39].

${ }^{4} \mathrm{O}$ dipolo elétrico oscilante será abordado na seção 2.6 

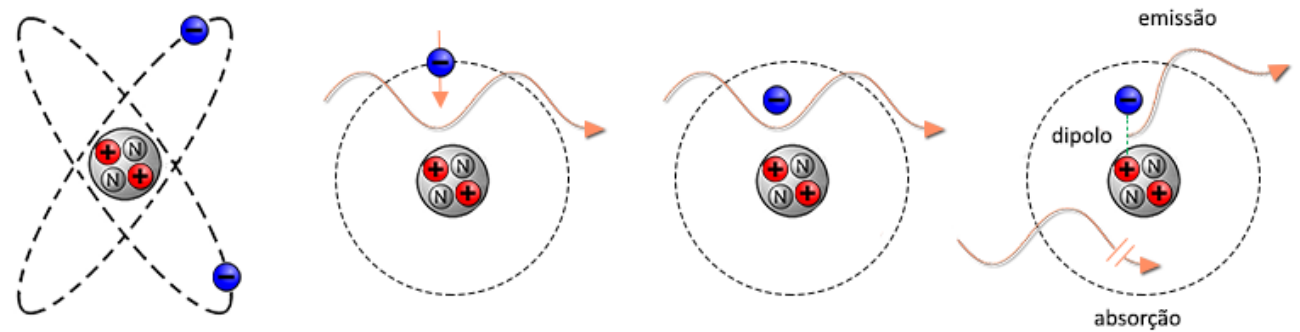

Figura 2.9: Etapas que ocorrem durante a colisão entre a luz e a matéria

No entanto, conforme foi visto na seção 2.4, o efeito de emissão não será considerado neste estudo. Porém, neste caso, devido às condições físicas que envolvem o efeito de emissão, ele passa a ser tratado como um efeito de dispersão. Essa mudança no tipo de tratamento do efeito pode ser feita devido ao fato das oscilações dos elétrons que formam o dipolo elétrico oscilante possuirem a mesma frequência da luz. Consequentemente, as ondas criadas pelo dipolo elétrico oscilante também possuem a mesma frequência da luz. Sendo assim, é possível considerar que ao invés das ondas estarem sendo criadas, elas estão sendo dispersadas segundo uma função de fase e um coeficiente de extinção; esses parâmetros serão estudados futuramente na seção 4.3. A Figura 2.10 ilustra a mudança no tipo de tratamento do efeito.
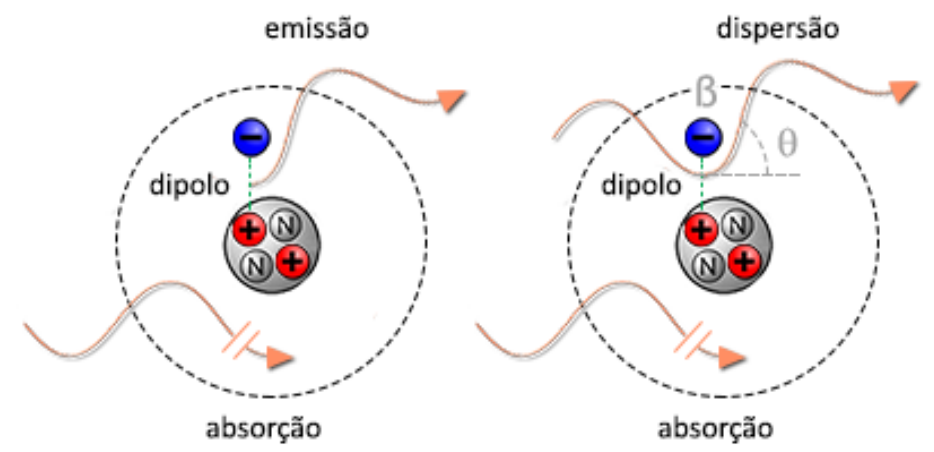

Figura 2.10: Adpatação do efeito de emissão para o efeito de dispersão

A definição matemática da dispersão da luz será apresentada na seção 4.3 .

\section{7}

\section{Regimes atmosféricos}

A luz solar se propaga pelo espaço (vácuo) em direção à atmosfera de algum planeta sem sofrer nenhum tipo de interação e, consequentemente, sem sofrer nenhuma alteração nas suas propriedades eletromagnéticas. No entanto, 
ao colidir com a atmosfera, a luz começa a interagir com os diversos tipos de matérias presentes nesta atmosfera. Na seção 2.3, definiu-se que a atmosfera é composta por gases, aerossóis, poeira, neblina, partículas sólidas, entre outros. Como cada um desses tipos de matérias possuem tamanhos e propriedades diferentes, então a forma com que os efeitos de absorção e dispersão acontecem também serão diferentes. Logo, torna-se um processo bastante complexo.

Na tentativa de minimizar a complexidade e de tornar viável o cálculo da absorção e da dispersão para cada tipo de matéria, foram definidos regimes atmosféricos que agrupam as matérias segundo uma relação existente entre o tamanho do raio da matéria e um determinado comprimento de onda. Esses agrupamentos garantem que todas as partículas de um mesmo grupo estão sujeitas ao mesmo cálculo de absorção e dispersão.

Nesta seção serão apresentados os três principais regimes atmosféricos, porém, é preciso levar em consideração um fato importante descrito na seção 2.5. Foi visto que a onda polarizada dispersada possui a mesma frequência (comprimento de onda) da onda incidente, ou seja, o processo de dispersão é elástico. Porém, vale lembrar que existem outros dois tipos de dispersão: inelástica ou parcialmente elástica ("Quasi-elastic"em inglês). A dispersão inelástica faz com que o comprimento de onda da luz dispersada seja diferente do comprimento de onda da luz incidente. Já a dispersão parcialmente elástica é o limiar entre a dispersão elástica e a inelástica, ou seja, é uma etapa de transição onde é possível obter ondas dispersadas com comprimento de onda ora igual ao da luz incidente, ora diferente ao da luz incidente. Sendo assim, uma vez definido que o processo de dispersão da atmosférica é elástico, é possível destacar quais os regimes aplicáveis à esse caso, são eles:

- Rayleigh - Dispersão que ocorre entre a luz e partículas com tamanho muito menor que o comprimento de onda da luz

- Mie - Dispersão que ocorre entre a luz e partículas com tamanho aproximadamente igual ao comprimento de onda da luz

- Geométrica - Dispersão que ocorre entre a luz e partículas com tamanho muito maior que o comprimento de onda da luz

Matematicamente, tem-se:

$$
\alpha=\frac{2 \pi r}{\lambda}= \begin{cases}<<1 & \text { Rayleigh } \\ \approx 1 & \text { Mie } \\ >>1 & \text { Geométrica }\end{cases}
$$

onde: 
$r=$ Raio da partícula (considerando-a uma esfera)

$\lambda=$ Comprimento de onda da luz incidente com respeito ao meio

No entanto, ainda é preciso estabelecer os limites entre os tipos de regimes a fim de definir qual deles deverá ser aplicado dependendo do tamanho do raio da partícula e o comprimento de onda de luz incidente. Os limites foram definidos a partir de uma análise de diversos estudos envolvendo dispersões [38] [47] [52] [50] [15]; sendo o mais importante o estudo feito por Wallace e Hobbs [71]. Os limites estabelecidos para cada tipo de regime e a Figura 2.11 definem o resultado dessa análise.

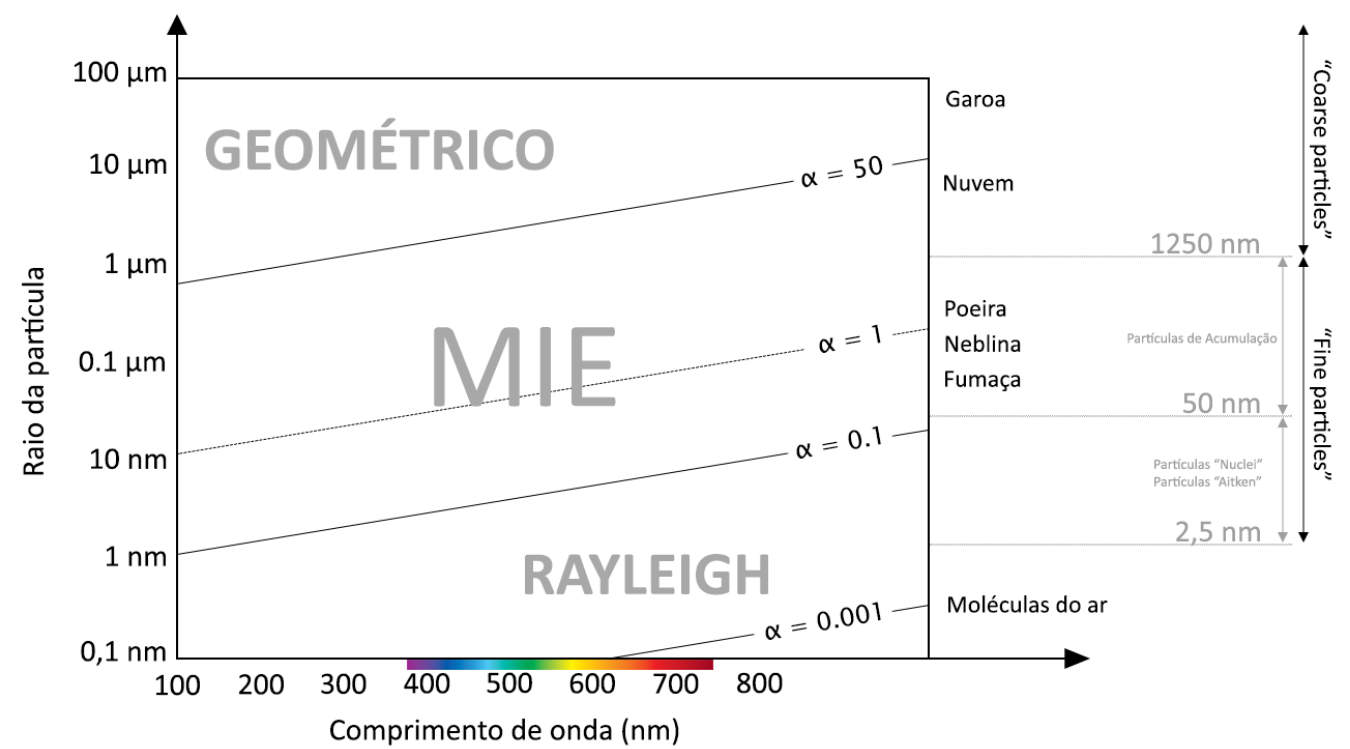

Figura 2.11: Resultado da análise dos regimes de dispersão

- Ignoradas - As partículas com tamanho de raio inferior a 0,1nm devem ser ignoradas pois não contribuem para o processo de dispersão

- Rayleigh - As partículas apresentam raios que variam, aproximadamente, de $0,1 \mathrm{~nm}$ até $1 \mathrm{~nm}$.

- Mie - As partículas apresentam raios que variam, aproximadamente, de $1 \mathrm{~nm}$ até $1000 \mathrm{~nm}$ (1 micrometro).

- Geométrico - As partículas apresentam raios acima de 1000nm (1 micrometro).

Conforme foi dito na seção 2.1, a Óptica Geométrica não será considerada nesse estudo e, consequentemente, o regime geométrico também não será 
considerado. Sendo assim, esse estudo irá abordar apenas o regime de Rayleigh e o regime de Mie.

As modelagens matemáticas desses regimes serão estudadas na seção 4.4.

\section{8}

\section{Profundidade óptica e Transmitância}

Os conceitos de profundidade óptica e transmitância são comumente confudidos devido às suas definições estarem relacionadas. A profundidade óptica é definida como a fração de radiação atenuada - devido a absorção e dispersão - durante a propagação da radiação entre dois pontos dentro do meio material. Porém, a transmitância é definida como a fração de radiação não atenuada - que não sofreu nem absorção e nem dispersão - durante a propagação da radiação entre dois pontos dentro do meio material.

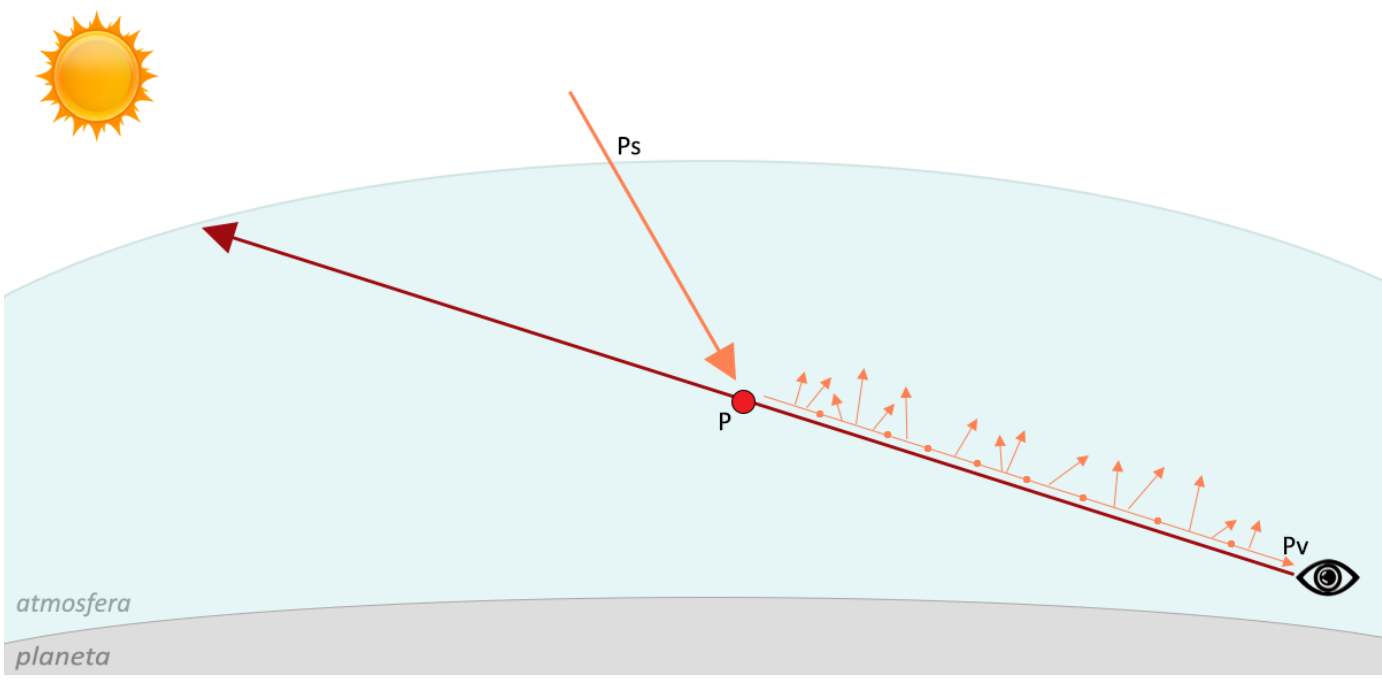

Figura 2.12: Profundidade óptica e Transmitância

Na Figura 2.12, é possível observar que o trecho $\overrightarrow{P_{s} P} P$ não sofre absorção e nem dispersão, sendo assim, pode-se dizer que a trasmitância é máxima. Porém, no trecho $\vec{P} \vec{P}_{v}$ pode-se observar que existem dispersões e absorções fazendo com que apenas uma fração da luz consiga atravessar de um ponto ao outro. Neste caso, a transmitância será definida em função da profundidade óptica, ou seja, do quanto de radiação foi atenuada.

A definição matemática da profundidade óptica e da transmitância serão apresentadas na seção 4.5. 


\section{9}

\section{Irradiância e Radiância}

Os conceitos de irradiância e radiância são comumente confudidos devido ao mal uso dos termos. A irradiância é definida como a intensidade do fluxo radiante, proveniente de todas as direções, que atinge uma dada superfície. Porém, a radiância é definida como a intensidade do fluxo radiante emitida por cada ponto da superfície dada uma determinada direção. A Figura 2.13 ilustra esse dois conceitos mostrando a radiação incidindo em um mesmo ponto da semi-esfera e uma fração da radiação sendo emitida ${ }^{5}$.
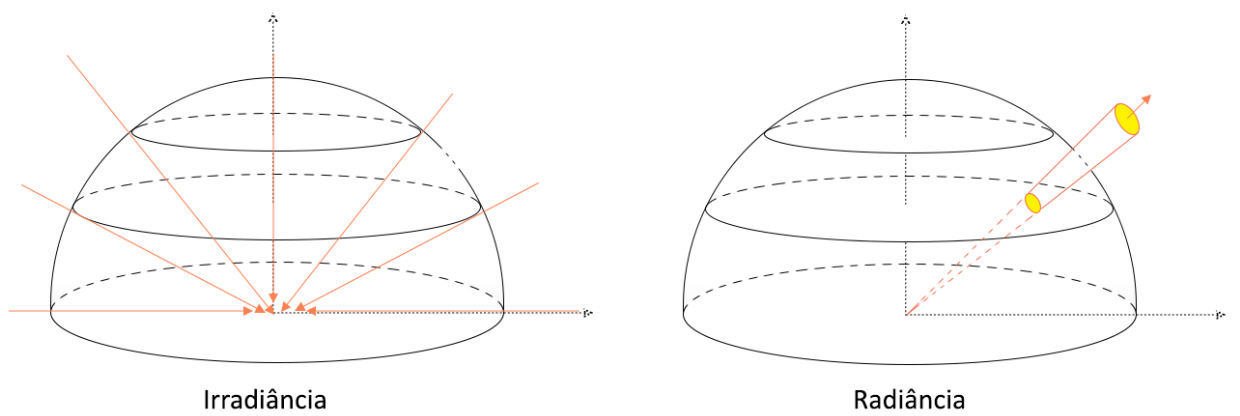

Figura 2.13: Irradiância e Radiância

A definição matemática da irradiância e da radiância serão apresentadas na seção 4.6.

\subsection{0}

\section{Dispersão atmosférica}

Dispersão atmosférica é o termo genérico utilizado para representar o modelo de propagação da luz - de um ponto ao outro - dentro da atmosfera. Existem, basicamente, três modelos:

- Sem dispersão

Esse modelo assume que a luz que atravessa a atmosfera de um ponto o outro sem sofrer nenhum tipo de dispersão, ou seja, a luz não sofreu colisão com nenhum matéria que compõe a atmosfera.

- Dispersão múltipla

A dispersão múltipla é um modelo que considera diversas dispersões da luz antes de chegar de um ponto ao outro. O exemplo abaixo descreve, passo-a-passo, de uma dispersão múltipla:

- Luz solar penetra a atmosfera

\footnotetext{
${ }^{5} \mathrm{~A}$ emissão está representada em forma do ângulo sólido (não abordado nesse estudo)
} 
- A luz solar colide com uma das matérias que compõem a atmosfera

- Parte da luz é absorvida e parte é dispersada

- A parte dispersada começa a atravessar a atmosfera

- A parte dispersada colide com uma das outras matérias que compõe a atmosfera

- Parte da luz dispersa é absorvida e parte é dispersada

- Esse processo se repete até chegar de um ponto ao outro

- Dispersão simples

A dispersão simples é uma simplificação do modelo de múltiplas dispersões. Esse tipo de dispersão considera uma única dispersão da luz antes de chegar de um ponto ao outro. O exemplo abaixo descreve, passoa-passo, de uma dispersão simples:

- Luz solar penetra a atmosfera

- A luz solar colide com uma das matérias que compõe a atmosfera

- Parte da luz é absorvida e parte é dispersada

- A parte dispersada não colide com mais nenhuma matéria que compõe a atmosfera e consegue chegar ao ponto de destino

Neste estudo, será estudado somente a dispersão simples devido à seguinte razão:

- Conforme foi dito na seção 1.2, esse estudo irá analisar as técnicas propostas por Bruneton e Schuler. Por mais que a técnica de Bruneton contemple a dispersão simples e a múltipla, a técnica de Schuler considera somente a dispersão simples. Então, para que seja possível analisar de igual para igual as duas técnicas, a dispersão múltipla não será considerada nesse estudo.

A modelagem matemática da dispersão será estudada na seção 4.7.

\subsection{1}

\section{Efeitos da dispersão atmosférica}

Nesta seção serão apresentados os principais efeitos que ocorrem devido a dispersão atmosférica. 


\subsection{1}

\section{Cor do céu}

A cor do céu pode ser entendida como uma combinação da percepção e interpretação da luz pelo olho humano com as formas pelas quais a luz interage com os materiais que compõem a atmosfera.

As formas pelas quais a luz interage com atmosfera foram definidas na seção 2.7 e classificadas em três regimes diferentes: Rayleigh, Mie e Geométrico ${ }^{6}$. O regime de Rayleigh é usado para tratar a interação da luz com partículas muito pequenas como as moléculas presentes no ar (gases) e o regime de Mie é usado para tratar a interação da luz com partículas maiores como aerossol, poeira, neblina, entre outros.

Em relação à percepção e interpretação da luz pelo olho humano, estudos mostram que o olho humano é mais sensível à cor vermelha, verde e azul, respectivamente [43] [35] [2].A Figura 2.14 apresenta as curvas de sensibilidade do olho humano em relação ao comprimento de onda.

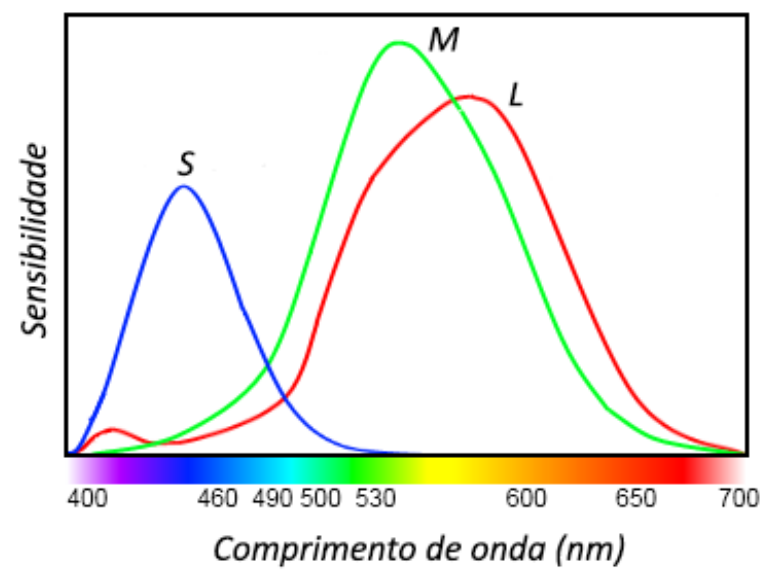

Figura 2.14: Sensibilidade dos cones do olho humano ao comprimento de onda

Com base nessas informações, será definida a cor do céu após a discussão, previamente, de duas situações com céu limpo. Céu limpo pode ser entendido como uma representação da composição da atmosfera onde só existam as moléculas do ar, ou seja, a presença de poluição, nuvens, poeiras e outras partículas serão ignoradas.

\section{Céu limpo durante o dia}

Diante da definição de céu limpo, pode-se considerar somente o regime de Rayleigh. Neste regime a dispersão ocorre com maior intensidade quando o comprimento de onda da luz é mais curto, ou seja, quando a cor tende

${ }^{6}$ Lembre-se que o regime geométrico não será considerado nesse trabalho 
mais para o violeta e azul. Sendo assim, durante o dia, a luz solar penetra a atmosfera e começa a dispersar um maior número de luz violeta e azul e deixa passar as outras luzes. Assim como ilustra a Figura 2.15.

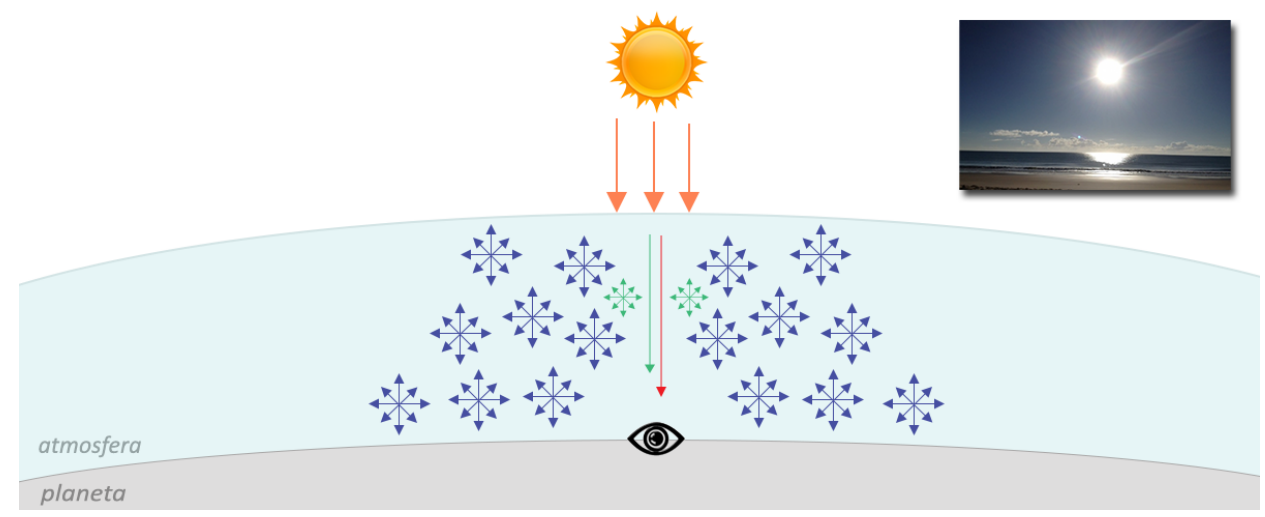

Figura 2.15: Cor do céu limpo durante o dia

No entanto, ainda é preciso esclarecer dois importantes pontos, são eles:

- Porque o céu é azul uma vez que a luz violeta também é bastante dispersada?

- A luz proveninente do Sol não tem a mesma quantidade de ondas para cada um dos comprimentos de onda, ou seja, existem mais ondas azuis do que violetas.

- Grande parte da luz violeta é absorvida na camada de ozônio, logo a quantidade de luzes violetas atrevessando a atmosfera é menor.

- Os olhos humanos são mais sensíveis à luz azul do que à luz violeta.

- A distância entre o topo da atmosfera e o observador está repleta de luz azul dispersada, ou seja, está muito presente em torno do observador

- O que as luzes não-dispersadas irão representar?

- Como as luzes violetas e azuis são dispersadas, ao olhar em direção ao sol, pode-se ver o restante das luzes não dispersadas. Essas luzes não dispersadas chegam aos olhos e estimulam os receptores da cor vermelha e verde. A cor secundária formada pelo vermelho e o verde é o amarelo, ou seja, é por essa razão que ao olhar para o Sol o enxerga-se amarelo. 


\section{Céu limpo ao amanhecer (ou entardecer)}

Existe um único fator que diferencia a cor amarelada do amanhecer (ou entardecer) da cor azul vista durante dia. Esse fator é a distância que a luz deve percorrer até chegar aos olhos do observador.

Durante o dia, a distância entre a entrada da luz do Sol e os olhos do observador está repleta de luz azul dispersada. No entanto, ao amanhecer (ou entardecer) essa distância torna-se muito maior pois o Sol está sendo visto no horizonte. Essa enorme distância faz com que as luzes azuis sejam dispersadas muito antes de chegarem aos olhos do observador. Sendo assim, grande parte da luzes que chegam no observador são verdes e vermelhas, ou seja, o olho humano interpreta como amarelo.

O fato do sol ser visto mais amarelo ou laranja ao amanhecer (ou entardecer) vai depender da quantidade de partículas maiores (abordadas pelo regime de Mie) que estão na atmosfera.

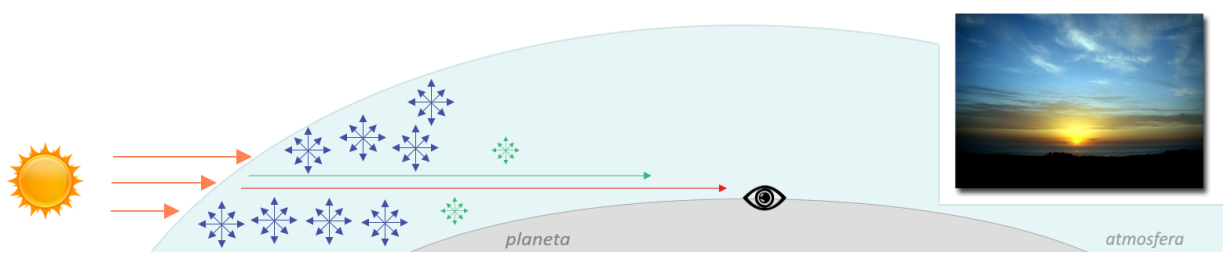

Figura 2.16: Cor do céu ao amanhecer/entardecer

\section{Céu completo}

Céu completo pode ser entendido como uma representação da composição da atmosfera onde existem moléculas do ar, poluição, nuvens, poeiras e outras partículas. Neste caso, deve-se considerar o regime de Rayleigh e de Mie.

Com um maior número de partículas na atmosfera é natural que a luz colida mais vezes e, consequentemente, se disperse mais vezes. Além disso, as partículas maiores dispersam as luzes com comprimentos de ondas mais longos, ou seja, existem também dispersões para as luzes verdes e vermelhas (o que não existia quando só haviam moléculas do ar). Por essa razão é possível ver o céu alaranjado ou avermelhado em algumas condições.

Dependendo no nível de poluição, o número de dispersão é tão grande que todos os comprimentos de onda chegam - atenuados - aos olhos do observador fazendo com que ele veja o céu acinzentado. A Figura 2.17 mostra esse processo. 


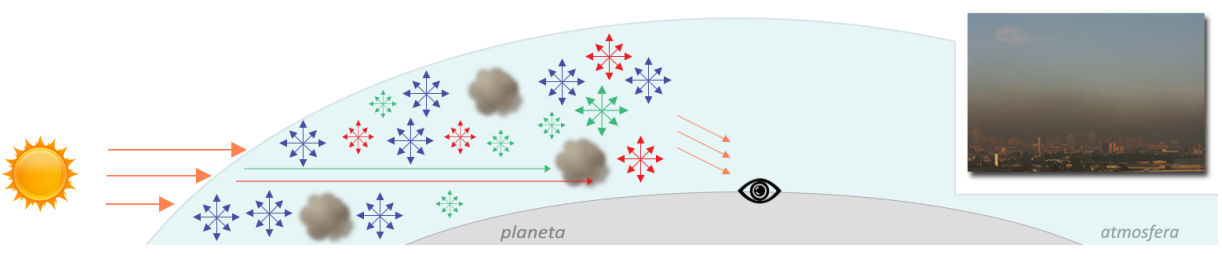

Figura 2.17: Cor do céu considerando Rayleigh e Mie

\subsection{2}

\section{Perspectiva aérea}

Perspectiva aérea é o efeito responsável por fazer com que objetos que estão muito distantes do observador fiquem embaçados e com a cor parecida com a cor do ambiente ao seu redor. Como a distância entre o observador e o objeto aumenta, o contraste entre eles diminui fazendo que a percepção dos detalhes do objeto também diminua. Além disso, a longas distâncias, a luz proveninente do Sol ainda não sofreu muitas dispersões devido as colisões com as partículas da atmosfera fazendo com que o objeto apareça em um tom mais esbranquiçado. Conforme os objetos vão se aproximando do observador, vão ficando mais azulados, amarelados, alaranjados, avermelhados ou acinzetados assim como acontece com a cor do céu. Caso o observador e objeto estejam no limite da atmosfera, o objeto será visualizado com uma nitidez maior, pois a luz proveniente do Sol não sofreu quase nenhuma interferência da atmosfera.

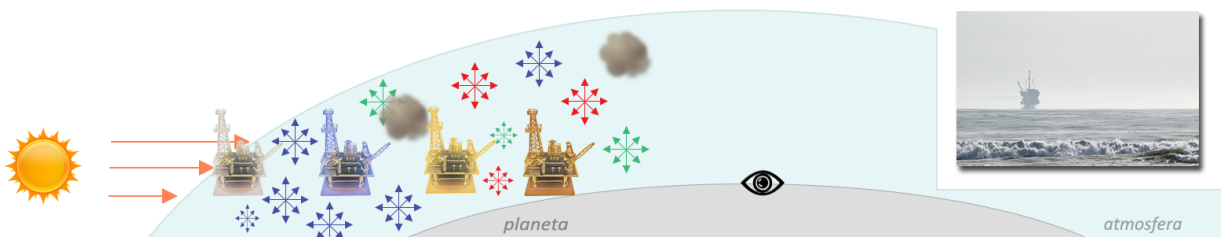

Figura 2.18: Perspectiva aérea 


\section{3}

\section{Trabalhos Relacionados}

A percepção da atmosfera - ou do céu, em um modo geral - sempre esteve presente na vida do ser humano. É possível validar essa afirmação observando e analisando obras de Leonardo da Vinci, Michelangelo e de diversos outros artistas que, ao longo de décadas, vêm tentando representar em suas pinturas a forma com que eles enxergavam o céu e como sua interação se dá com outros elementos paisagísticos. A Figura 3.1 apresenta uma obra de Leonardo da Vinci [13] e outra de Michelangelo [17] onde é perceptível a representação da perspectiva atmosférica, pois as montanhas mais distantes estão sofrendo influência da atmosfera e estão pintadas com cores mais próximas da cor do céu.

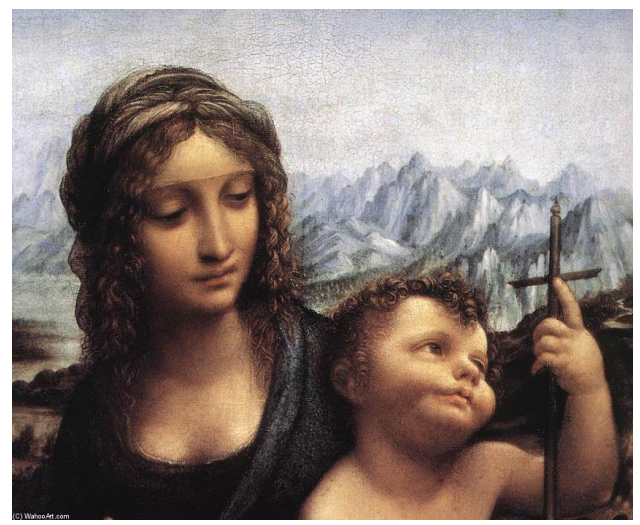

Madonna of the Yarnwinder (Leonardo da Vinci)

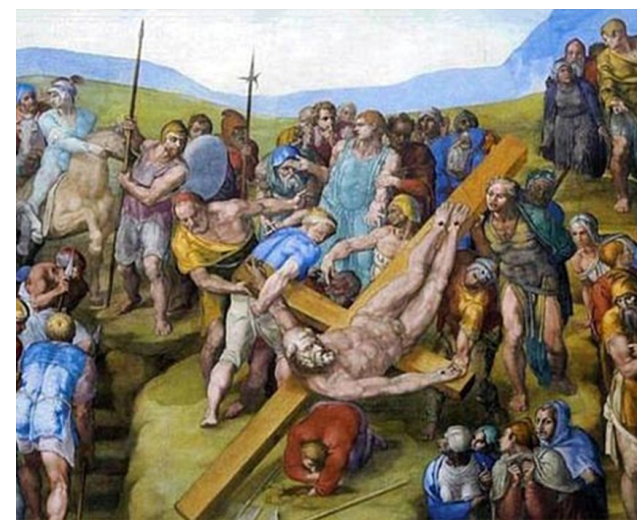

The Crucifixion of St. Peter (Michelangelo)

Figura 3.1: Obras de artes que mostram a percepção do céu

No entanto, físicos e matemáticos também eram fascinados pelo céu, mas de uma forma bem diferente. Eles não queriam pintá-lo; eles queriam entendêlo. Durante muitas gerações, esses pesquisadores buscaram entender o porquê do céu ser azul durante o dia e ser alaranjado durante o nascer/pôr do Sol. Essa dúvida foi sanada quando o físico John William Strutt ("Rayleigh") [26], ganhador do Prêmio Nobel, conseguiu representar o fenômeno de dispersão atmosférica que, posteriormente, foi complementado com as considerações Mie [18].

Uma vez definidos os modelos matemáticos que representam a dispersão atmosférica, muitos estudos foram realizados por pesquisadores da área de computação gráfica a fim de representar, virtualmente, o fenômeno de 
dispersão. Esses pesquisadores definiram duas grandes vertentes para a representação computacional do fenômeno de dispersão:

- Representação baseada em modelo físico

Esse tipo de representação costuma ser bastante utilizada em aplicações científicas onde é importante que haja uma maior fidelidade entre o resultado obtido a partir do modelo físoco e o que acontece na realidade. Esse tipo de representação possui um custo computacional mais elevado, pois precisa levar em consideração um maior número de interações para obter um resultado mais preciso, além de utilizar modelos matemáticos e físicos mais sofisticados.

- Representação baseada em modelos analíticos e aproximações

Esse tipo de representação costuma ser bastante utilizada em aplicações gráficas que precisam ser interativas e/ou em aplicações sensíveis a problemas críticos de performance. Geralmente, a representação envolve dados previamente calculados ou modelos matemáticos e físicos mais simples. Essas simplificações são importantes para diminuir o custo computacional e agilizar a obtenção dos resultados do modelo analítico/aproximado. No entanto, essa simplificação, muitas vezes, faz com que o resultado seja menos fiel com a realidade.

Com as definições das representações computacionais e com o conhecimento físico sobre o fenômeno, descrito no capítulo 2, pode-se apresentar os principais estudos relacionados a esse tema, são eles:

Em 1987, Klassen et al. [45] apresentaram a primeira tentativa de construir um modelo de iluminação para calcular a cor do céu levando em consideração os efeitos de dispersão causados pelas partículas suspensas no ar, ou seja, utilizado apenas a contribuição de Rayleigh.

Em 1991, Kaneda et al. [44] tentaram representar, fotorealisticamente, cenários abertos considerando diversas condições climáticas. Embora a qualidade dos resultados finais tenham sido aquém do esperado, o estudo tornou-se famoso devido ao fato de ser o primeiro a considerar a integração entre as contribuições de Rayleigh e de Mie.

Em 1993, Nishita et al. [54] foram os primeiros a considerar a visualização da atmosfera vista de um ponto no espaço, vide a Figura 3.2. No entanto, esse artigo não contempla o caso do observador estar localizado na superfície do planeta. Além disso, o artigo não leva em consideração a densidade da atmosfera e calcula somente uma única dispersão ("Single Scattering", em inglês). 
Em 1996, Nishita et al. [53] desenvolveram um novo modelo que contemplava o cálculo de múltiplas dispersões ("Multiple Scattering", em inglês). Além disso, também considerava as contribuições de Rayleigh e Mie.

Em 1999, Preetham et al. [58] publicaram uma nova proposta totalmente diferente do que havia sido tentado até o momento. Nela, foi proposta uma forma analítica para calcular a cor do céu. Mas, em 2007, Zotti et al. [73] descobriram que a proposta apresentava - em determinadas condições resultados incoerentes como, por exemplo, densidade da atmosfera com valores negativos.

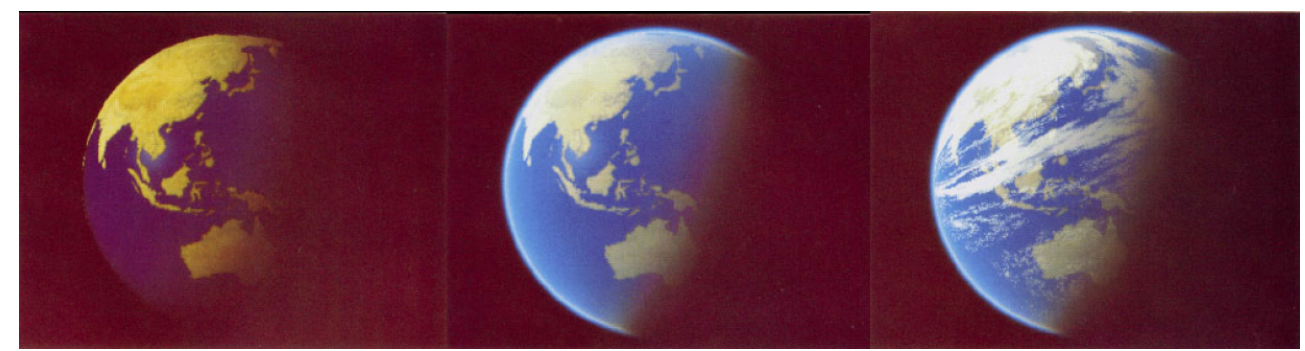

Figura 3.2: Resultado obtido por Nishita em 1993

A partir de um determinado ponto, os estudos sobre dispersão atmosférica começaram a ficar direcionados para a melhoria da velocidade e para renderização em tempo real. Ou seja, o foco deixou de ser qualidade gráfica para processamento em GPU. Essa mudança se deu devido à evolução das placas de vídeo e da sua capacidade de armazenar e manipular texturas de forma eficiente. Com isso, tornou-se possível elaborar novas técnicas utilizando esse recurso de hardware.

Em 2002, Hoffman e Preetham [42] aprimoraram o trabalho Preetham et al. [58] e adicionaram o cálculo de absorção para as contribuições de Rayleigh e Mie usando programação em GPU via shaders para conseguir resultados em tempo real.

Em 2004, O’Neil [22] apresentou um método aproximado para renderizar a atmosfera terrestre baseado no modelo proposto por Nishita et al. [54]. Nele, O'Neil armazena informações sobre interseção de um raio com o planeta, fator de escala para o comprimento óptico para o regime de Rayleigh e Mie em textura. Essa textura é calculada em pré-processamento otimizando o tempo de renderização, uma vez que, será usada apenas como uma tabela de consulta sem que haja a necessidade de ser recalculada a cada interação.

Em 2005, O’Neil [55] publica um novo artigo, só que dessa vez seguindo um caminho um pouco diferente. O'Neil propõe o uso de funções analíticas para calcular a cor da atmosfera usando vertex shader e fragment shader. 
Em 2006, Wenzel [72] apresentou um método eficiente para calcular, em pré-processamento, os efeitos parciais de uma única dispersão e armazenar seus resultados em uma textura 2D. Esse método foi implementado na CryEngine2 [3], sendo a primeira implementação conhecida de um modelo físico minimanente plausível de ser utilizado em um motor de jogo ("Game Engine", em inglês).

Em 2007, Schafhitzel et al. [60] apresentaram uma forma de calcular, em pré-processamento, os efeitos completos de uma única dispersão e armazenar seus resultados em uma textura 3D. Essa proposta foi baseada em O'Neil [22]. Embora o cálculo seja muito preciso, ele contempla somente um ponto de vista, ou seja, como se o observador estive olhando apenas para um lugar.

Em 2008, Bruneton e Neyret [32] apresentaram um método baseado da proposta de Schafhitzel [60] só que dessa vez capaz de calcular múltiplas dispersões, além de permitir diversos pontos de vista, ou seja, observador tem total liberdade para olhar em qualquer direção. No entanto, é preciso calcular em pré-processamento a textura 4D.

Em 2010, Elek et al. [36] generalizaram o modelo atmosférico para contemplar atmosferas com densidade arbitrárias.

Em 2012, Schuler [61] publica uma nova abordagem que simplifica e acelera os cálculos de uma única dispersão. Essa melhoria é tão significativa que reduz a carga da integração numérica a ponto de permitir que todo o processo seja calculado em tempo real e sem pré-processamento.

A Figura 3.3 apresenta um infográfico com a evolução das técnicas de visualização da dispersão atmosférica. Algumas explicações resumidas desses artigos podem ser encontrados no trabalho de Kment et al. [68]. Esse relatório de referência apresenta uma revisão geral do fenômeno de dispersão e de algumas técnicas que se propõe a renderizar o fenômeno. 
Um estudo sobre técnicas de renderização do fenômeno de dispersão atmosférica

\section{Modelo}

analítico e aproximacões

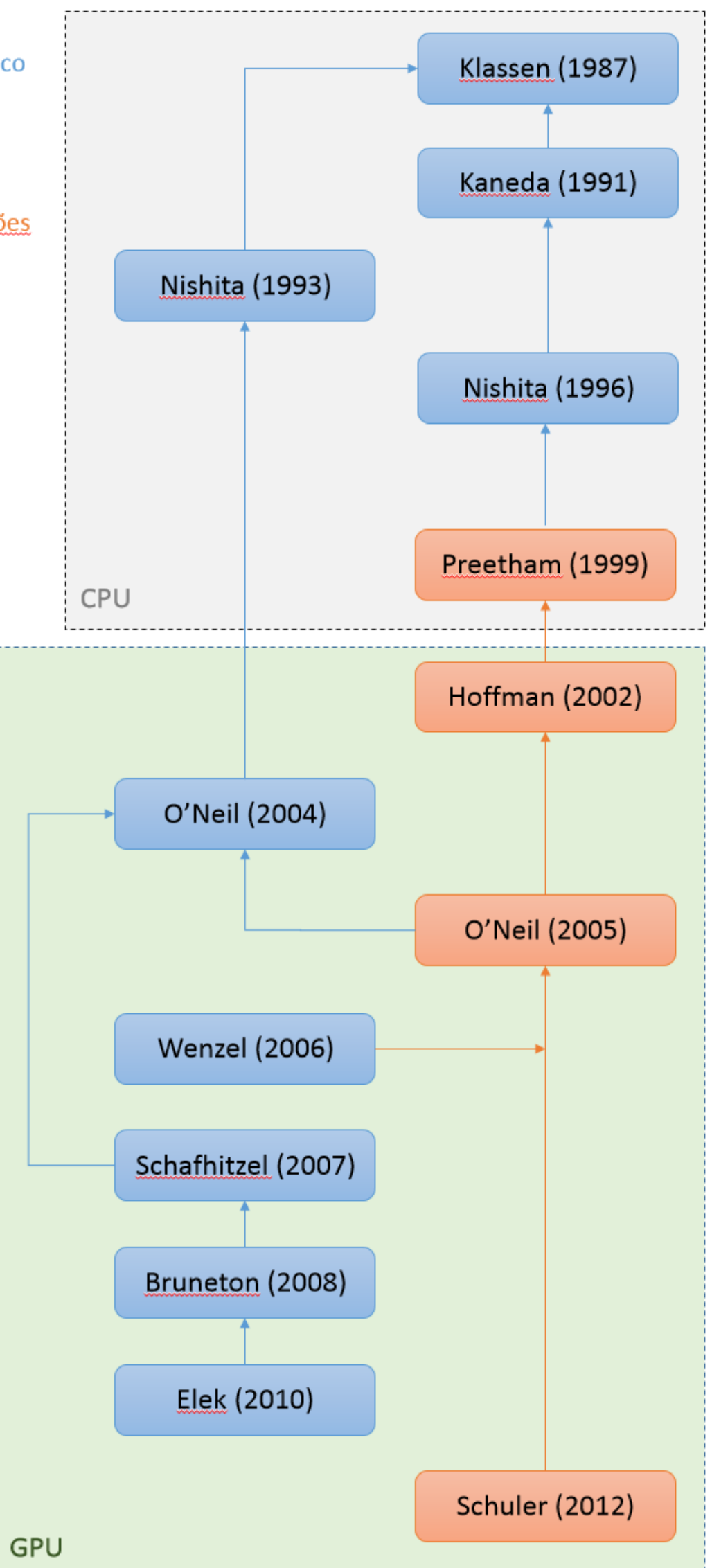

Figura 3.3: Infográfico contendo a evolução das técnicas 


\section{4 Modelo matemático da dispersão atmosférica}

Neste capítulo serão apresentadas as fórmulas e os modelos matemáticos que descrevem alguns dos conceitos físicos citados no capítulo 2. No entanto, serão apresentadas somente as equações mais relevantes para o entendimento do fenômeno de dispersão atmosférica a fim de manter o escopo deste estudo.

\section{1}

\section{Densidade atmosférica}

Na seção 2.3, foi visto que a atmosfera pode ficar mais densa ou mais rarefeita dependendo do quão distante o ponto de interesse está da superfície do planeta. Essa afirmação pode ser justificada da seguinte forma:

Utilizando a segunda lei de Newton [8] e o princípio de Stevin [29] definese:

$$
\frac{d P}{d h}=-\rho g
$$

onde:

$\frac{d P}{d h}=$ Variação entre a pressão e a altura

$\rho=$ Densidade atmosférica

$g=$ Gravidade

A lei dos gases ideais [12] define:

$$
\rho=\frac{P M}{R T}
$$

onde:

$\rho=$ Densidade atmosférica

$M=$ Massa molecular atmosférica

$R=$ Constante universal dos gases perfeitos

$T=$ Temperatura ambiente

Substituindo a equação 4.1.2 na equação 4.1.1, obtém-se:

$$
\frac{d P}{P}=-\frac{M g}{R T} d h
$$

Integrando a equação 4.1.3 no intervalo de [0; h], tem-se: 


$$
\begin{aligned}
\int_{P_{0}}^{P_{h}} \frac{d P}{P} & =\int_{0}^{h}-\frac{M g}{R T} d h \\
\ln \left(P_{h}\right)-\ln \left(P_{0}\right) & =-\frac{M g}{R T} h \\
P_{h} & =P_{0} \exp \left(-\frac{M g}{R T} h\right)
\end{aligned}
$$

A equação 4.1 .4 é também conhecida na literatura como equação baromêtrica. Na equação barômetrica, é possível definir um fator de escala para a altura como:

$$
H=\frac{R T}{M g}
$$

Substituindo a equação 4.1.5 na equação 4.1.4, tem-se a fórmula que define a pressão atmosférica em relação à altura.

$$
P_{h}=P_{0} \exp \left(-\frac{h}{H}\right)
$$

onde:

$P_{h}=$ Pressão no ponto $h$

$P_{0}=$ Pressão ao nível do mar $(\mathrm{h}=0)$

$h=$ Altura

$H=$ Fator de escala para a altura

Substituindo a equação 4.1.2 na equação 4.1.6, tem-se a fórmula que define a densidade atmosférica em relação à altura.

$$
\rho_{h}=\rho_{0} \exp \left(-\frac{h}{H}\right)
$$

Sendo assim, pode-se definir a equação geral da densidade atmosférica como:

$$
\rho(h)=\rho_{0} \exp \left(-\frac{h}{H}\right)
$$

onde:

$\rho(h)=$ Densidade em um determinado ponto $h$

$\rho_{0} \quad=$ Densidade a nível do mar $(\mathrm{h}=0)$ 


\section{2}

\section{Polarização}

$\mathrm{Na}$ seção 2.5, foi definido que esse estudo trataria apenas do processo de polarização por dispersão devido ao dipolo elétrico oscilante, logo, serão introduzidas as principais equações que definem esse processo, porém, a aplicação dessas equações será feita somente na seção 4.3.

O processo de polarização é definido em termos da polarizabilidade [31] [24]. A polarizabilidade é o termo genérico utilizado para representar a capacidade que a matéria tem de mudar sua distribuição eletrônica em resposta a um campo elétrico externo. A polarizabilidade é definida pela equação 4.2.1 proposta por Lorentz-Lorenz [56] [14] que relaciona o número de moléculas por unidade de volume e o complexo do índice de refração ${ }^{1}$ das partículas.

$$
\alpha=\frac{3}{4 \pi N}\left(\frac{m^{2}-1}{m^{2}+2}\right)
$$

onde:

$N=$ Número de moléculas por unidade de volume

$n=$ Índice de refração

$m=(n-i k)=$ Função que define o complexo do índice de refração de uma partícula

A equação 4.2.1 de Lorentz-Lorenz pode ser simplificada para descrever a polarizabilidade de partículas muito pequenas. Logo, pode-se redefinir o valor de $\alpha$, como:

$$
\alpha=\frac{1}{4 \pi N}\left(n^{2}-1\right)
$$

Uma vez definida a polarizabilidade, é preciso relacioná-la com o dipolo. Essa relação é dada em função do momento do dipolo elétrico. O momento do dipolo elétrico é diretamente dependente da polarizabilidade e inversamente proporcional a intensidade de um campo elétrico externo.

$$
\overrightarrow{p_{0}}=\alpha \overrightarrow{E_{0}}
$$

onde:

$\alpha=$ Polarizabilidade

$\overrightarrow{E_{0}}=$ Campo elétrico externo

\footnotetext{
${ }^{1}$ A teoria sobre o complexo do índice de refração não será abordada deste estudo, porém para maiores detalhes recomenda-se [49] ou [27]
} 
Além disso, existem outros fatores importantes que ajudam a definir o estado de polarização, como os Parâmetros de Stokes [6] [30] [69]. Dentre os parâmetros definidos por Stokes, o principal interesse é em:

$$
I=|E|^{2}
$$

onde:

$I=$ Intensidade

$E=$ Campo elétrico

\section{3}

\section{Dispersão da luz}

$\mathrm{Na}$ seção 2.5, foi visto que uma onda não-polarizada pode ser transformada em uma onda polarizada através do processo de dispersão devido ao dipolo elétrico oscilante. Na seção 2.6, foi visto como de fato ocorre o processo de dispersão devido ao dipolo elétrico oscilante. Nesta seção serão introduzidas as equações que definem esses processos a fim de obter uma equação geral que transforme uma luz não-polarizada em uma luz polarizada através do processo de dispersão devido ao dipolo elétrico oscilante.

Baseado na teoria de radiação do dipolo (quando o tamanho da partícula é muito menor que o comprimento de onda), o campo elétrico da luz dispersada (quando a distância do campo elétrico até sua origem é muito menor que o comprimento de onda) é definido como:

$$
\vec{E}=\frac{k^{2} \overrightarrow{p_{0}} \sin (\gamma)}{r}
$$

onde:

$k=$ Fator derivado da aceleração do dipolo elétrico oscilante

$p_{0}=$ Momento de dipolo

$\gamma=\hat{A}$ gulo entre o momento de dipolo $\vec{p}$ e a direção de propagação da luz dispersada

$r=$ Distância do campo elétrico até sua origem

Foi visto na seção 2.5 que a luz polarizada pelo dipolo elétrico oscilante contém ondas eletromagnéticas que podem oscilar perpendicularmente e/ou paralelamente a um plano de referência seguindo a direção de propagação da onda. Consequentemente, podem conter campos elétricos perpendiculares e paralelos ao plano de referência. Diante desse fato, pode-se definir o campo elétrico da luz como uma composição desses dois componentes: 


$$
\vec{E}=\vec{E}_{\text {perpendicular }}+\vec{E}_{\text {paralelo }}
$$

Aplicando a equação 4.3.1 em cada um dos componentes do campo elétrico, tem-se:

$$
\begin{aligned}
\vec{E}_{\text {perpendicular }} & =\frac{k^{2} \vec{p}_{0 \text { perpendicular }} \sin \left(\gamma_{1}\right)}{r} \\
\vec{E}_{\text {paralelo }} & =\frac{k^{2} \vec{p}_{\text {0paralelo }} \sin \left(\gamma_{2}\right)}{r}
\end{aligned}
$$

onde:

$\gamma_{1}=$ Ângulo entre o vetor perpendicular e o plano de dispersão

$\gamma_{2}=$ Ângulo entre o vetor paralelo e a direção de propagação da luz

incidente subtraído de um ângulo de dispersão $\theta$

Aplicando a equação de polarizabilidade 4.2 .3 nos dois componentes do campo elétrico, tem-se:

$$
\begin{aligned}
\vec{E}_{\text {perpendicular }} & =\frac{k^{2} \alpha \sin \left(\gamma_{1}\right)}{r} \vec{E}_{\text {0perpendicular }} \\
\vec{E}_{\text {paralelo }} & =\frac{k^{2} \alpha \sin \left(\gamma_{2}\right)}{r} \vec{E}_{0 \text { paralelo }}
\end{aligned}
$$

A Figura 4.1 ilustra, resumidamente, os campos elétricos da onda, os momentos do dipolo elétrico oscilante, o ângulo de dispersão, os ângulos entre os momentos do dipolo e a direção de observação e o plano de referência.

Aplicando a equação 4.2.4 - definida como um dos parâmetros de Stokes - nas equações 4.3.5 e 4.3.6 transforma-se as equações definidas em função do campo elétrico da luz em equações definidas em função da intensidade da luz.

$$
\begin{aligned}
I_{\text {perpendicular }} & =\left|\vec{E}_{\text {perpendicular }}\right|^{2} \\
I_{\text {perpendicular }} & =\frac{k^{4} \alpha^{2} \sin ^{2}\left(\gamma_{1}\right)}{r^{2}}\left|\vec{E}_{0 \text { perpendicular }}\right|^{2}=\frac{k^{4} \alpha^{2} \sin ^{2}\left(\gamma_{1}\right)}{r^{2}} I_{0 \text { perpendicular }} \\
I_{\text {paralelo }} & =\left|\vec{E}_{\text {paralelo }}\right|^{2} \\
I_{\text {paralelo }} & =\frac{k^{4} \alpha^{2} \sin ^{2}\left(\gamma_{1}\right)}{r^{2}}\left|\vec{E}_{0 \text { paralelo }}\right|^{2}=\frac{k^{4} \alpha^{2} \sin ^{2}\left(\gamma_{2}\right)}{r^{2}} I_{0 \text { paralelo }}
\end{aligned}
$$




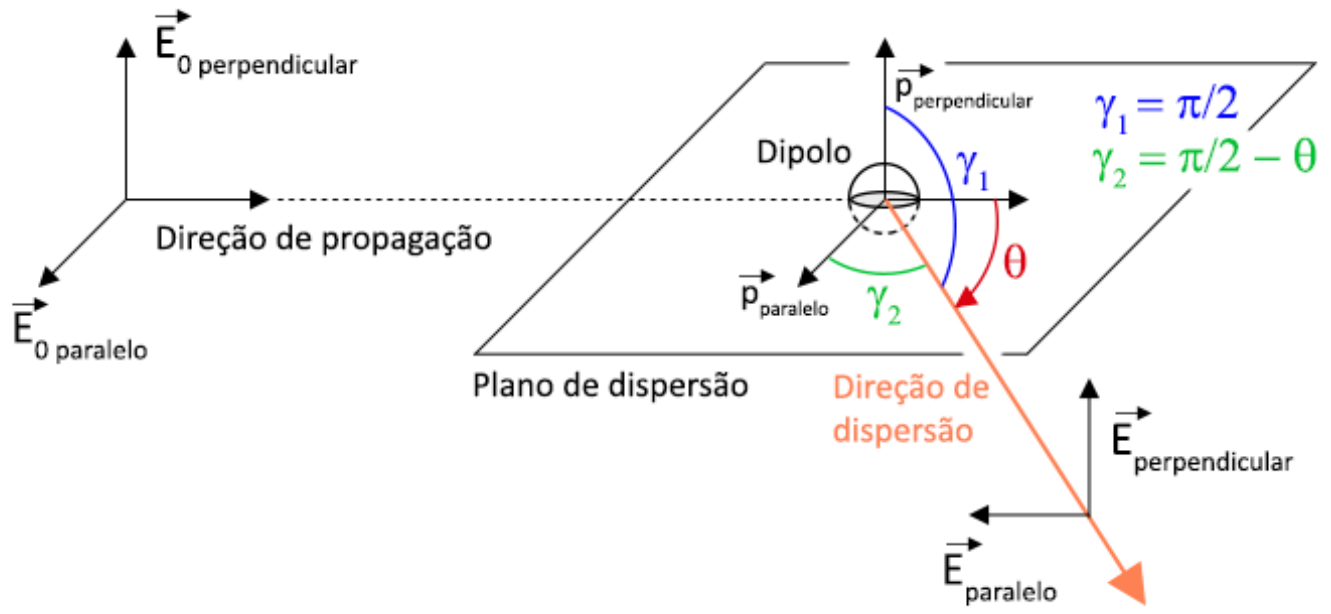

Figura 4.1: Visão geral da interação entre os vetores de campo elétrico e o dipolo elétrico oscilante

Na seção 2.5, definiu-se que a luz não-polarizada é composta por ondas eletromagnéticas que vibram em infinitos planos perpendiculares à direção de propagação da luz. Sendo assim, a distribuição média dessas ondas permite afirmar que:

$$
I_{0 \text { perpendicular }}=I_{0 \text { paralelo }}=\frac{I_{0}}{2}
$$

Unificando as equações 4.3.7, 4.3 .8 e 4.3.9, tem-se:

$$
\begin{aligned}
& I=I_{\text {paralelo }}+I_{\text {perpendicular }} \\
& I=\frac{k^{4} \alpha^{2} \sin ^{2}\left(\gamma_{1}\right)}{r^{2}} I_{0 \text { perpendicular }}+\frac{k^{4} \alpha^{2} \sin ^{2}\left(\gamma_{2}\right)}{r^{2}} I_{0 \text { paralelo }} \\
& I=\frac{k^{4} \alpha^{2}}{r^{2}} \frac{I_{0}}{2}\left(\sin ^{2}\left(\gamma_{1}\right)+\sin ^{2}\left(\gamma_{2}\right)\right)
\end{aligned}
$$

Aplicando $\gamma_{1}=\frac{\pi}{2}$ e $\gamma_{2}=\frac{\pi}{2}-\theta$ (conforme ilustrado na Figura 4.1) e resolvendo as identidades trigonométricas decorrente dessa ação, tem-se:

$$
I=\frac{k^{4} \alpha^{2}}{r^{2}} \frac{I_{0}}{2}\left(1+\cos ^{2}(\theta)\right)
$$

onde: 
$I=$ Intensidade da luz dispersada

$I_{0}=$ Intensidade da luz incidente

$k=$ Fator derivado da aceleração do dipolo elétrico oscilante

$\alpha=$ Polarizabilidade

$r=$ Distância do campo elétrico até sua origem

Definindo e substituindo o valor de $\mathbf{k}$ na equação 4.3.11, tem-se:

$$
\begin{gathered}
k=\frac{2 \pi}{\lambda} \\
I=\left(\frac{2 \pi}{\lambda}\right)^{4} \frac{\alpha^{2}}{r^{2}} \frac{I_{0}}{2}\left(1+\cos ^{2}(\theta)\right)
\end{gathered}
$$

Substituindo a equação de Lorentz-Lorenz 4.2.2, tem-se:

$$
I=\left(\frac{2 \pi}{\lambda}\right)^{4}\left(\frac{n^{2}-1}{4 \pi N}\right)^{2} \frac{I_{0}}{2 r^{2}}\left(1+\cos ^{2}(\theta)\right)
$$

Sendo assim, pode-se definir a equação geral da intensidade da onda dispersada (neste caso, polarizada) pelo dipolo elétrico oscilante após ter sido colidido por uma onda não-polarizada como:

$$
I(\lambda, \theta)=\left(\frac{2 \pi}{\lambda}\right)^{4}\left(\frac{n^{2}-1}{4 \pi N}\right)^{2} \frac{I_{0}}{2 r^{2}}\left(1+\cos ^{2}(\theta)\right)
$$

onde:

$\lambda=$ Comprimento de onda da luz incidente

$N=$ Número de moléculas por unidade de volume

$n=$ Índice de refração de uma partícula

\section{4}

\section{Regimes atmosféricos}

Foi visto na seção 2.5 que pode-se considerar o efeito de emissão - gerado na colisão entre a luz e a matéria - como uma aproximação do efeito de dispersão através da definição de um coeficiente de dispersão e uma função de fase. Foi visto também na seção 2.7 que a forma de calcular a absorção e a dispersão realizada pela matéria depende do regime atmosférico no qual ela está classificada. Sendo assim, pode-se concluir que para cada regime existe uma forma diferente de absorção, funções de fase e coeficientes de dispersão 
diferentes. Nesta seção serão apresentados esses três parâmetros para o regime de Rayleigh e para o regime de Mie.

\subsection{1}

\section{Regime de Rayleigh}

John William Strutt - também conhecido como Lord Rayleigh - publicou três artigos no final do século XIX [65],[66] e [67] que, juntos, descrevem suas teorias e fórmulas propostas para representar o fenômeno de dispersão atmosférica. O regime de Rayleigh assume:

- As partículas (matérias) que sofrem colisão são muitos menores que o comprimento de onda da luz que incidente. Então, o campo elétrico dentro da partícula pode ser considerado uniforme.

- A dispersão da onda eletromagnética é baseada na teoria do dipolo elétrico oscilante. Devido ao fato de serem partículas muito pequenas, são consideradas como um único dipolo.

- As partículas são esféricas e isotrópicas.

- As partículas não possuem absorção.

A partir dessa equação pode-se definir a absorção, a função de fase e o coeficiente de extinção para o regime de Rayleigh.

\section{Absorção}

Na seção 2.4, foi visto que a interação entre a radiação e a matéria gera efeitos de absorção e dispersão (que juntos, são chamados de extinção). No entanto, o regime de Rayleigh não considera o efeito de absorção. Sendo assim, pode-se definir a seguinte relação:

$$
\begin{aligned}
& E_{\text {extincao }}=E_{\text {absorcao }}+E_{\text {dispersao }} \\
& E_{\text {extincao }}=E_{\text {dispersao }}
\end{aligned}
$$

onde:

$E_{\text {extincao }}=$ Energia total extinta

$E_{\text {absorcao }}=$ Energia extinta pelo efeito de absorção

$E_{\text {dispersao }}=$ Energia extinta pelo efeito de dispersão

Consequentemente:

$$
\begin{aligned}
& \beta_{\text {extincao }}=\beta_{\text {absorcao }}+\beta_{\text {dispersao }} \\
& \beta_{\text {extincao }}=\beta_{\text {dispersao }}
\end{aligned}
$$


onde:

$\beta_{\text {extincao }}=$ Coeficiente de extinção

$\beta_{\text {absorcao }}=$ Coeficiente de absorção

$\beta_{\text {dispersao }}=$ Coeficiente de dispersão

\section{Função de fase}

$\mathrm{Na}$ seção 2.4, foi visto que a interação entre a radiação e a matéria gera um efeito de dispersão responsável por redirecionar a luz incidente para outra trajetória de propagação. Esse redirecionamento pode ser representado, matematicamente, através da chamada função de fase.

A função de fase é o termo genérico utilizado para representar a distribuição angular da luz dispersada por uma partícula. Essa distribuição é dada em função de um ângulo $\theta$ em relação à direção de propagação da luz incidente.

No regime de Rayleigh, a função de fase é definida como:

$$
P(\cos \theta)=\frac{3}{4}\left(1+\cos ^{2}(\theta)\right)
$$

Pela Figura 4.2 pode-se observar que a distribuição é simétrica porém, não é isotrópica em todas as direções devido a função de fase ser dada em relação a $1+\cos ^{2}(\theta)$.
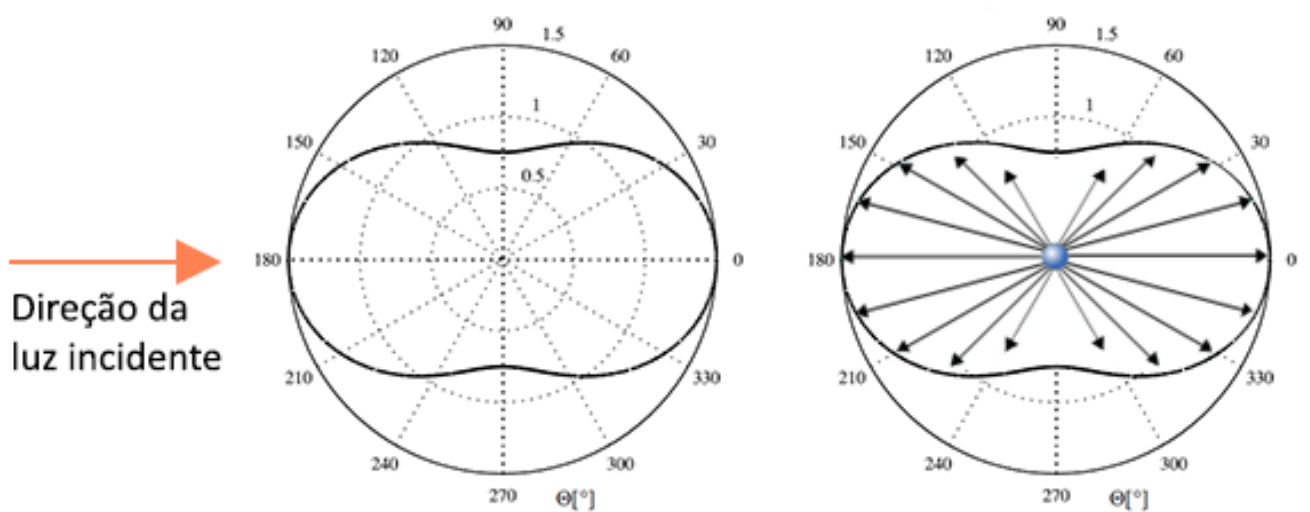

Figura 4.2: Representação da função de fase e da luz dispersada segundo o regime de Rayleigh

Note que a função de fase está definida em função de $\cos (\theta)$. Isso se deve ao fato de ser uma nomenclatura usual na astronomia onde o ângulo é medido 
em relação ao eixo Norte/Sul (Azimute). Caso seja necessário compreender mais sobre o assunto, recomenda-se: [59] e [57].

\section{Coeficiente de extinção}

$\mathrm{Na}$ seção 2.4, foi visto que a interação entre a radiação e a matéria gera efeitos de absorção e dispersão (que juntos, são chamados de extinção) responsáveis por atenuar (extinguir parte de) a intensidade da radiação. No entanto, dependendo do comprimento de onda da luz incidente e do tipo de matéria a luz pode sofrer mais ou menos extinção. Essa variação do quanto a luz pode ser extinta pode ser representada, matematicamente, através do chamado coeficiente de extinção.

O coeficiente de extinção é calculado com base na teoria do complexo do índice de refração, da seção transversal de dispersão e dos ângulos sólidos porém, esses tópicos estão fora do escopo desse estudo. Caso seja necessário compreender mais sobre o assunto, recomenda-se: [48], [4], [64], [28] e [70]. Sendo assim, resumidamente, será definido o coeficiente de extinção do regime de Rayleigh.

A seção transversal total pode ser definida, a partir da seção transversal diferencial, como:

$$
\sigma=\int_{0}^{2 \pi} \int_{0}^{\pi} \frac{d \sigma}{d \Omega} \sin (\theta) d \theta d \phi
$$

Para a luz não-polarizada, a dispersão é dada por:

$$
\begin{aligned}
I & =I_{0} \frac{1}{r^{2}} d \sigma \\
d \sigma & =\frac{I r^{2}}{I_{0}}
\end{aligned}
$$

Logo, pode-se definir a seção transversal diferencial como:

$$
\frac{d \sigma}{d \Omega}=\frac{I r^{2}}{I_{0}} \frac{1}{d \Omega}
$$

Aplicando a equação 4.3.15 na equação 4.4.6, tem-se:

$$
\frac{d \sigma}{d \Omega}=\left(\frac{2 \pi}{\lambda}\right)^{4}\left(\frac{n^{2}-1}{4 \pi N}\right)^{2} \frac{1}{2}\left(1+\cos ^{2}(\theta)\right)
$$

Aplicando a equação 4.4 .7 na equação 4.4.4, tem-se: 


$$
\begin{aligned}
& \sigma=\int_{0}^{2 \pi} \int_{0}^{\pi}\left(\frac{2 \pi}{\lambda}\right)^{4}\left(\frac{n^{2}-1}{4 \pi N}\right)^{2} \frac{1}{2}\left(1+\cos ^{2}(\theta)\right) \sin (\theta) d \theta d \phi \\
& \sigma=\left(\frac{2 \pi}{\lambda}\right)^{4}\left(\frac{n^{2}-1}{4 \pi N}\right)^{2} \frac{1}{2} \int_{0}^{2 \pi} \int_{0}^{\pi} \sin (\theta)+\cos ^{2}(\theta) \sin (\theta) d \theta d \phi \\
& \sigma=\frac{8 \pi^{3}\left(n^{2}-1\right)^{2}}{3 N^{2} \lambda^{4}}
\end{aligned}
$$

O coeficiente de dispersão total é dado pelo produto da seção transversal total 4.4.8 e o número de moléculas por unidade de volume.

$$
\beta_{\text {dispersao }}=\sigma N=\frac{8 \pi^{3}\left(n^{2}-1\right)^{2}}{3 N \lambda^{4}}
$$

Sendo assim, pode-se definir a equação geral do coeficiente de extinção como:

$$
\beta_{\text {extincao }}(\lambda)=\beta_{\text {dispersao }}(\lambda)=\frac{8 \pi^{3}\left(n^{2}-1\right)^{2}}{3 N \lambda^{4}}
$$

Note que, no caso específico do regime de Rayleigh, o coeficiente de extinção é calculado somente em função da dispersão. Isso se deve ao fato do regime de Rayleigh não considerar absorção, conforme foi definido na sub-seção 4.4.1. Por essa razão, também pode-se encontrar na literatura o uso do termo coeficiente de dispersão para representar o que seria, na verdade, o coeficiente de extinção com a contribuição da absorção igual a zero.

Sendo assim, ao analisar um determinado processo de dispersão atmosférica cujos os efeitos de absorção e dispersão são diferentes de zero, é preciso realizar o cálculo do coeficiente de extinção considerando tanto o coeficiente de absorção quanto o coeficiente de dispersão. Neste caso, é possível encontrar na literatura o uso do termo coeficiente de atenuação para representar o coeficiente de extinção.

\subsection{2}

\section{Regime de Mie}

Primeiramente, será explicado a diferença do que é chamado de teoria de Mie e regime de Mie. A teoria de Mie é, na verdade, uma solução analítica completa - descrita por Gustav Mie [18] - para as equações de Maxwell [62] [16] [9] para a dispersão de radiação eletromagnética por partículas esféricas. Já o regime de Mie é a união da teoria de Mie com outros conceitos descritos 
por outros pesquisadores como, por exemplo, Lorenz que ajudou a expandir o conceito da dispersão para partículas esféricas dielétricas [41] [51] [56].

No seção 4.3 foi vista a explicação para o processo de dispersão da luz para um dipolo elétrico (válida para o regime de Rayleigh). No entanto, é preciso expandir essa explicação para diversos dipolos elétricos para que seja possível explicar o processo de dispersão da luz no regime de Mie. Essa expansão não é trivial de ser explicada e foge do escopo desse estudo. Logo, será apresentado somente as principais características do regime, que são:

- Considera-se somente colisões com partículas (matérias) que possuem, aproximadamente, o mesmo tamanho que o comprimento de onda da luz que incidente.

- As partículas são esféricas e isotrópicas.

- As partículas podem ou não possuir absorção.

- Por se tratar de um processo de dispersão para partículas esféricas e dielétricas, pode-se utilizar a teoria dos dipolos elétrico oscilante levando em consideração que são diversos dipolos elétricos (ao contrário de um único dipolo conforme visto no regime de Rayleigh). ${ }^{2}$

A Figura 4.3 ilustra, resumidamente, a diferença entre uma partícula no regime de Rayleigh e outra no regime de Mie.
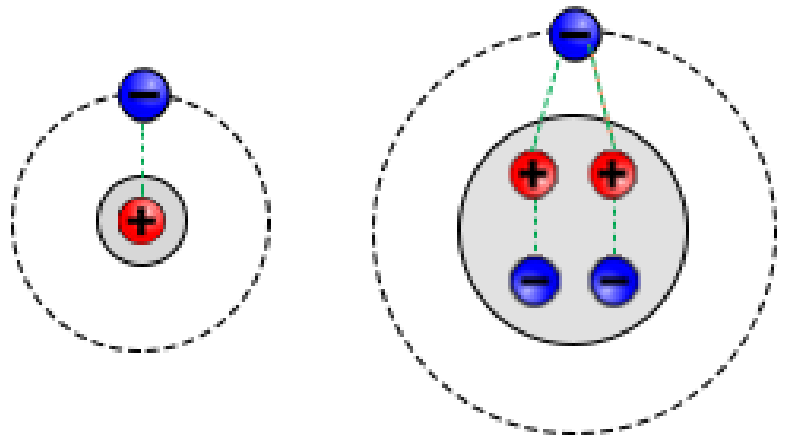

Figura 4.3: Diferença entre a partícula no regime de Rayleigh (esquerda) e no regime de Mie (direita)

${ }^{2} \mathrm{O}$ regime de Rayleigh é um sub-caso do regime de Mie 


\section{Absorção}

As partículas que são consideradas no regime de Mie geralmente absorvem parte da energia da luz incidente. No entanto, cada tipo de partícula apresenta um índice de refração diferente e, consequentemente, absorvem parte da energia de forma e intensidade diferente. Diante disso, não será estabelecida nenhuma equação geral que defina a absorção.

\section{Função de fase}

A função de fase de Mie é bastante complexa de ser calculada devido à forma com os diversos dipolos elétricos do material interagem entre eles e com a radiação incidente. Para isso, aproxima-se a função de fase do regime de Mie para a equação de fase de Henyey-Greenstein [40] melhorada por Cornette and Shanks [34]:

$$
P(\cos \theta)=\frac{3\left(1-g^{2}\right)}{8 \pi\left(2+g^{2}\right)} \frac{\left(1+\cos ^{2} \theta\right)}{\left(1+g^{2}-2 g \cos \theta\right)^{\frac{3}{2}}}
$$

onde:

$g=$ Fator direcional

A variação do valor de $g$ altera a simetria de dispersão da luz da seguinte forma:

$$
g \begin{cases}<0 & \text { Maior intensidade na direção oposta da luz incidente. } \\ =0 & \text { Homogeneamente, assim como a dispersão de Rayleigh. } \\ >0 & \text { Maior intensidade na mesma direção de luz incidente. }\end{cases}
$$

A Figura 4.4 ilustra a função de fase e a dispersão da luz no regime de Mie quando o valor de $g$ é maior do que zero (chamada em inglês por forward scattering). Caso $g$ fosse menor do que zero (chamada em inglês por backward scattering), bastaria espelhar essa Figura verticalmente para obter o resultado esperado.

\section{Coeficiente de extinção}

O coeficiente de extinção do regime de Mie é a soma do coeficiente de absorção mais o coeficiente de dispersão.

$$
\beta_{\text {extincao }}=\beta_{\text {absorcao }}+\beta_{\text {dispersao }}
$$




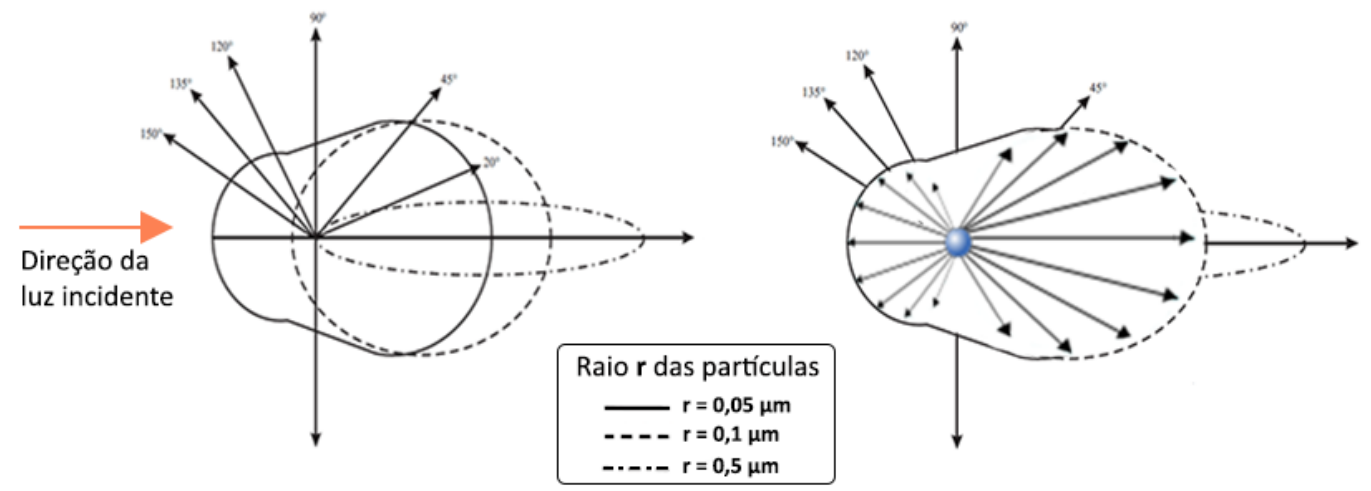

Figura 4.4: Dispersão da luz no regime de Mie

onde:

$\beta_{\text {extincao }}=$ Coeficiente de extinção

$\beta_{\text {absorcao }}=$ Coeficiente de absorção

$\beta_{\text {dispersao }}=$ Coeficiente de dispersão

Foi visto em 4.4.2 que o coeficiente de absorção depende do tipo de partículas que está sendo analisada. Já o coeficiente de dispersão é similiar ao coeficente de dispersão do regime de Rayleigh definido na equação 4.4.9 porém sem a dependência do comprimento de onda, ou seja:

$$
\beta_{\text {dispersao }}=\frac{8 \pi^{3}\left(n^{2}-1\right)^{2}}{3 N}
$$

\section{5}

\section{Profundidade óptica e Transmitância}

Na seção 2.3, foi visto que a atmosfera é mais rarefeita quando se está mais afastado da superfície do planeta e mais densa quando se está mais próximo da superfície do planeta. A partir disso, definiu-se a equação 4.1.8 que relaciona a densidade da atmosfera em relação a altura.

$\mathrm{Na}$ seção 2.4, foi visto que a interação entre a radiação e a matéria gera efeitos de absorção e dispersão responsáveis por atenuar a radiação. Logo, é natural pensar que regiões mais rarafeitas da atmosfera existirão menos interações (menos absorções e dispersões) e, consequentemente, menos atenuação. Em contrapartida, em regiões mais densas da atmosfera existirão mais interações e, consequentemente, mais atenuação.

Na seção 2.8, foi visto que a profundidade óptica é a fração de radiação atenuada durante a propagação dessa radiação entre dois pontos dentro do 
meio material. Logo, ao pensar na luz propagando-se pelo meio material podese assumir que a luz sofrerá atenuações diferentes ao longo da sua trajetória devido a diferença de densidade da atmosfera. Então, de forma geral, pode-se definir a profundidade óptica como o somatório das várias atenuações ao longo de um determinado caminho:

$$
\tau\left(S_{0}, S\right)=\int_{S_{0}}^{S} \sum \beta_{\text {extincao }}(\lambda) \rho(s) d s
$$

onde:

$\beta_{\text {extincao }}(\lambda)=$ Coeficiente de extinção

$\rho(s) \quad=$ Função de densidade atmosférica

Uma outra forma de definir a profundidade óptica é através do uso da lei de Beer-Lambert [1] obtendo:

$$
I=I_{0} \exp \left(-\tau\left(S_{0}, S\right)\right)
$$

onde:

$I=$ Intensidade da luz

$I_{0}=$ Intensidade da luz incidente

Ainda na seção 2.8, foi visto que a transmitância é definida como a fração de radiação não atenuada durante a propagação da radiação entre dois pontos dentro do meio material. Manipulando a equação 4.5.2, podemos facilmente extrair a equação que define a transmitância.

$$
\begin{gathered}
\frac{I}{I_{0}}=\exp \left(-\tau\left(S_{0}, S\right)\right) \\
T\left(S_{0}, S\right)=\exp \left(-\tau\left(S_{0}, S\right)\right)
\end{gathered}
$$

Substituindo a equação 4.5.1 na equação 4.5.4 obtém-se a equação geral da transmitância em função da profundidade óptica.

$$
T\left(S_{0}, S\right)=\exp \left(-\int_{S_{0}}^{S} \sum \beta_{\text {extincao }}(\lambda) \rho(s) d s\right)
$$




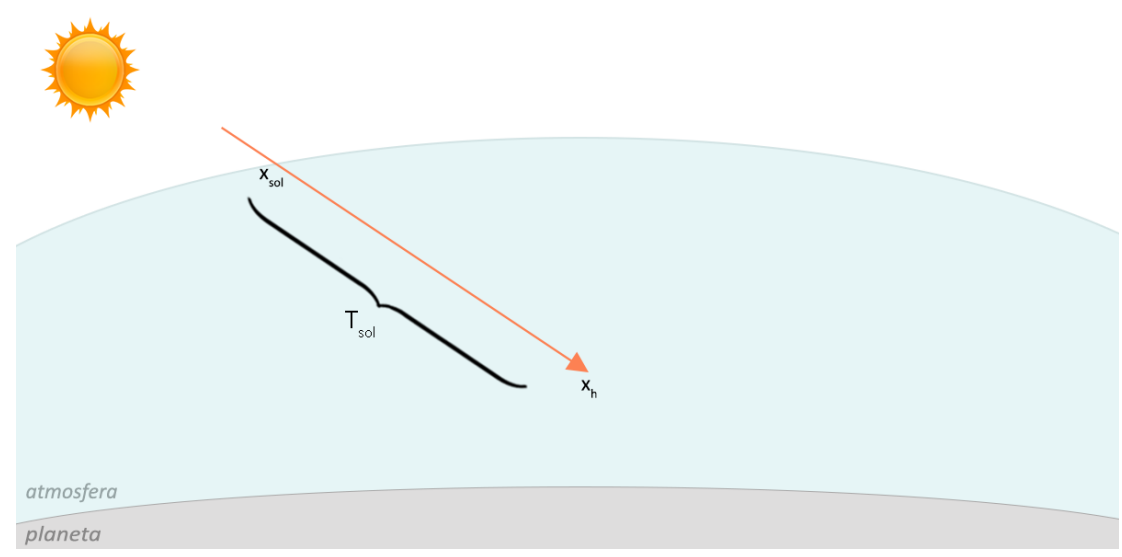

Figura 4.5: Transmitância

\section{6}

\section{Irradiância e Radiância}

Na seção 2.9 foi visto a definição de irradiância e radiância. Porém, para esse estudo, o interesse está direcionado à dois casos específicos: a radiância na superfície do planeta (também encontrada na literatura como reflexão) e o cálculo da radiância em um ponto qualquer dentro do meio material (também encontrada na literatura como luz dispersada, assim como nesse estudo).

- Radiância na superfície do planeta

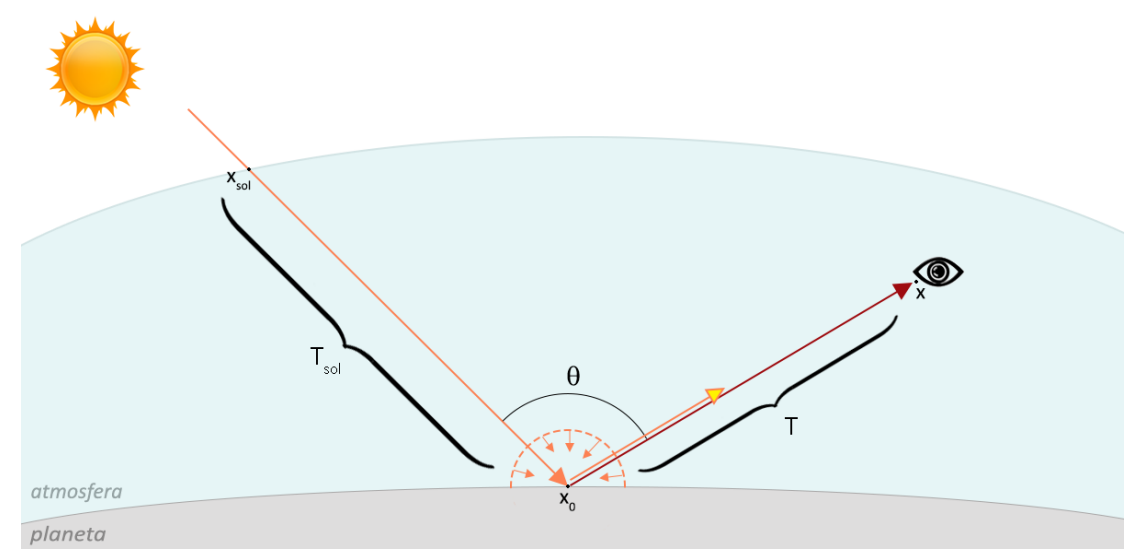

Figura 4.6: Radiância na superfície do planeta

A Figura 4.6 ilustra o caso da radiância na superfície do planeta. A partir dela, pode-se especificar cada um dos termos que irão compor a equação de radiância devido a reflexão no ponto $x_{0}$ na superfície.

$$
I_{x_{0}}=\frac{\alpha_{x_{0}}}{\pi} \int_{0}^{2 \pi} T_{\text {sol }}\left(x_{s o l}, x_{0}\right) I_{x_{s o l}} f(\theta) d \theta
$$


onde:

$I_{x_{0}} \quad=$ Intensidade da luz no ponto $x_{0}$

$\alpha_{x_{0}} \quad=$ Fator de reflectância no ponto $x_{0}$

$\frac{1}{\pi}=$ Fator de normalização devido a integração sobre o hemisfério

$T_{\text {sol }}\left(x_{\text {sol }}, x_{0}\right)=$ Transmitância entre os pontos $x_{s o l}$ e $x_{0}$

$I_{x_{\text {sol }}} \quad=$ Intensidade da luz incidente (neste caso, a luz solar)

$f(\theta) \quad=$ Função de fase

- Radiância em um ponto qualquer do meio material

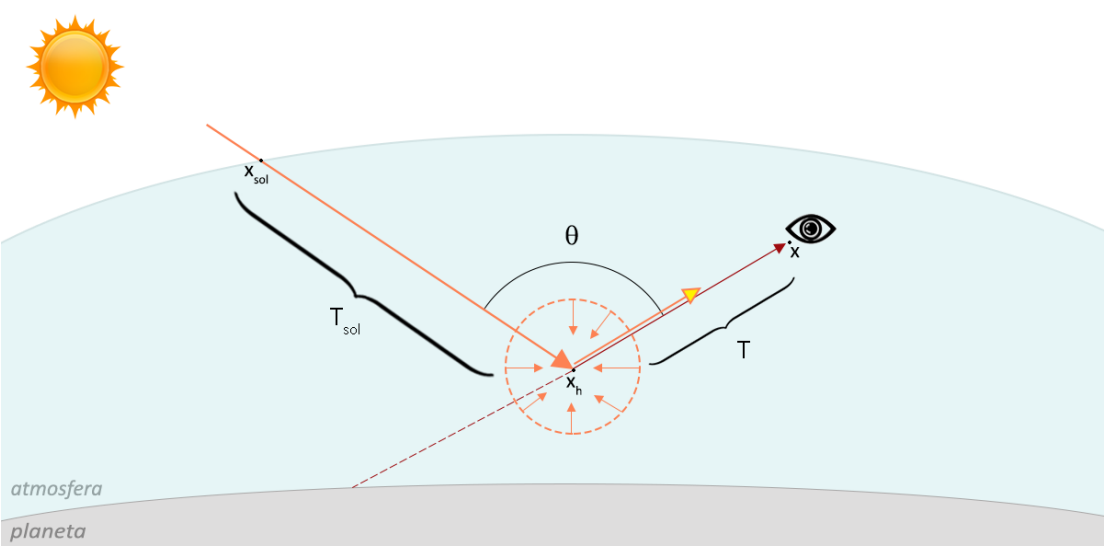

Figura 4.7: Radiância em um ponto qualquer do meio material

A Figura 4.7 ilustra o caso da radiância em qualquer ponto do meio material. A partir dela, podemos especificar cada um dos termos que irão compor a equação de radiância no ponto $x_{h}$ no meio material.

$$
I_{x_{h}}=\int_{0}^{4 \pi} \sum \beta_{\text {extincao }}(\lambda) P(\cos \theta) T_{\text {sol }}\left(x_{\text {sol }}, x_{h}\right) I_{x_{\text {sol }}} d \theta
$$

onde:

$I_{x_{h}} \quad=$ Intensidade da luz no ponto $x_{h}$

$\beta_{\text {extincao }}(\lambda)=$ Coeficiente de extinção (dependente do regime atmosférico)

$P(\cos \theta) \quad=$ Função de fase (dependente do regime atmosférico)

$T_{\text {sol }}\left(x_{\text {sol }}, x_{h}\right)=$ Transmitância entre os pontos $x_{\text {sol }}$ e $x_{h}$

$I_{x_{\text {sol }}} \quad=$ Intensidade da luz incidente (neste caso, a luz solar) 


\section{7}

\section{Dispersão atmosférica}

Foi visto na seção 2.10, que a luz pode não sofrer nenhuma dispersão, uma única dispersão ou múltiplas dispersões. Nesse estudo, será estudado apenas o modelo de uma única dispersão. Neste modelo, a luz incide na atmosfera pelo ponto $x_{\text {sol }}$, colide uma única vez no ponto $x_{0}$ e é redirecionada para a direção da visão do observador $\overrightarrow{x_{0}} x$.

Nas seções 4.4, 4.5 e 4.6 foram vistas as principais equações que definem os diversos aspectos que envolvem a dispersão da luz; desde o tipo do regime atmosférico até as equações de atenuação da luz ao longo de uma trajetória. No entanto, ainda é preciso interligar esses equações e formar uma equação geral que define todo o processo de dispersão atmosférica.

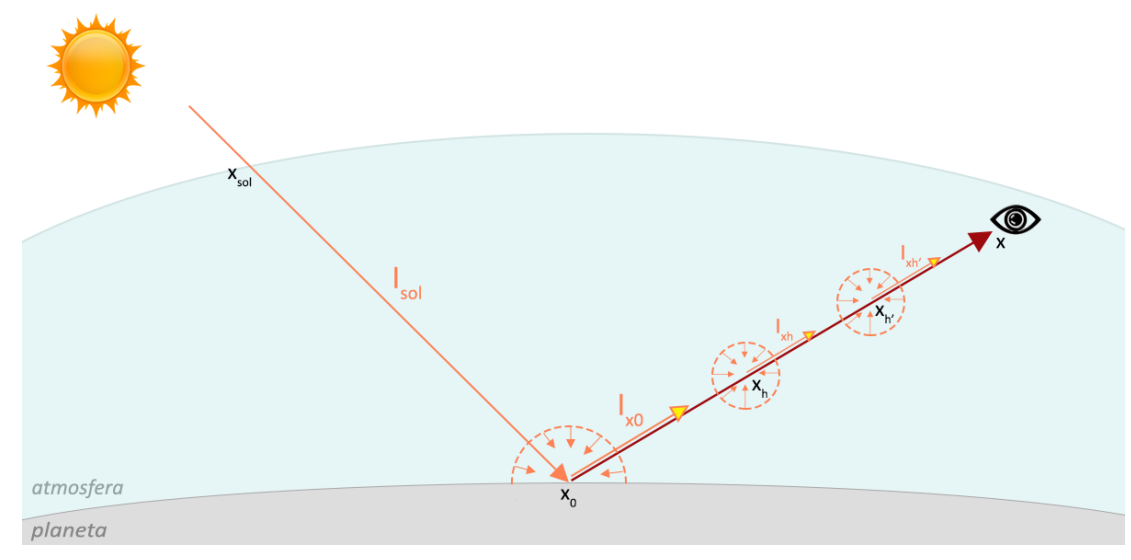

Figura 4.8: Modelo de dispersão simples

A Figura 4.8 ilustra o processo de dispersão atmosférica simples. A partir dela, é possível observar que a luz que chega aos olhos do observador é a soma da luz do sol $\left(I_{s o l}\right)$ atenuada de $x_{s o l} \rightarrow x_{0}$, da luz refletida na superfície $\left(I_{x_{0}}\right)$ atenuada de $x_{0} \rightarrow x$ e do somatório das diversas contribuições da luz dispersada no meio material $\left(I_{x_{h}}\right)$ atenuadas de $x_{0} \rightarrow x$.

$$
I_{x}=T\left(x_{s o l}, x_{0}\right) I_{s o l}+T\left(x_{0}, x\right) I_{x_{0}}+\int_{x_{0}}^{x} T\left(x_{h}, x\right) I_{x_{h}}
$$

A resolução da equação 4.7 .1 permitirá representar o fenômeno de dispersão atmosférica simples. Sendo assim, a próxima etapa é conhecer como cada uma das técnicas resolve essa equação. 


\section{5}

\section{Estudo das técnicas}

No capítulo 1, definiu-se que esse estudo irá explicar e analisar duas técnicas diferentes usadas para representar o fenômeno de dispersão atmosférica. A técnica de Bruneton e Neyret [32] (baseada em modelo físico) e a técnica de Schuler [61] (baseada em modelo analítico e aproximações). Nesse capítulo serão apresentados os detalhes de cada técnica e suas implementações.

Primeiramente, serão definidos alguns pontos em comum entre as duas técnicas, são eles:

- O planeta é considerado uma esfera perfeita, assim como toda e qualquer órbita ou camada ao seu redor.

- As duas técnicas permitem qualquer posição do observador, ou seja, a posição do observador pode variar desde a superfície do planeta até qualquer ponto no espaço.

- Ao calcular o fenômeno de dispersão atmosférica (considerando apenas uma única dispersão) pode-se simplificar o cálculo da radiância para uma simples aproximação do produto escalar da normal da superfície do planeta com a direção da luz, permitindo assim, a execução em tempo real. Isso se deve ao fato do modelo de única dispersão considerar apenas uma única fonte de luz, usualmente, o Sol. A Figura 5.1 ilustra essa situação.

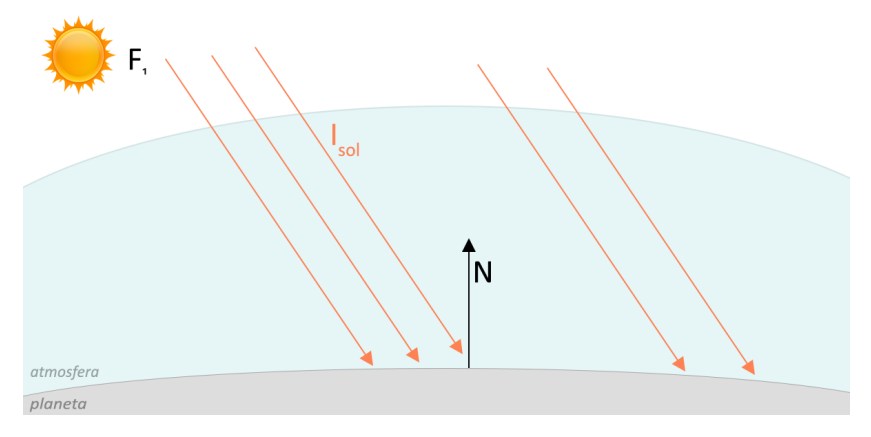

Figura 5.1: Aproximação da radiância em uma única dispersão

No modelo de múltiplas dispersões, que considera diversas fontes de luz, o calculo da radiância é mais complexo devido a necessidade de calcular o somatório das luzes provenientes de diversas direções incidentes em um mesmo ponto de inspeção. A Figura 5.2 ilustra essa situação. 


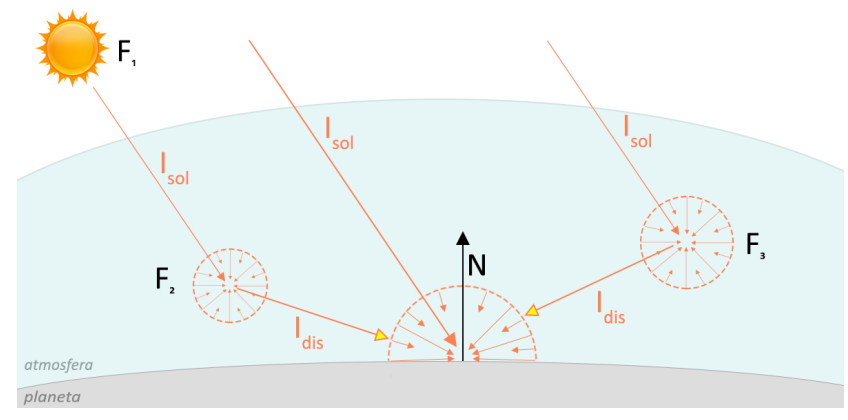

Figura 5.2: Radiância em múltiplas dispersões

onde:

$N=$ Normal da superfície

$F_{i}=$ Fonte de luz

$I_{\text {sol }}=$ Luz solar

$I_{d i s}=$ Luz dispersada

- A fonte de luz (Sol, neste caso) está tão distante do ponto de onde está sendo feita a análise da dispersão atmosférica que os raios podem ser considerados paralelos.

- A densidade da atmosfera varia em relação a altitude (conforme visto na seções 2.3 e 4.1) e não em relação a latitude e longitude.

- O sistema de coordenadas é baseado na nomenclatura astrônomica, conforme é ilustrado na Figura 5.3.

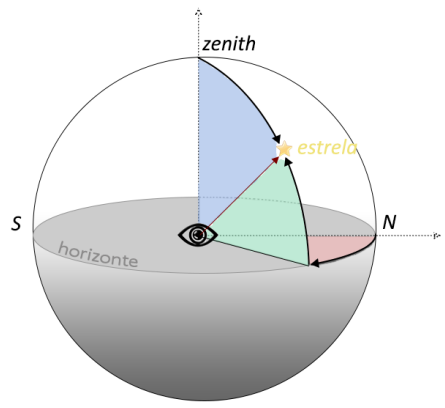

Ângulo de zenith: medido a partir da vertical

Ângulo de elevação/altitude: medido de baixo para cima a partir do horizonte

Ângulo de azimuth: medido no sentido horário a partir no Norte

Direção para onde o observador está olhando

Figura 5.3: Sistema de coordenadas astronômico

- É muito recorrente o uso do cosseno do ângulo com o eixo zenith, conforme é ilustrado na Figura 5.4. 


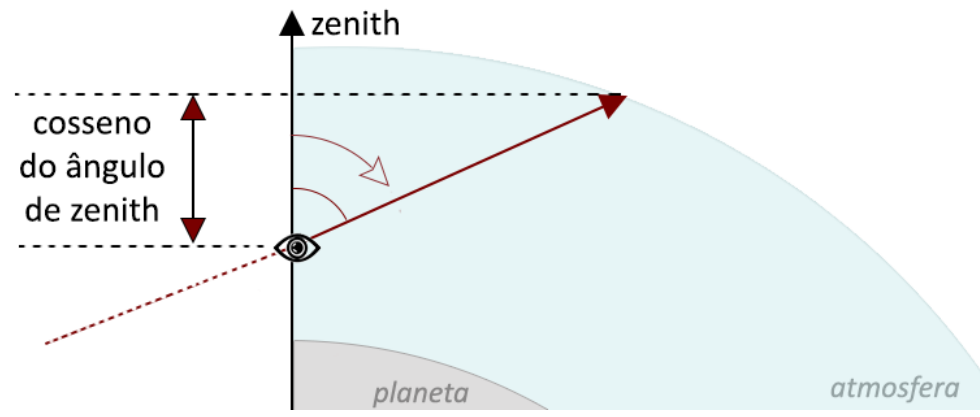

Figura 5.4: Cosseno do ângulo de zenith

\section{1}

\section{Bruneton e Neyret}

A técnica proposta por Bruneton e Neyret [32] é baseada em um modelo físico que representa o fenômeno. Sendo assim, tende a considerar equações com maior rigor físico-matemático a fim de tornar a visualização do fenômeno de dispersão atmosférica mais fotorealística. Por outro lado, a busca pela fidelidade com o mundo real faz com que esse tipo de modelo torne-se mais custoso devido a complexidade de se calcular essas equações; equações estas que já foram explicadas e definidas nesse estudo nos capítulos 2 e 4, respectivamente. Logo, nesta seção pode-se apresentar apenas os detalhes de implementação da técnica.

\subsection{1}

\section{Detalhes de implementação}

A técnica original considera múltiplas dispersões e os regimes atmosféricos de Rayleigh e de Mie. Porém, nesse estudo, será considerado apenas um sub-caso da técnica original: uma única dispersão e apenas o regime atmosférico de Rayleigh. Sendo assim, será feita uma simplificação no modelo de Bruneton e Neyret da seguinte forma:

1. Redução das etapas de pré-processamento

A etapa original de dispersão simples consiste de cinco programas (cada um com vertex e fragment shader) em pré-processamento, conforme ilustra a Figura 5.5. Essa etapa gera, no total, três texturas 2D e duas texturas $3 \mathrm{D}$ quando considerado apenas o regime atmosférico de Rayleigh. Caso o regime atmosférico de Mie seja considerado, é gerada mais uma textura 3D.

No entanto, é possível realizar uma simplificação na proposta de Bruneton e Neyret. Pode-se reduzir para dois programas (cada um com 


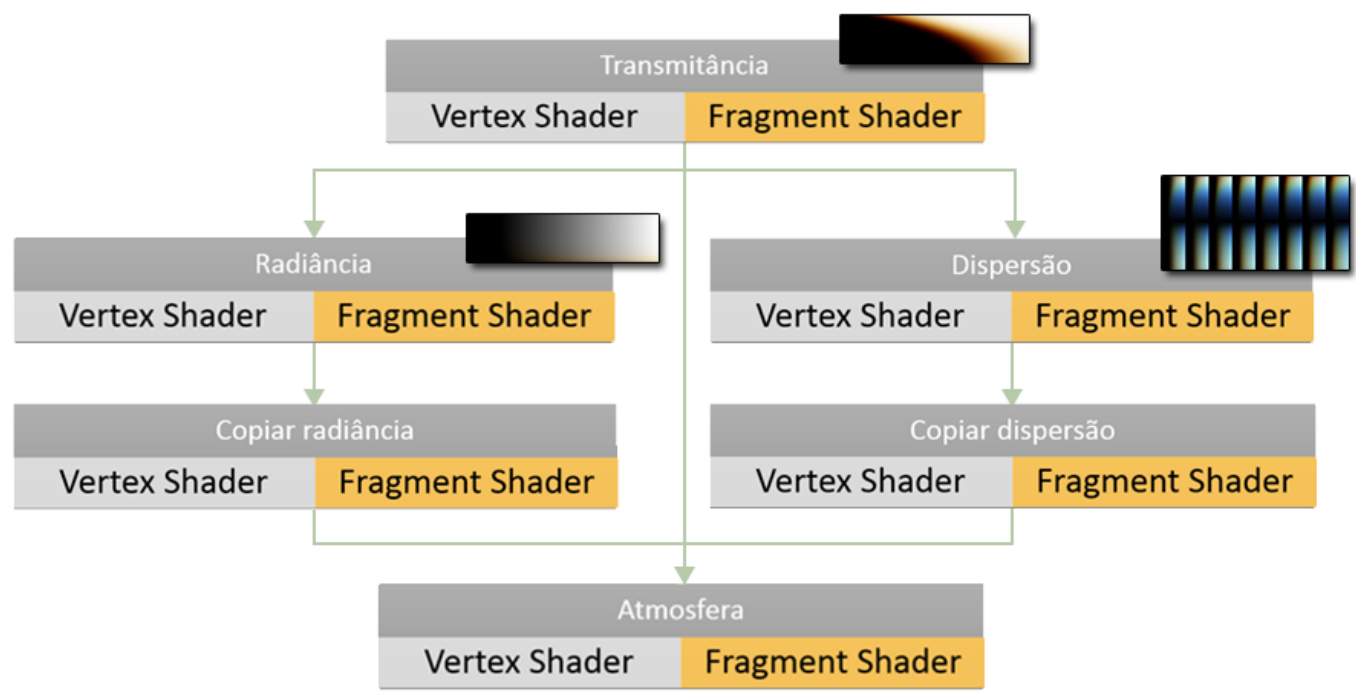

Figura 5.5: Esquemático das etapas de renderização proposta por Bruneton e Neyret para dispersão simples considerando apenas o regime de Rayleigh

vertex e fragment shader) em pré-processamento, conforme ilustra a Figura 5.6. Isso faz com que seja gerada apenas uma textura $2 \mathrm{D}$ e uma textura 3D. Sendo assim, a simplificação proporciona a redução de três programas, duas texturas 2D e uma textura 3D (avaliada no capítulo de resultados). Essa redução só é possível de ser feita porque os shaders eliminados não são necessários para o cálculo do fenômeno de dispersão atmosférica considerando apenas uma única dispersão. Logo, ao implementar a técnica de Bruneton e Neyret completa (com múltiplas dispersões) é necessário incluir esses shaders novamente.

\subsection{2}

\section{Renderização}

Na Figura 5.6 pode-se observar que são utilizados três programas diferentes para renderizar o fenômeno de dispersão atmosférica. Os dois primeiros são utilizados em pré-processamento e apenas o programa Atmosfera é utilizado em tempo real. A seguir, estão os pontos mais importantes desses programas: 


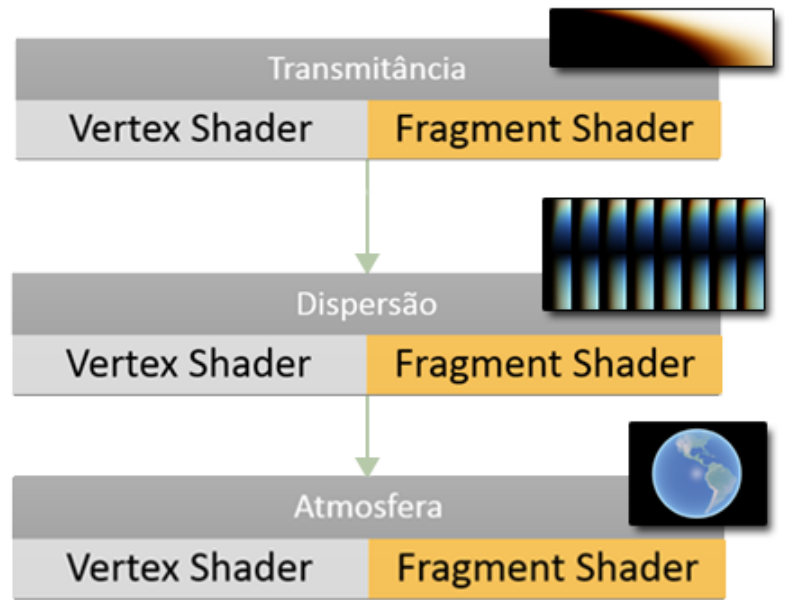

Figura 5.6: Esquemático das etapas de renderização proposta nesse estudo para dispersão simples considerando apenas o regime de Rayleigh

\subsection{3}

\section{Transmitância}

O programa Transmitância é utilizado para calcular a transmitância, conforme foi visto nas seções 2.8 e 4.5 e gerar uma textura 2D com o resultado desse cálculo. Ele deve ser o primeiro programa a ser executado durante a etapa de pré-processamento, pois seu resultado é utilizado como entrada para os outros programas como Radiância e Dispersão.

A primeira etapa do cálculo da transmitância é determinar a altitude (dentro da atmosfera) e o cosseno do ângulo de incidência do Sol. Através da Figura 5.7 pode-se observar os limites da altitude e do ângulo de incidência do Sol. A altitude pode variar da superfície do planeta até o topo da atmosfera ${ }^{1}$ e o cosseno do ângulo de incidência pode variar de até o momento em que o raio solar tangencia a superfíce do planeta. ${ }^{2}$.

\footnotetext{
${ }^{1}$ Lembre-se que o observador pode ter qualquer altitude, porém o cálculo da transmitância é feito apenas dentro da camada atmosférica.

${ }^{2}$ Lembre-se que é bastante utilizado o cosseno do ângulo de zenith.
} 


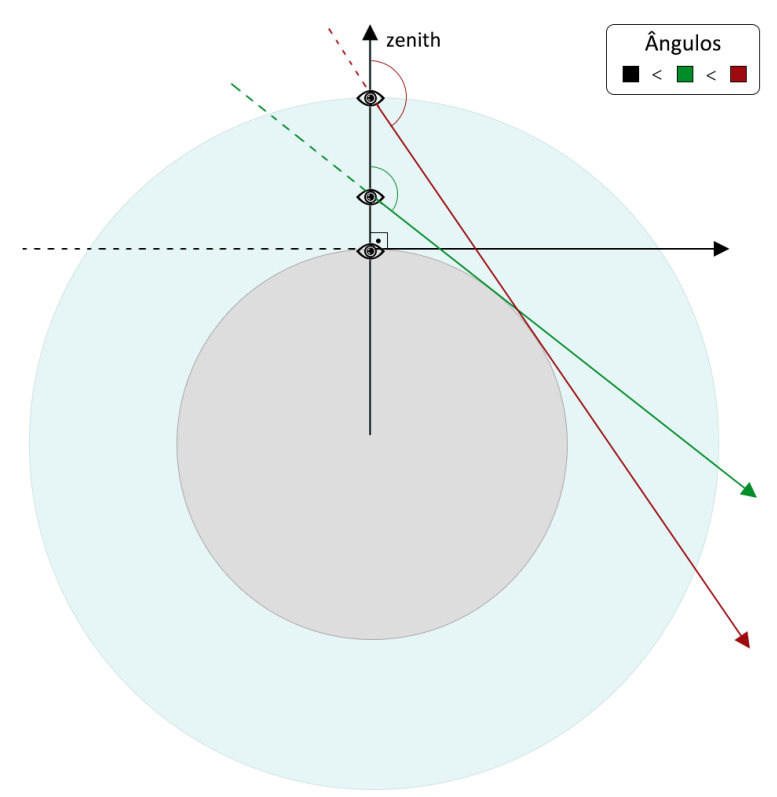

Figura 5.7: Limites da altitude e do cosseno do ângulo de incidência do Sol

A segunda etapa é calcular a menor distância do raio solar (determinado em função da altitude e do cosseno do ângulo de incidência do Sol) com a superfície do planeta ou com o topo da atmosfera. Para isso, é necessário calcular a interseção desse raio com a superfície do planeta e com a atmosfera. O cálculo da interseção pode ser feito facilmente através do uso da fórmula de Bhaskara. Uma vez definidos os pontos de interseção (raízes da equação de Bhaskara), basta escolher o menor caminho no sentido de propagação do raio (para a colisão com a atmosfera, escolhe-se a maior raiz da equação de Bhaskara enquanto a colisão com o planeta escolhe-se a menor raiz). A Figura 5.8 ilustra essa etapa. 


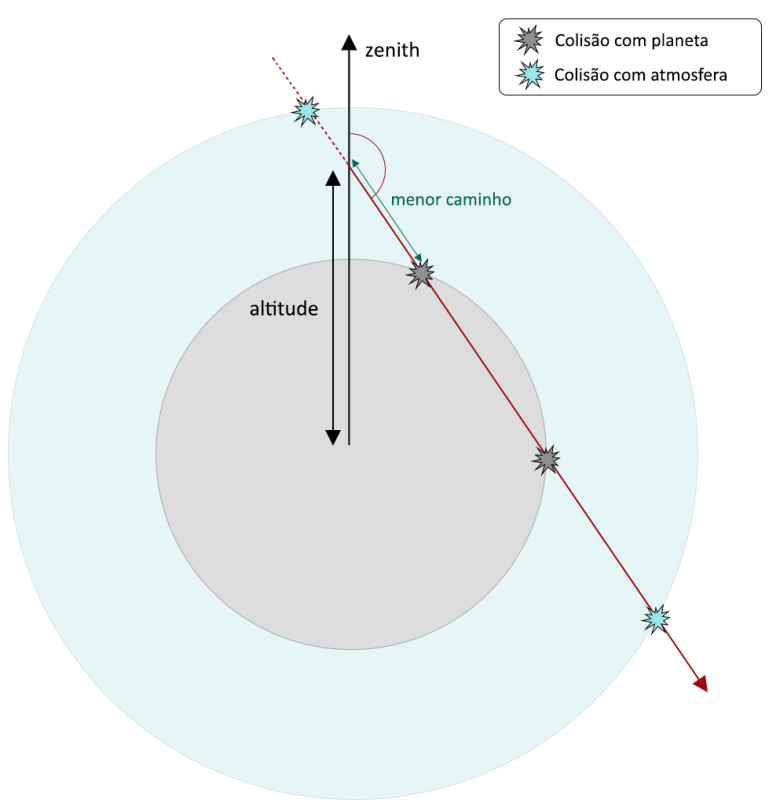

Figura 5.8: Pontos de interseção e menor distância entre o observador e o ponto de interseção

A terceira etapa é calcular a profundidade óptica. Para calcular a profundidade óptica, divide-se o menor caminho (encontrado na segunda etapa) em diversos pedaços menores, conforme ilustra o lado esquerdo da Figura 5.9. Após a divisão, calcula-se a integral ao longo do menor caminho levando em consideração cada um dos pedaços. O cálculo da integral é possível de ser feito através de trigonometria usando apenas a altitude e o ângulo de incidência da luz. O lado direito da Figura 5.9 ilustra, resumidamente, como pode deve ser pensado o cálculo da integral via trigonometria.
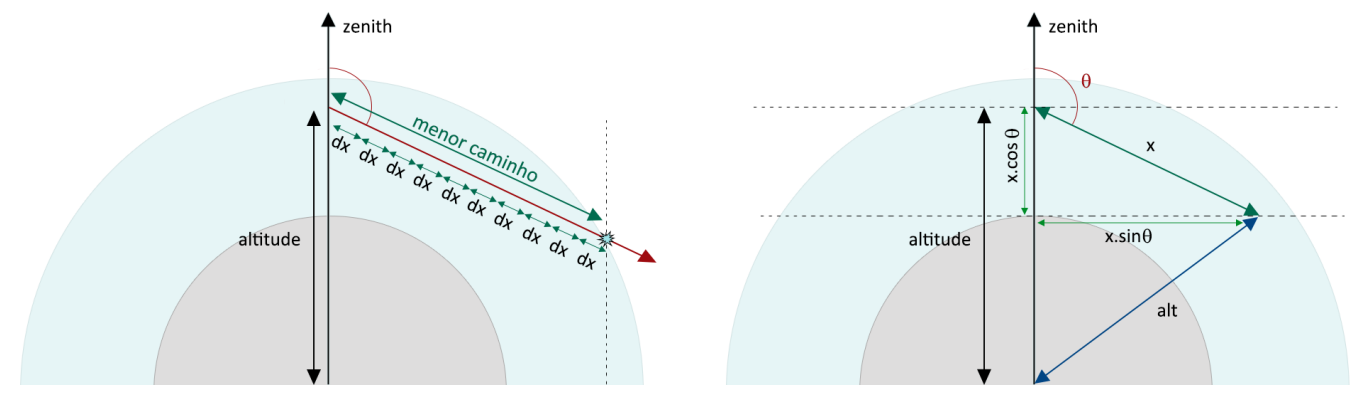

Figura 5.9: Cálculo da profundidade óptica 
A etapa final é calcular a equação de transmitância 4.5.5 definida na seção 4.5 usando o resultado do cálculo da profundidade óptica.

A Figura 5.10 ilustra o resultado do cálculo da transmitância, onde o eixo das abscissas representa o cosseno do ângulo de incidência da luz e o eixo das ordenadas representa a altitude dentro da camada atmosférica.

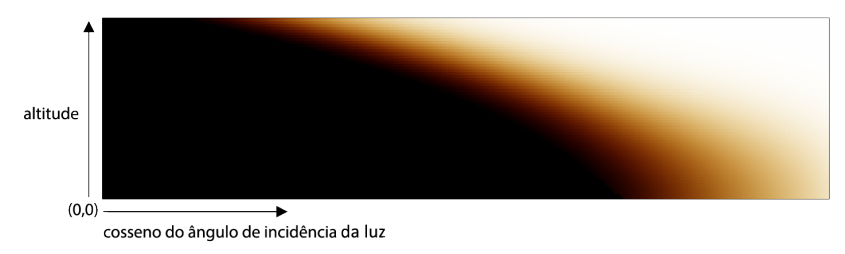

Figura 5.10: Resultado da transmitância

\subsection{4 \\ Dispersão}

O programa Dispersão é utilizado para calcular a dispersão (ou radiância no meio material), conforme foi visto nas seções 2.9 e 4.6 e gerar uma textura 4D (que pode ser entendida como uma textura 3D que armazena informações de 4 variáveis) com o resultado desse cálculo.

A principal etapa do cálculo da dispersão é determinar o cosseno do ângulo de incidência da luz, o cosseno do ângulo de visão (para onde o observador está olhando) e o cosseno do ângulo entre a direção da luz e a direção de visão do observador para cada altura dentro da atmosfera. No entanto, a dificuldade é conseguir armazenar esses valores de forma eficiente sem que sejam necessárias diversas texturas e/ou texturas com altas resoluções. Para isso, Bruneton e Neyret fizeram uma reparametrização. Nessa reparametrização, os cálculos realizados para determinar os valores dos cossenos são realizados em função da altura relativa do observador em relação à superfície do planeta. Com essa modificação são evitados alguns artefatos em função de problemas de precisão numérica.

Além disso, são feitas outras modificações que tratam problemas de descontinuidade na linha do horizonte. ${ }^{3}$ Após realizar essas modificações, o cálculo da dispersão continua a ser executado de forma similar ao estudado na transmitância, ou seja, divide-se o caminho percorrido pela luz em diversos segmentos, integra-se cada segmento e assim por diante.

A Figura 5.11 ilustra o resultado do cálculo da dispersão, onde o eixo das abscissas representa o cosseno do ângulo de incidência da luz, o eixo das ordenadas representa o cosseno do ângulo de visão e a profundidade representa

${ }^{3}$ A reparametrização pode ser encontrada no artigo de Bruneton e Neyret [32] 
a altitude dentro da camada atmosférica. Conforme foi dito anteriormente a textura 3D, resultante do cálculo de dispersão, é utilizada para representar quatro parâmetros. O quarto parâmetro é o cosseno do ângulo visão-luz que pode ser observado em forma de diversas subdivisões a cada camada da textura $3 \mathrm{D}$.

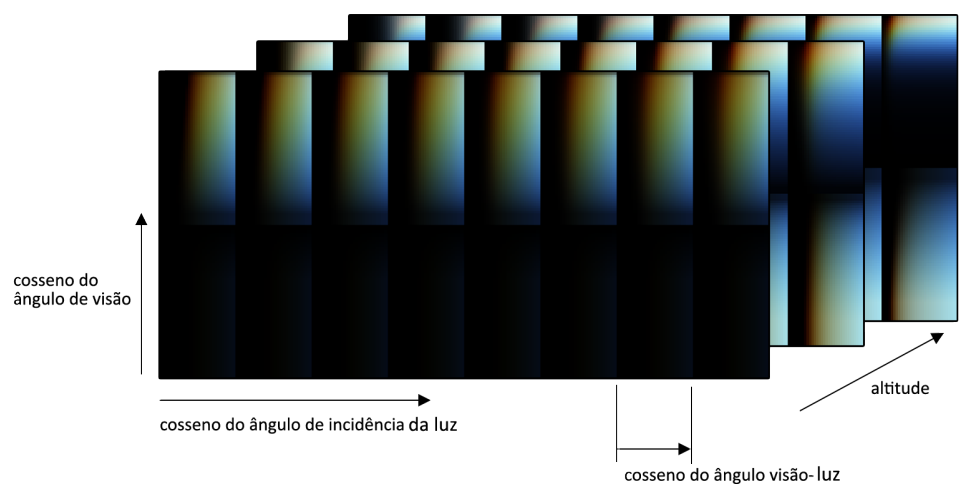

Figura 5.11: Resultado da dispersão considerando apenas o regime de Rayleigh

\subsection{5}

\section{Atmosfera}

O programa Atmosfera é utilizado para renderizar o processo de dispersão atmosférica.

A primeira etapa é calcular a altitude do observador e o ângulo de visão (para onde o observador está olhando). A segunda etapa é obter a distância do observador até o planeta através do uso da equação de Bhaskara. A terceira etapa é calcular a cor da superfície do planeta. A quarta etapa é calcular a cor do Sol. A quinta etapa é obter a cor do céu através das texturas de transmitância e dispersão. A etapa final é combinar as cores das etapas anteriores.

\section{2}

Schuler

O técnica proposta por Christian Schuler [61] é baseada em um modelo analítico e de aproximações. Sendo assim, tende a considerar equações com menor rigor físico-matemático a fim de otimizar os cálculos e agilizar processo de renderização. Por outro lado, isso torna a visualização do fenômeno de dispersão atmosférica menos fotorealística, uma vez que as equações utilizadas para representar o fenômeno são mais simples. Ao analisar a fórmula geral da dispersão amosférica 4.7.1, observa-se que existem diversas etapas onde é necessário calcular a transmitância. Diante desse fato, Schuler propôs uma 
aproximação matemática que otimiza o cálculo da transmitância devido a uma modificação na função de Chapman $C h(x, \chi)^{4}$ que será descrita ainda nesta seção. Porém, primeiramente, é preciso descrever alguns conceitos importantes utilizados por Schuler.

\subsection{1}

\section{Funções e Aproximações racionais}

Ao trabalhar com polinômios, pode-se realizar qualquer operação matemática básica como soma, subtração, multiplicação e divisão. No entanto, ao dividir polinômios nem sempre obtem-se outro polinômio (ao contrário das outras operações). Sendo assim, forma-se um quociente/fração que é chamado de função racional.

Já a aproximação racional consiste em definir uma fração ou o conjunto de frações que melhor aproximam um determinado valor. Esse valor que se pretende aproximar pode ser racional ou irracional. Isso se deve ao fato de se considerado apenas uma aproximação do valor e não o valor exato. Se o valor for racional, a aproximação é outra fração que, embora não seja equivalente, é mais simples e pode substituir em certas aplicações a fração que se pretende aproximar.

Esse estudo não irá se apronfudar na teoria sobre as funções e aproximações racionais. Caso seja necessário conhecer mais sobre o assunto recomenda-se: [5], [25], [7] e [10].

\section{2 .2}

\section{Massa de ar}

Nas seções 2.8 e 4.5 foi visto como é definida e calculada a transmitância. No entanto, ainda pode-se extrair um conceito a partir da transmitância chamado de massa de ar. A massa de ar é definida como o somatório da densidade atmosférica ao longo de um determinado caminho.

$$
m=\int_{S_{0}}^{S} \rho(s) d s
$$

\section{2 .3}

\section{A função de Chapman}

A função de Chapman é definida como uma função que calcula o somatório da densidade atmosférica em um dado raio/caminho dentro de uma ${ }^{4} \chi$ é a letra grega Chi. 
atmosfera esfericamente simétrica, decrescendo exponencialmente conforme a altura. Para entender melhor essa definição, será usada, como base, a Figura 5.12 .

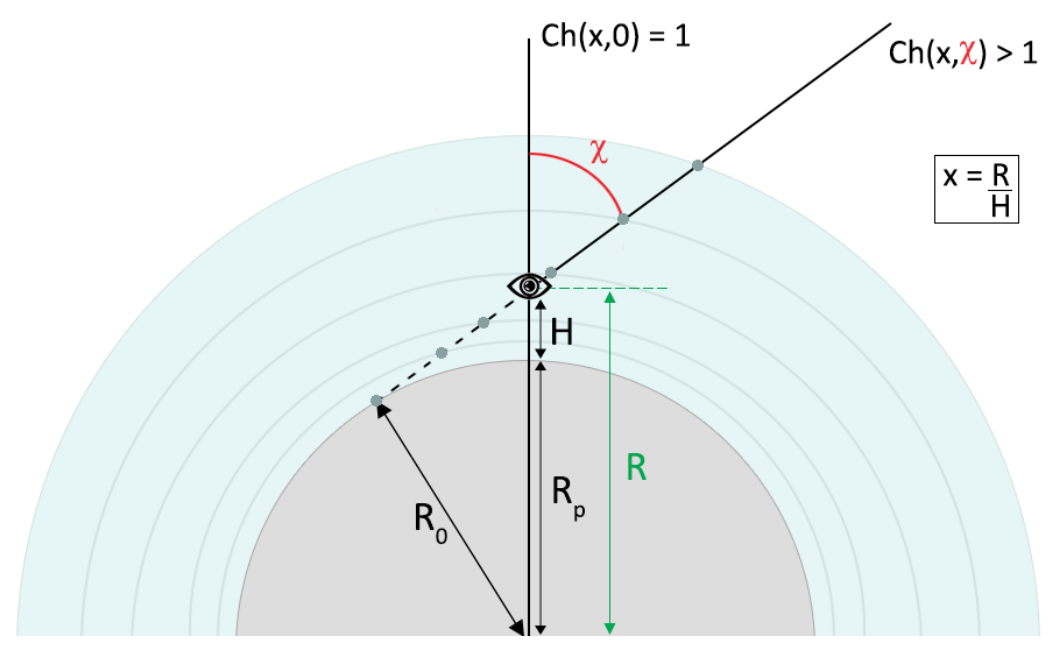

Figura 5.12: Função de Chapman

onde:

$R_{p}=$ Raio do planeta

$R_{0}=$ Menor altitude (relativa ao centro do planeta)

$R=$ Maior altitude (relativa ao centro do planeta)

$\chi=$ Angulo de incidência

$H=$ Fator de escala para a altura

$x=$ Altitude do observador normalizada

Na Figura 5.12 pode-se observar algumas sub-órbitas entre o planeta e o topo da atmosfera mas podem haver infinitas sub-órbitas. Através delas podese criar uma equação que define a altura em qualquer ponto - dado um ponto inicial e um parâmetro de escala - apenas usando a equação do círculo/esfera de cada uma dessas sub-órbitas.

$$
R(t)=\sqrt{R_{0}^{2}+t^{2}}
$$

onde:

$R_{0}=\mathrm{R} \sin \chi$

$t=$ Parâmetro de escala

Foi visto também nas seções 2.3 e 4.1 como é definida e calculada a densidade atmosférica. Com isso, pode-se combinar a equação de densidade atmosférica 4.1 .8 com a equação da massa de ar 5.2.1 e a equação da altura em um órbita qualquer 5.2.2, obtendo: 


$$
m=\rho_{0} \int_{r \cos \chi}^{\infty} \exp \left(\frac{R_{p}-\sqrt{R_{0}^{2}+t^{2}}}{H}\right) d t
$$

Porém, calcular a equação 5.2.3 não é trivial a não ser para um único caso: quando o ângulo de incidência é igual a zero. Nesse caso, a massa de ar é a coluna de ar sobre o observador, ou seja:

$$
\begin{aligned}
& m_{\perp}=\rho_{0} \exp \left(\frac{R_{p}-R}{H}\right) H \\
& m_{\perp}=\rho_{0} \exp \left(-\frac{h}{H}\right) H
\end{aligned}
$$

Aparentemente, essa situação está sem saída pois apenas um caso específico da equação da massa de ar é simples de ser calculado. Logo, o ideal seria conseguir uma maneira de relacionar $m_{\perp}$ com alguma outra equação mais simples a fim de resolver $m$. Neste momento, surge a função de Chapman [33] definida como:

$$
m=m_{\perp} C h(x, \chi)
$$

Em 1996, Kocifaj [46] descreve uma equação analítica que define a função de Chapman para usos gerais e não especificamente para a dispersão atmosférica. Porém, essa equação não é eficiente o bastante para ser utilizada em aplicações de tempo real devido a diversas razões como, por exemplo, o cálculo de uma função de erro, problemas de precisão numérica dependendo dos valores de $x$ e $\chi$, etc. Porém, Schuler a utilizou como base para a criação da sua variação da função de Chapman.

$$
\begin{gathered}
C h(x, \chi)=\frac{1}{2} \cos (\chi)+\frac{1}{2} \exp \left(\frac{x \cos ^{2}(\chi)}{2}\right) \operatorname{erfc}\left(\sqrt{\frac{x \cos ^{2}(\chi)}{2}}\right) \\
\left(\frac{1}{x}+2-\cos ^{2}(\chi)\right) \sqrt{\frac{\pi x}{2}}
\end{gathered}
$$

Representado graficamente, em um intervalo de $0^{\circ}<\chi<90^{\circ}$, pela Figura 5.13. 


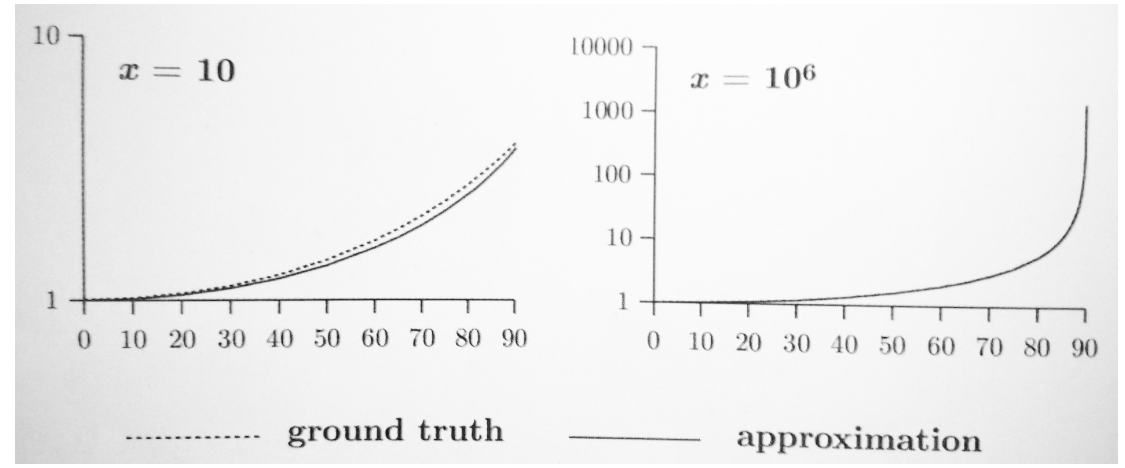

Figura 5.13: Representação gráfica da função de Chapman extraída do livro GPU Pro 3 [37]

\subsection{4}

\section{A função de Chapman segundo Schuler}

Após analisar a equação 5.2.6 e o gráfico 5.13, Schuler pode entender melhor a função de Chapman descrita por Kocifaj [46] e extrair algumas propriedades importantes para a sua própria função de Chapman, são elas:

1. A função é simétrica em relação à $\chi$

$$
C h(x, \chi)=C h(x,-\chi)
$$

Somente o cosseno do ângulo de incidência é considerado na equação 5.2.6 (devido à natureza do problema) tornando possível reduzir a variação do ângulo: $0^{\circ}<\chi<180^{\circ}$.

2. A função é unitária em $\chi=0$

$$
C h(x, 0)=1
$$

Como $m_{\perp}$ está relacionada com $m$, essa propriedade torna-se importante quando se está tratando de ângulos incidentes muito pequenos.

3. A função possui um limite para altos valores de $x$

$$
\lim _{x \rightarrow \infty} C h(x, \chi)=\frac{1}{\cos \chi}
$$

Quando o observador está muito distante do planeta, considera-se o planeta como sendo praticamente plano. Nestas condições, a função de 
Chapman é aproximada para a sua forma mais simples que é uma função secante.

Devido ao limite para altos valores de $x$ (terceira propriedade), sugerese a possibilidade da criação de uma aproximação racional. No entanto, essa aproximação precisava ter a menor ordem possível para que possa ser utilizdo em uma aplicação de tempo real. Sendo assim, Schuler buscou uma função racional de primeira ordem para o cosseno que aproximasse o limite inferior da função a 1 e o limite superior da função a um valor igual a função de Chapman avaliada em $\chi=90^{\circ}$ (descrita por Schuler como $C h_{\|}(x)$ ).

Através dessas características (que podem ser observadas na Figura 5.13), Schuler chegou à seguinte equação:

$$
C h(c, \chi)=\frac{c}{(c-1) \cos (\chi)+1}
$$

onde:

$C h(c, \chi)=$ Função aproximada de Chapman

$c=C h_{\|}(x)=$ Função de Chapman avaliada em $\chi=90^{\circ}$

$|\chi|<90^{\circ}=$ Módulo de ângulo de incidência é menor que $90^{\circ}$

Porém, essa equação deixa dois pontos importantes em aberto, são eles:

- Como calcular $c$ eficientemente?

Por mais que Schuler tenha definido uma aproximação para a função de Chapman, ela ainda possui uma dependência da função de Chapman de Kocifaj quando $\chi=90^{\circ}$. Sendo assim, para uma aplicação onde o observador está parado ainda é possível calcular em pré-processamento o valor de $c$ usando a equação 5.2 .6 mas, em uma aplicação onde o observador se movimenta livremente, a equação torna-se muito custosa de ser calculada em tempo-real. Logo, também foi preciso criar uma aproximação para $c$.

$$
c=C h_{\|}(x)=\left(\frac{1}{2 x}+1\right) \sqrt{\frac{\pi x}{2}}
$$

Por mais que a equação 5.2.11 seja mais simples, Schuler a simplifica ainda mais assumindo que $x$ é um valor muito alto. Com isso, é possível ignorar o termo $\frac{1}{2 x}$ e tornar a equação dependente apenas de $\sqrt{x}$. 


$$
\begin{aligned}
& c=C h_{\|}(x)=\sqrt{\frac{\pi x}{2}} \\
& c=C h_{\|}(x)=1.2533 \sqrt{x}
\end{aligned}
$$

onde:

$$
\sqrt{\frac{\pi}{2}} \cong=1.2533=\text { Constante de } c
$$

- A primeira propriedade diz que o ângulo de incidência pode variar de $0^{\circ}<\chi<180^{\circ}$. Então, porque a equação é aproximada apenas entre $0^{\circ}<\chi<90^{\circ} ?$

Schuler percebeu que, para ângulos maiores que $90^{\circ}$, a sua função crescia hiperbolicamente; o que ia de encontro com a definição da função de Chapman que diz que a função cresce exponencialmente. Sendo assim, Schuler precisou definir uma nova equação que abrangisse ângulos de incidência de maiores que $90^{\circ}$ usando apenas ângulos de $0^{\circ}$ até $90^{\circ}$.

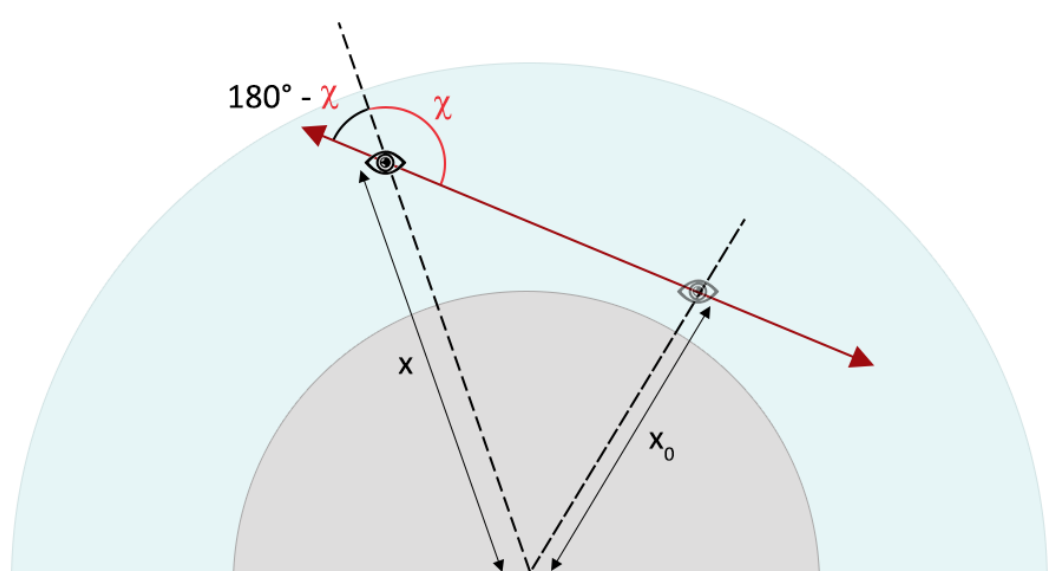

Figura 5.14: Massa de ar ao longo de um caminho

Veja a Figura 5.14. Schuler define uma equação que considera toda a massa de ar ao longo de um caminho usando funções de Chapman. Ela determina que a massa de ar total é a soma da massa de ar para trás do observador mais a massa de ar para frente do observador ao longo de um determinado caminho.

$$
m_{L}=\rho\left[C h(x, \chi)+C h\left(x, 180^{\circ}-\chi\right)\right]
$$

Ao analisar a equação 5.2.13 trigonometricamente, obteve-se: 


$$
m_{L}=2 \rho \exp \left(x-x_{0}\right) C h_{\|}\left(x_{0}\right)
$$

onde:

$$
\begin{array}{ll}
x_{0} & =x \sin \chi \\
\rho \exp \left(x-x_{0}\right) & =\text { Função que descreve a densidade entre dois pontos }
\end{array}
$$

Combinando as equações 5.2.13 e 5.2.14, tem-se:

$$
C h(x, \chi)=2 \exp \left(x-x_{0}\right) C h_{\|}\left(x_{0}\right)-C h\left(x, 180^{\circ}-\chi\right)
$$

Ou seja, se a função de Chapman é conhecida para $0^{\circ}<\chi<90^{\circ}$ então ele é conhecida também $0^{\circ}<\chi<180^{\circ}$.

\section{2 .5}

\section{Detalhes de implementação}

Após definir uma aproximação para a função de Chapman 5.2.15, Schuler precisou ajustar e melhorar alguns detalhes a fim de torná-la compatível com casos específicos do fenômeno, além de deixar sua equação mais precisa e eficiente para que pudesse ser utilizada em aplicações de tempo-real. Ele fez três importantes modificações, são elas:

1. Intervalo numérico

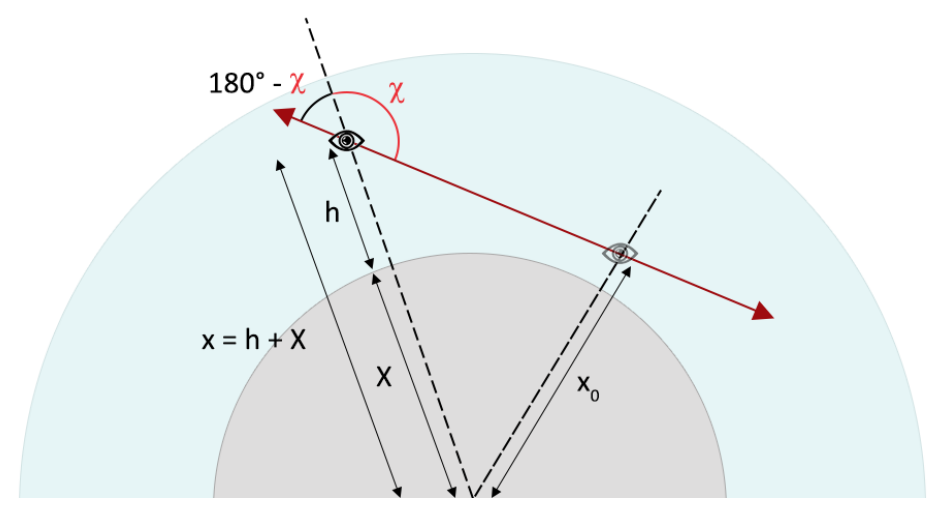

Figura 5.15: Modificação da função de Chapman para tratar o problema de precisão numérica

A primeira modificação é feita a fim de resolver um problema de precisão numérica que ocorre quando o valor de $x$ é muito maior que o valor de $x_{0}$ devido ao fato da equação de Chapman basear-se em $\exp \left(x-x_{0}\right)$; 
conforme foi visto na equação 5.2.15. Para resolver esse problema, modificou-se a função de Chapman da seguinte forma:

$$
C h_{h}(X, h, \chi)=C h(X+h, \chi) \exp (-h)
$$

onde:

$X=$ Altitude de referência (geralmente é o raio do planeta, ou seja, nível do mar)

$h=$ Altitude do observador em relação a $X$

$\chi=$ Ângulo de incidência

A inclusão do termo $\exp (-h)$ na equação 5.2.16 pode ser facilmente justificada através da seguinte igualdade:

$$
\exp \left(x-x_{0}\right) \exp (-h)=\exp \left(X-x_{0}\right)
$$

2. Distâncias aproximadas

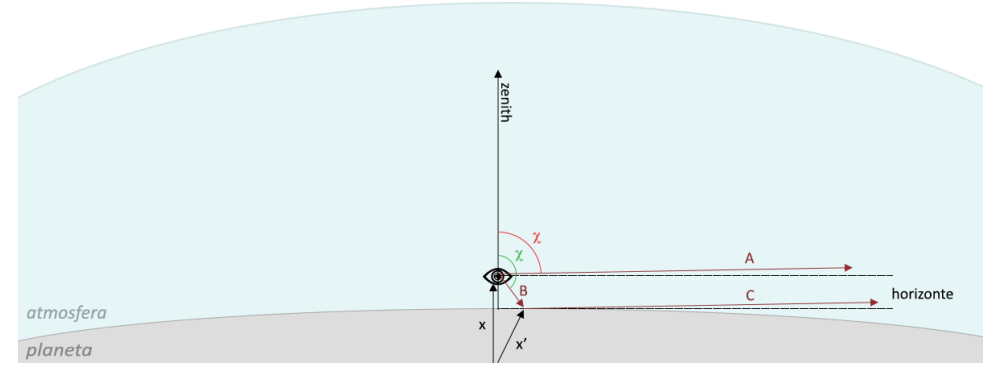

Figura 5.16: Modificação da função de Chapman para tratar caminhos com distâncias aproximadas

A segunda modificação é feita para tratar caminhos que possuem distâncias aproximadas. Schuler precisava se certificar de que sua aproximação da função de Chapman também contemplava esse tipo de situação. Um caso abordado por Schuler foi o dos raios refletidos, conforme é ilustrado na Figura 5.16. Para entender essa situação, Schuler definiu três equações diferentes que representam a massa de ar ao longo de três caminhos distintos, são elas:

$$
\begin{aligned}
& m_{A}=C h(x, \chi) \\
& m_{B}=C h\left(x, 180^{\circ}-\chi\right)-C h\left(x^{\prime}, 180^{\circ}-\chi\right) \\
& m_{C}=C h\left(x^{\prime}, \chi\right)
\end{aligned}
$$


É possível notar que $m_{A}$ e $m_{C}$ são equações que possuem o ângulo de incidência menor que $90^{\circ}$ (logo possuem uma equação similar) e que $m_{B}$ possui o ângulo maior que $90^{\circ}$ justificando a diferença na forma como as equações são descritas.

Ao considerar o observador muito próximo da superfície refletora (oceano, por exemplo) e com ângulo de incidência muito próximo da linha do horizonte, é possível considerar que $m_{A} \cong m_{B}+m_{C}$. Porém, ao aplicar e analisar essa condição, Schuler percebeu que sua aproximação não era válida pois a forma como foi escrita a equação do denominator da equação 5.2.10 e a constante de $c$ da equação 5.2.12 não permitiam confirmar a igualdade. Sendo assim, Schuler definiu uma nova aproximação:

$$
C h(c, \chi)=\frac{c}{c \cos (\chi)+1}
$$

onde:

$$
\begin{aligned}
& C h(c, \chi)=\text { Função aproximada de Chapman } \\
& c=\sqrt{x}=\text { Raiz da distância até o observador }
\end{aligned}
$$

Schuler percebeu que a remoção da constante de $c$ não fazia muita diferença no resultado visual, ao contrário da mudança no denominador. No entanto, Schuler afirma que não há perda na qualidade visual caso a posição do observador esteja pelo menos na casa das centenas (escala usualmente usada na representação da dispersão atmosférica). Caso seja necessário ajustar eventuais problemas visuais devido a posição do observador, Schuler afirma que o aumento do coeficiente de dispersão atmosférico ajuda na melhoria desses resultados.

3. Eficiência do uso da função exponencial e da função de potência de dois A terceira modificação é feita para substituir uso da função exponencial $\left(e^{x}\right)$ pelo uso da potência de $2\left(2^{x}\right)$. Isso se deve ao fato do custo de execução de uma ser maior do que a outra. No entanto, a substituição exige que todos os fatores de escala também sejam modificados da seguinte forma: ao invés de usar o fator integral da escala para a altura $H$ precisa-se usar apenas $50 \%$ desse fator, o coeficiente de dispersão $\beta$ também precisa ser apenas $50 \%$ e assim por diante. 


$$
\begin{array}{r}
H_{50}=H \ln 2 \\
\beta_{50}=\beta \ln 2
\end{array}
$$

\section{2 .6}

\section{Renderização}

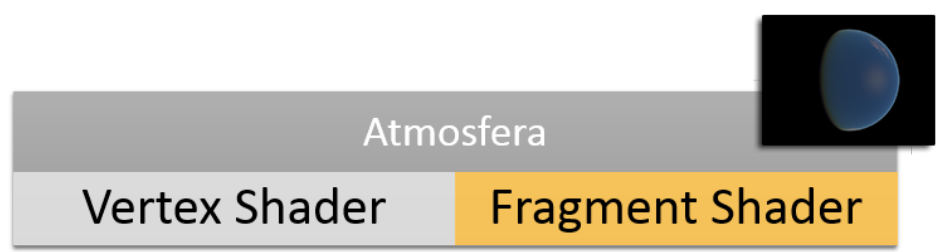

Figura 5.17: Esquemático das etapas de renderização da proposta de Schuler

Na Figura 5.17 pode-se observar que é utilizado apenas um único programa para renderizar o fenômeno de dispersão atmosférica. O programa Atmosfera é utilizado em tempo real, ou seja, não há nenhuma etapa de préprocessamento. A seguir, estão os pontos mais importantes desse programa.

\subsection{7}

\section{Atmosfera}

O programa Atmosfera é utilizado para calcular a transmitância, a dispersão e renderizar o processo de dispersão atmosférica.

A primeira e segunda etapa são similares as etapas do programa Atmosfera de Bruneton e Neyret, ou seja, calcular a altitude do observador, o ângulo de visão (para onde o observador está olhando) e obter a distância do observador até o planeta (usando a equação de Bhaskara). A partir daí, começam as mudanças.

A etapa seguinte consiste em verificar se houve ou não colisão com o planeta através do uso do ponto de interseção calculado na etapa anterior. Diante disso, existem duas possibilidades: houve colisão ou não houve colisão com o planeta. A principal diferença entre os dois casos é que quando há colisão, é necessário considerar a cor da superfície do planeta, reflexões devido ao oceano e outros fatores desta natureza; além do cálculo da transmitância e da dispersão. Caso não haja colisão, basta calcular a transmitância e a dispersão. Em ambos os casos, a transmitância e a dispersão são calculadas da seguinte forma: 
1. Calcula-se os limites do caminho percorrido pela luz na atmosfera

2. Define-se, antes da primeira integração, os principais parâmetros para o cálculo da transmitância e da dispersão: cosseno no ângulo de incidência do Sol, altitude (dentro da atmosfera), cosseno do ângulo de visão, quantidade de segmentos que serão integrados, entre outros.

3. Integra-se cada segmento da seguinte forma:

- Calcula-se a altitude ao longo do caminho

- Normaliza-se a altitude em relação a 50\% da altura (de acordo com a terceira modificação proposta por Schuler)

- Calcula-se o cosseno do ângulo de incidência e o de visão para o segmento

- Calcula-se a massa de ar ao longo do segmento utilizando a função de Chapman

- Calcula-se a transmitância utilizando o resultado da função de Chapman

- Calcula-se a dispersão utilizando o resultado da função de Chapman

Ambas as técnicas possuem código-fonte, minimamente, documentado que auxiliam no entendimento das técnicas. Sendo assim, ao unir esse estudo aos artigos originais e seus respectivos códigos-fonte, o autor acredita que seja possível o entendimento detalhado (fenômeno físico e renderização) das técnicas sem que haja necessidade de material complementar. 


\section{6}

\section{Resultados}

Neste capítulo serão apresentados os resultados, uma discussão sobre eles e suas limitações. No entanto, é importante ressaltar que (em todas as técnicas) não foram considerados os tamanhos físicos, em disco, dos arquivos que contém o código-fonte que implementam as técnicas; sejam eles códigos executados em $\mathrm{CPU}^{1}$ ou GPU ${ }^{2}$. Em outras palavras, estão sendo considerados somente os arquivos gerados pelas técnicas uma vez que, inerentemente, ambas as técnicas possuem código-fonte e que, por sua vez, podem possuir tamanhos diferentes dependendo da forma e das práticas de implementação.

\section{1}

\section{Hardware e tecnologia utilizada}

Os resultados apresentados a seguir foram obtidos através da execução das técnicas propostas nesse estudo em um computador com a seguinte especificação: Processador Intel Core i5 3.40GHz, 8GB de memória RAM, placa de vídeo NVIDIA GeForce GTX 560, Monitor Samsung SyncMaster T220M 60Hz, HD SATA com 750 MB e sistema operacional Windows 8 (versão 64 bits). Essas mesmas técnicas foram executadas em outros computadores com especificações similares e não apresentaram diferença significativa em seus resultados comparado aos resultados obtidos com a especificação citada anteriormente.

Embora não tenham sido feitos testes experimentais em computadores com especificações defasadas (em relação a especificação anterior) e em dispositivos móveis, vale salientar a necessidade do uso de uma tecnologia que tenha suporte a programação de shaders, textura 3D e, dependendo da técnica a ser utilizada, é preciso que haja um espaço de armazenamento mínimo que permita armazenar os arquivos gerados pelas técnicas (conforme ilustra a Figura 6.16).

As técnicas foram implementadas utilizando $\mathrm{C}++$, OpenGL e GLSL ${ }^{3}$. No entanto, é possível implementá-las utilizando quaisquer linguagens de programação que dêem suporte aos requisitos citados anteriormente.

\footnotetext{
${ }^{1}$ Central Processing Unit

${ }^{2}$ Graphics Processing Unit

${ }^{3}$ OpenGL Shading Language
} 
Um estudo sobre técnicas de renderização do fenômeno de dispersão atmosférica

\section{2}

\section{Captura do tempo}

Para capturar o tempo de execução, foi necessário utilizar as funções QueryPerformanceFrequency e QueryPerformanceCounter. Essas funções são responsáveis por capturar o tempo com alta precisão numérica.

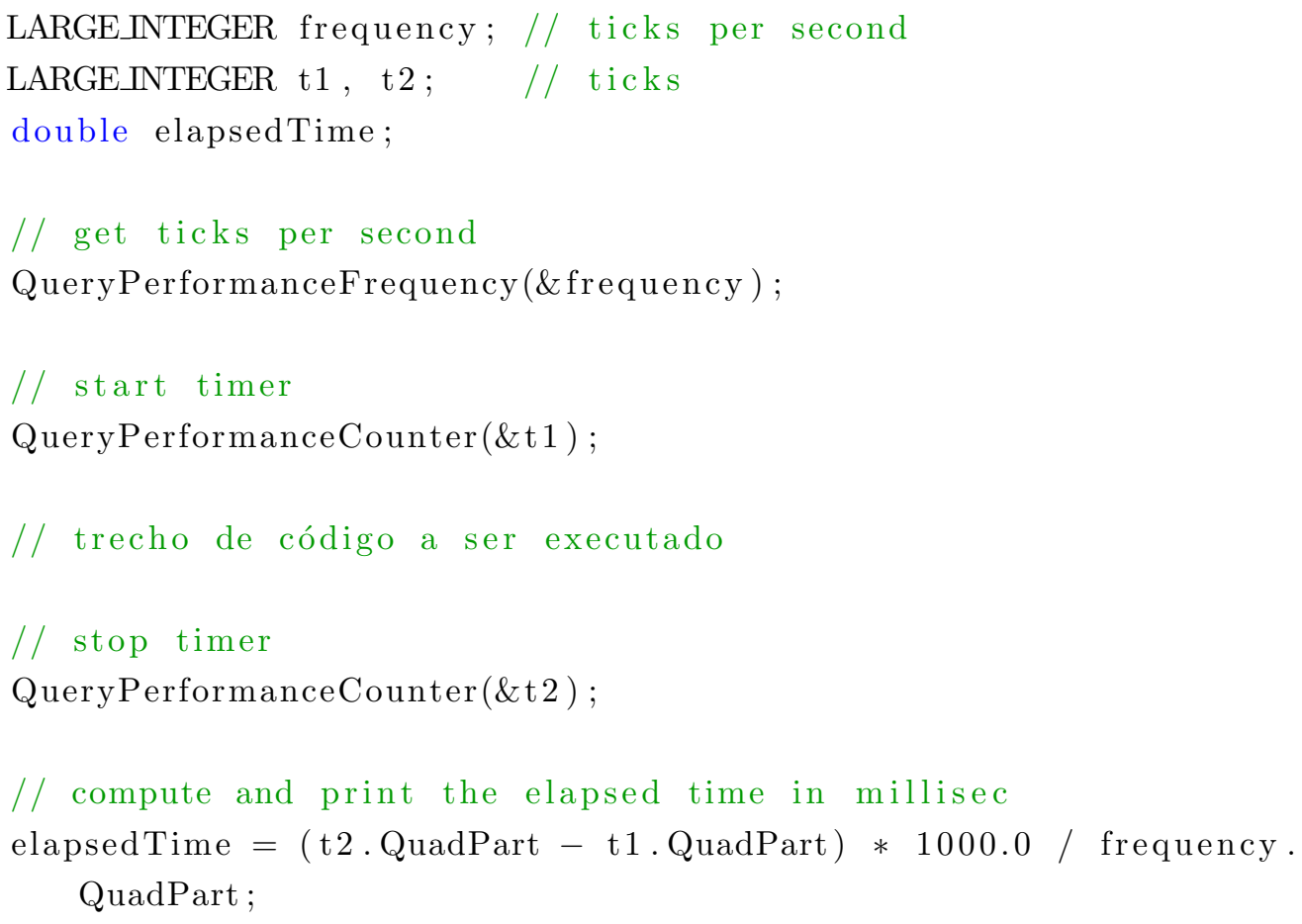


Um estudo sobre técnicas de renderização do fenômeno de dispersão atmosférica

6.3

\section{Principais parâmetros utilizados durante a etapa de desenvolvimento}

\begin{tabular}{|c|c|}
\hline Rayleigh - Coeficiente de dispersão & $5.8 \mathrm{e}-3,1.35 \mathrm{e}-2,3.31 \mathrm{e}-2 \mathrm{~m}-1$ \\
\hline Rayleigh - Coeficiente de absorção ( $\neq$ coef.extincão $)$ & $0.0,0.0,0.0 \mathrm{~m}-1$ \\
\hline Rayleigh - Altura & $8.0 \mathrm{~km}$ \\
\hline Mie - Coeficiente de dispersão & $4.0 \mathrm{e}-3,4.0 \mathrm{e}-3,4.0 \mathrm{e}-3 \mathrm{~m}-1$ \\
\hline Mie - Coeficiente de absorção $(\neq$ coef.extincão $)$ & $4.4 \mathrm{e}-4,4.4 \mathrm{e}-4,4.4 \mathrm{e}-4 \mathrm{~m}-1$ \\
\hline Mie - Altura & $1.2 \mathrm{~km}$ \\
\hline Mie - Fator direcional (simetria da dispersão) & 0.8 \\
\hline Planeta - Raio do planeta & $6360 \mathrm{~km}$ \\
\hline Planeta - Raio da camada atmosférica & $6420 \mathrm{~km}$ \\
\hline Transmitância - Tamanho da textura & $256 \times 64$ \\
\hline Transmitância - Números de amostra para integração & 500 \\
\hline Radiância - Tamanho da textura & $256 \times 64 \times 32$ \\
\hline Radiância - Números de amostra para integração & 50 \\
\hline
\end{tabular}

\section{4}

Técnica: Bruneton e Neyret, dispersão simples e regime atmosférico de Rayleigh

- Consumo de Memória

Todas as texturas geradas possuem 16 bits de precisão e são representadas em ponto flutuante. As dimensões, a quantidade de canais e os tipos de textura estão descritos diretamente no eixo de texturas da Figura 6.1 que contém o resultado do consumo de memória.

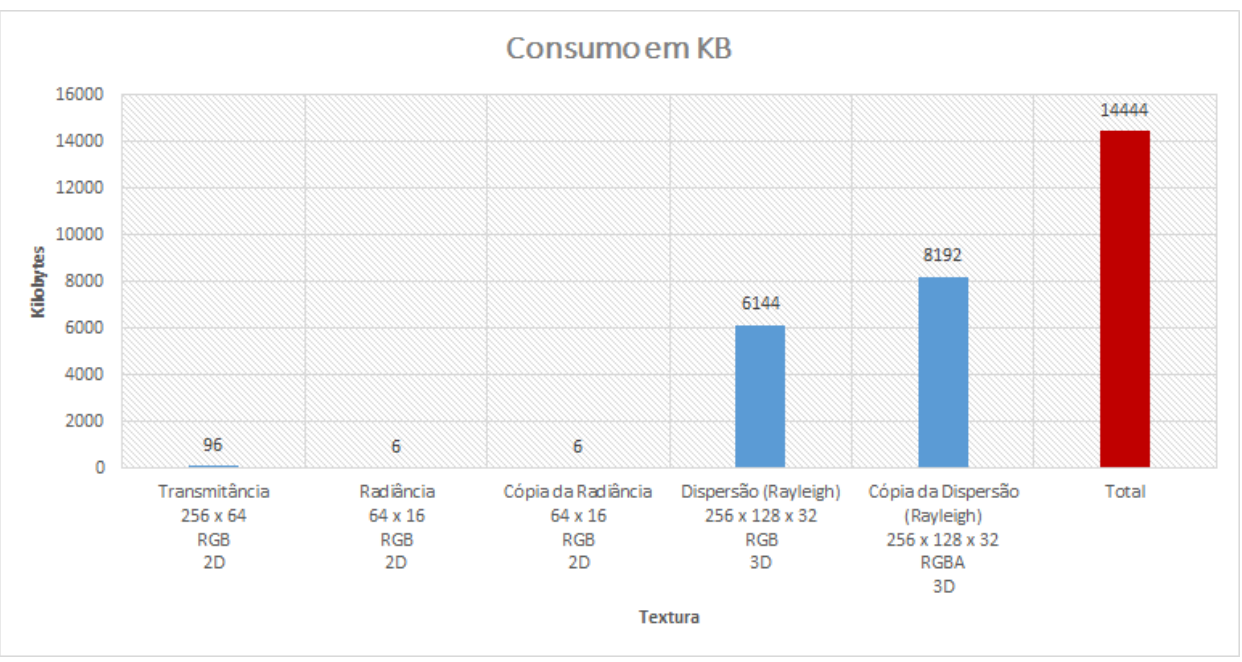

Figura 6.1: Consumo de memória em Kilobytes 
O consumo total de memória dessa técnica é de 14444 kilobytes, ou seja, aproximadamente 14 megabytes. Lembrando que a medição de consumo de memória não está levando em consideração o tamanho físico dos arquivos, em disco, que contém o código-fonte.

- Tempo de execução

Foram realizadas cinco amostras diferentes do tempo de execução a fim de medir o tempo médio de execução de cada etapa. A Figura 6.2 ilustra o tempo para cada etapa em cada amostra. O tempo total médio de execução da técnica é de 14528,8 microsegundos, ou seja, aproximadamente 14,53 milisegundos.

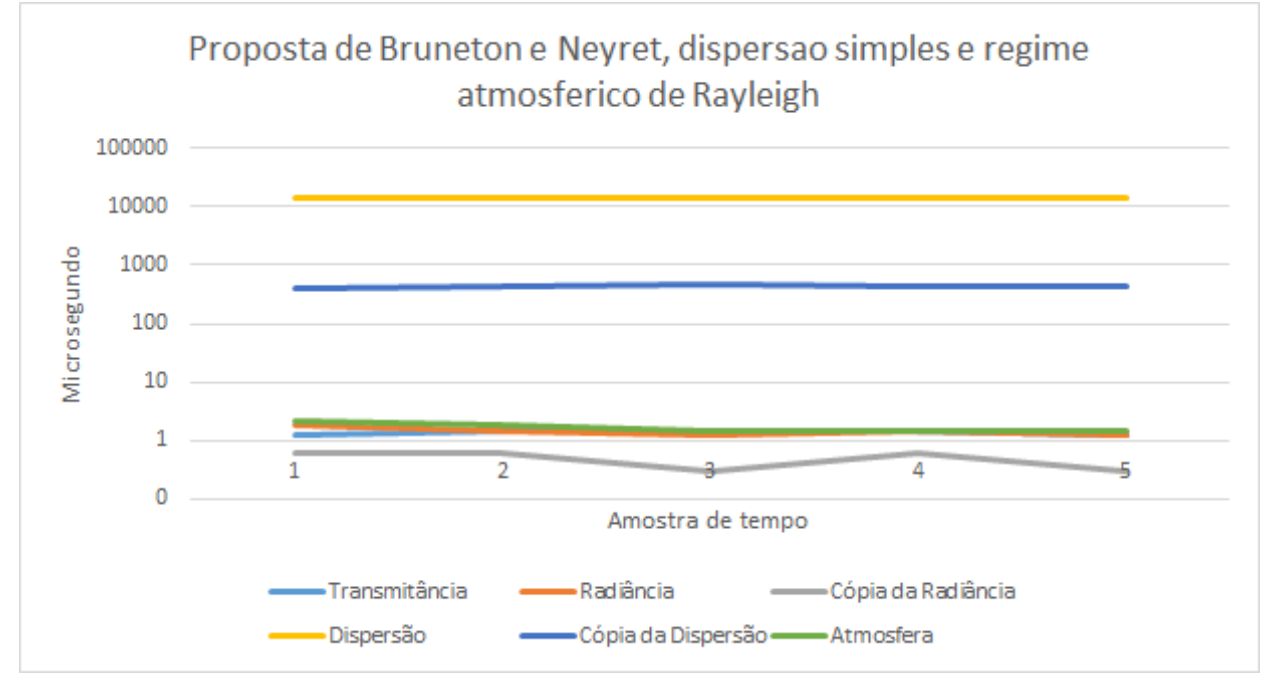

Figura 6.2: Tempo de execução em microsegundos

- Resultado da renderização

Os resultados obtidos são similares aos resultados obtidos na versão simplificada. Logo, os resultados dessa técnica estão representados na seção de resultado da renderização da técnica simplificada (descrita na seção a seguir).

\section{5}

\section{Técnica: Bruneton e Neyret "simplificada", dispersão simples e regime atmosférico de Rayleigh}

Nesta técnica, foram feitas modificações em relação a técnica original, são elas:

- Foram removidas as etapas de cálculo e cópia da radiância Esta etapa é possível de ser realizada devido ao fato de, em um cenário de única dispersão, ser possível aproximar o cálculo de radiância por um produto escalar entre a direção da luz incidente e a normal da superfície. Ilustrado pela Figuras 5.1 e 5.2 . 
- União da etapa de cálculo e cópia da dispersão Esta união de etapas permitiu remover uma etapa e a necessidade do canal de alpha (utilizado para armazenar o coeficiente angular do regime de Mie) da textura gerada pela cópia da dispersão.

- Consumo de Memória

Todas as texturas geradas possuem 16 bits de precisão e são representadas em ponto flutuante. As dimensões, a quantidade de canais e os tipos de textura estão descritos diretamente no eixo de texturas da Figura 6.3 que contém o resultado do consumo de memória.

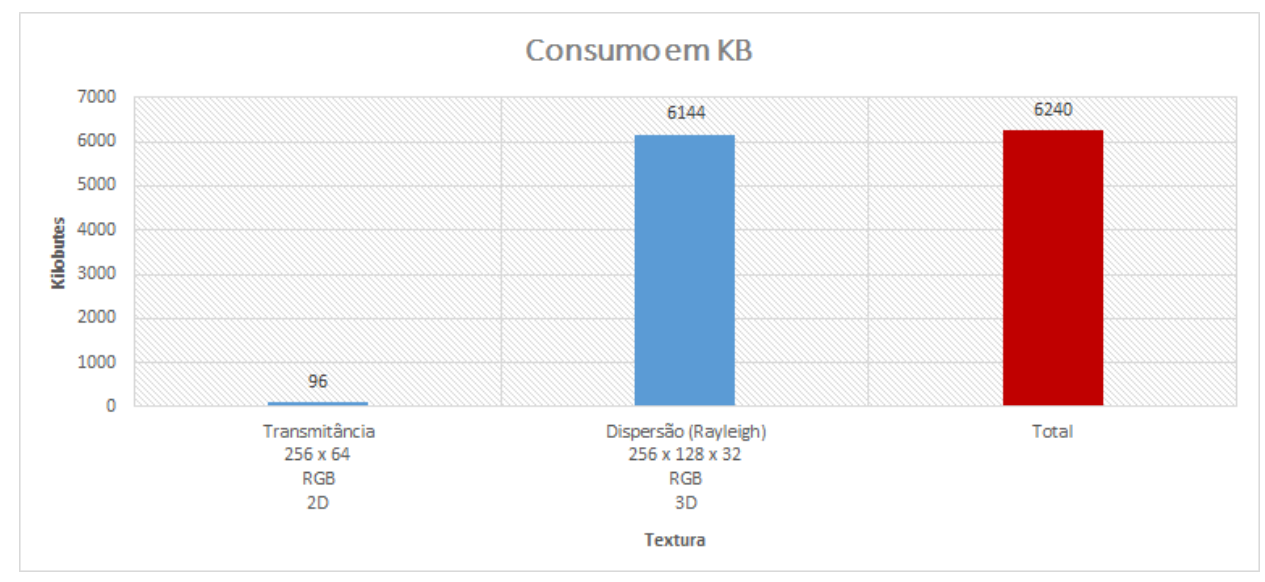

Figura 6.3: Consumo de memória em Kilobytes

O consumo total de memória dessa técnica é de 6240 kilobytes, ou seja, aproximadamente 6 megabytes. Lembrando que a medição de consumo de memória não está levando em consideração o tamanho físico dos arquivos, em disco, que contém o código-fonte.

- Tempo de execução

Foram realizadas cinco amostras diferentes do tempo de execução a fim de medir o tempo médio de execução de cada etapa. A Figura 6.4 ilustra o tempo para cada etapa em cada amostra. O tempo total médio de execução da técnica é de 14081,3 microsegundos, ou seja, aproximadamente 14,08 milisegundos.

- Resultado da renderização

Foram considerados diversos pontos de vista (no espaço, próximo ao horizonte, ao entrar na atmosfera, ao pôr-do-Sol, etc) a fim de observar como a técnica representa cada um desses pontos. As Figuras 6.5, 6.6, 6.7, 6.8 e 6.9 ilustram o resultado da técnica de Bruneton e Neyret "simplificada"com dispersão simples e regime atmosférico de Rayleigh. Esses resultados também podem ser considerados os mesmos para a técnica Bruneton e Neyret com dispersão simples e regime atmosférico de Rayleigh. 
Um estudo sobre técnicas de renderização do fenômeno de dispersão atmosférica

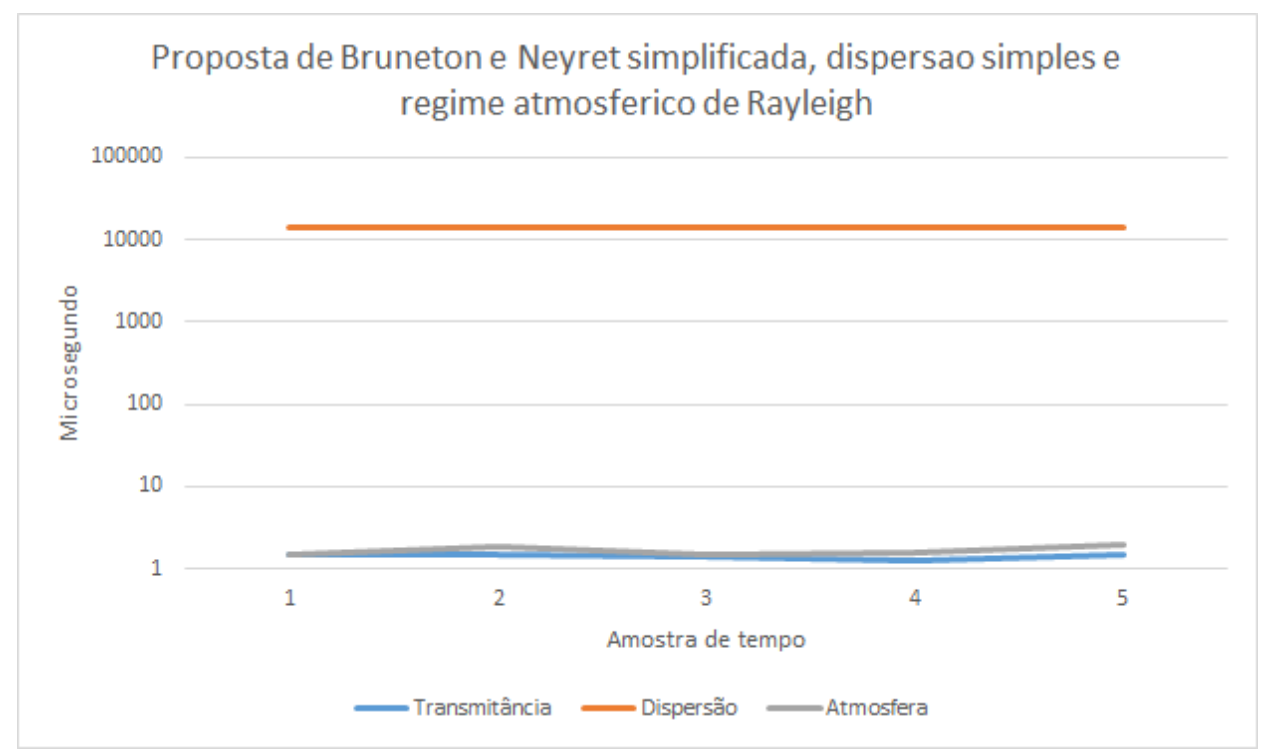

Figura 6.4: Tempo de execução em microsegundos

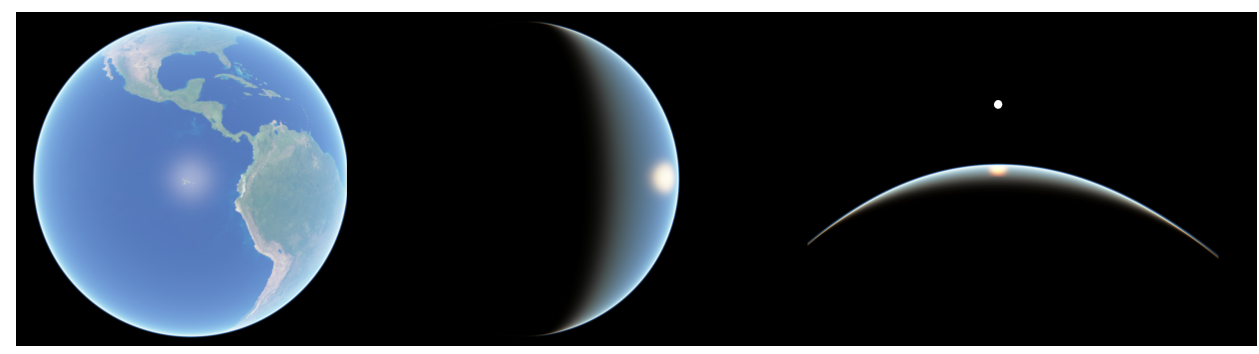

Figura 6.5: Atmosfera observada do espaço (mais distante da superfície do planeta)

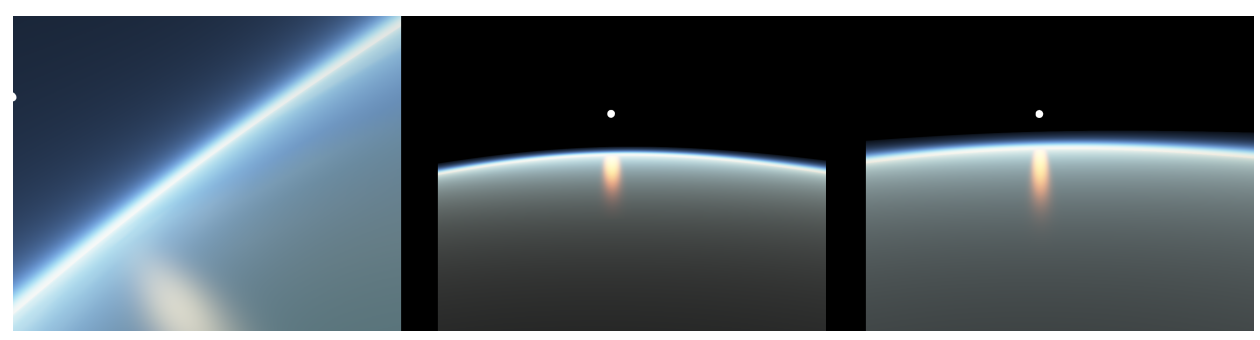

Figura 6.6: Atmosfera observado do espaço (mais próximo da superfície do planeta)

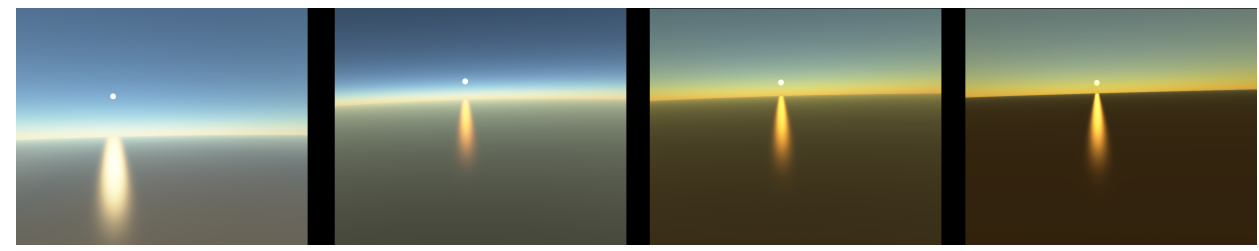

Figura 6.7: Ponto de vista (ao entrar/dentro) da atmosfera 


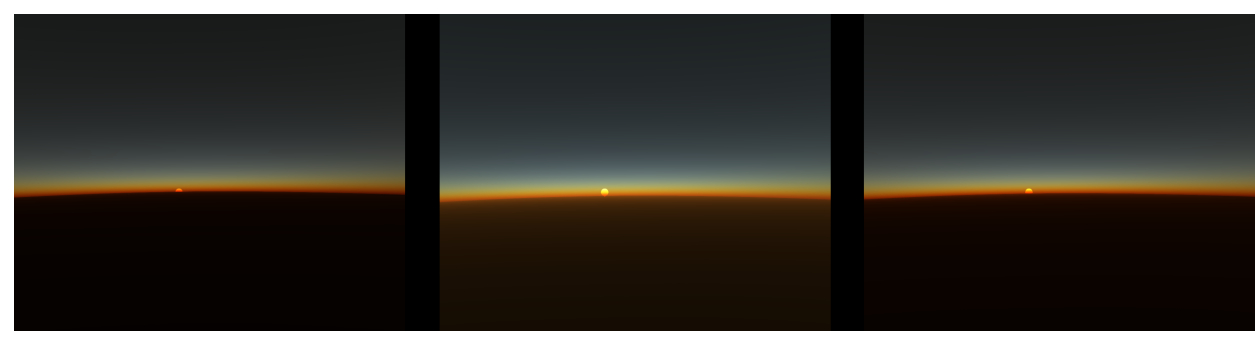

Figura 6.8: Pôr-do-Sol

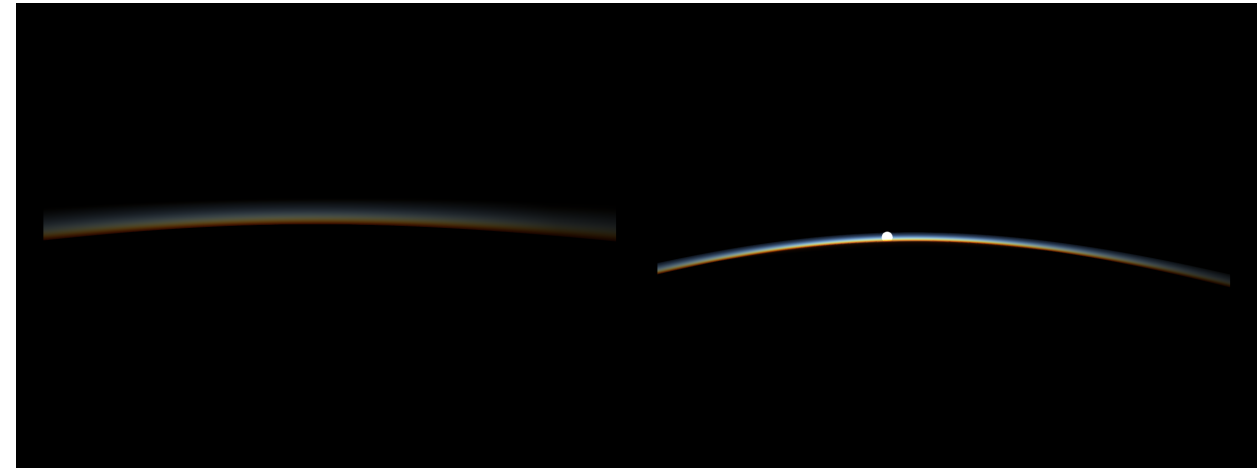

Figura 6.9: Contorno da atmosfera vista da parte oculta do planeta

6.6

Técnica: Schuler, com dispersão simples e regime atmosférico de Rayleigh

- Consumo de Memória

Foi visto no início desse capítulo que não estão sendo considerados os arquivos que contém o código-fonte das técnicas devido ao fato de serem arquivos inerentes de qualquer implementação. Sendo assim, ao analisarmos a técnica proposta por Schuler (que não utiliza etapas de pré-processamento e não gera nenhuma textura), estamos assumindo que não há consumo de memória na utilização da técnica. ${ }^{4}$

- Tempo de execução

Foram realizadas cinco amostras diferentes do tempo de execução a fim de medir o tempo médio de execução de cada etapa. A Figura 6.10 ilustra o tempo para cada etapa em cada amostra.

O tempo total médio de execução da técnica é de 1,3976 microsegundos, ou seja, aproximadamente 0,0014 milisegundos.

${ }^{4}$ Por mais que os arquivos com código-fonte não estejam sendo considerados nesse estudo, tenha em mente que eles possuem tamanho físico e consomem memória 
Um estudo sobre técnicas de renderização do fenômeno de dispersão atmosférica

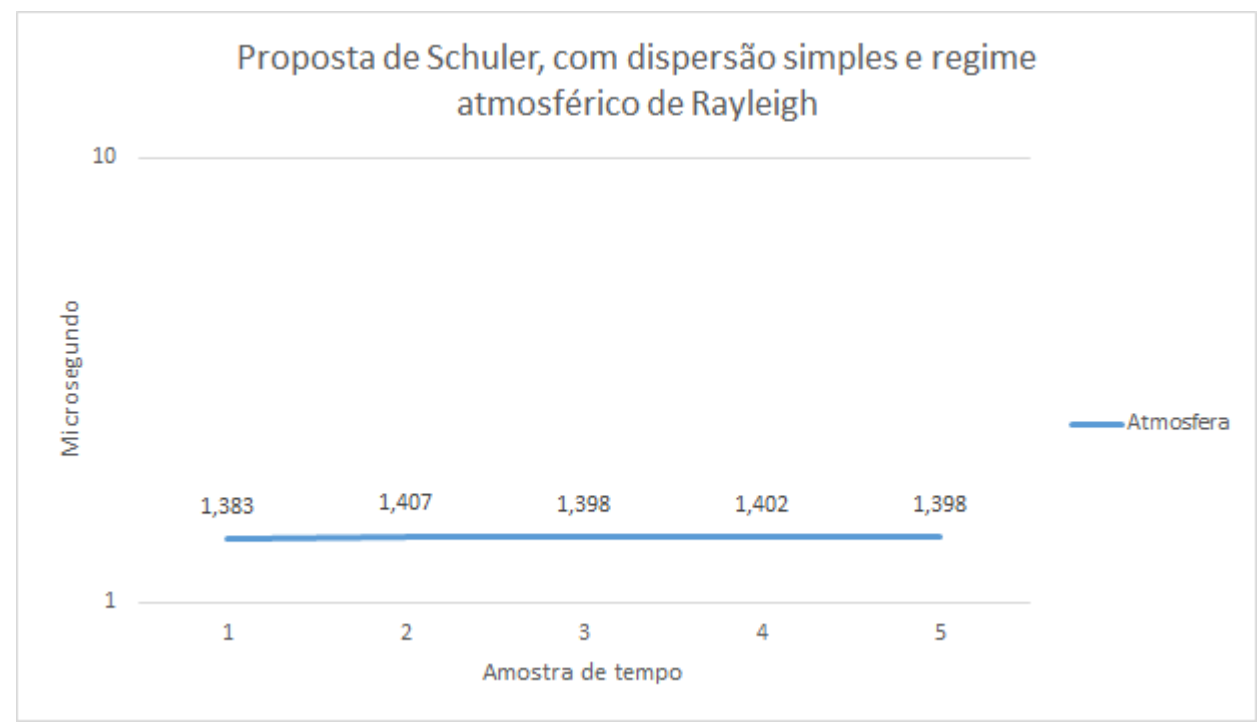

Figura 6.10: Tempo de execução em microsegundos

- Resultado da renderização

Foram considerados diversos pontos de vista (no espaço, próximo ao horizonte, ao entrar na atmosfera, ao pôr-do-Sol, etc) a fim de observar como a técnica representa cada um desses pontos. As Figuras 6.6, 6.6, 6.6, 6.6 e 6.6 ilustram o resultado da técnica de Schuler.

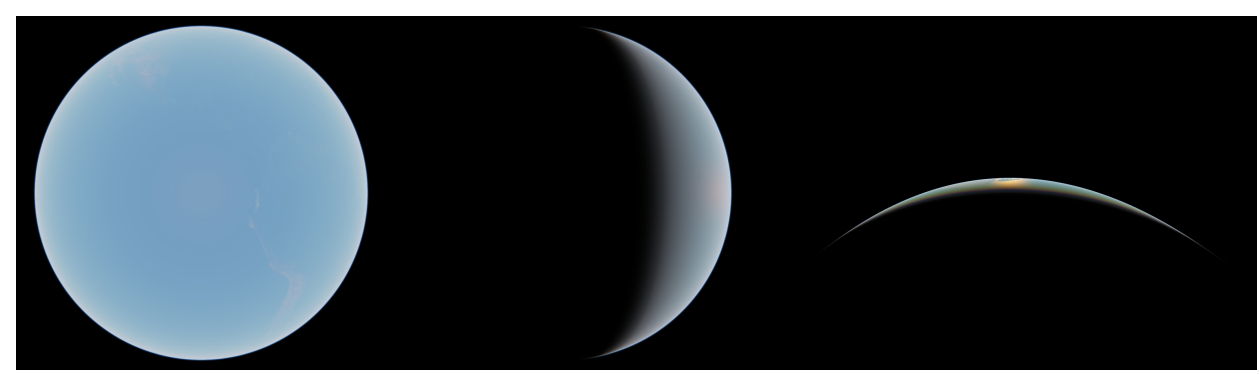

Figura 6.11: Atmosfera observada do espaço (mais distante da superfície do planeta) 
Um estudo sobre técnicas de renderização do fenômeno de dispersão atmosférica

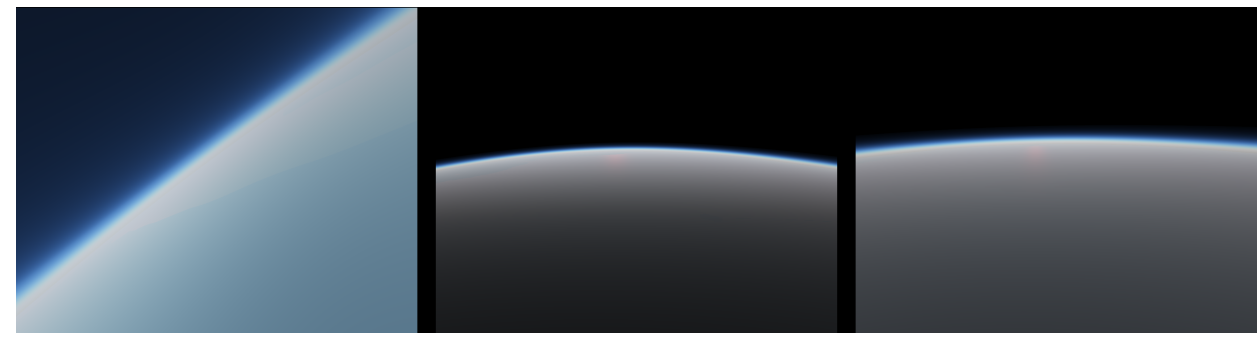

Figura 6.12: Atmosfera observado do espaço (mais próximo da superfície do planeta)

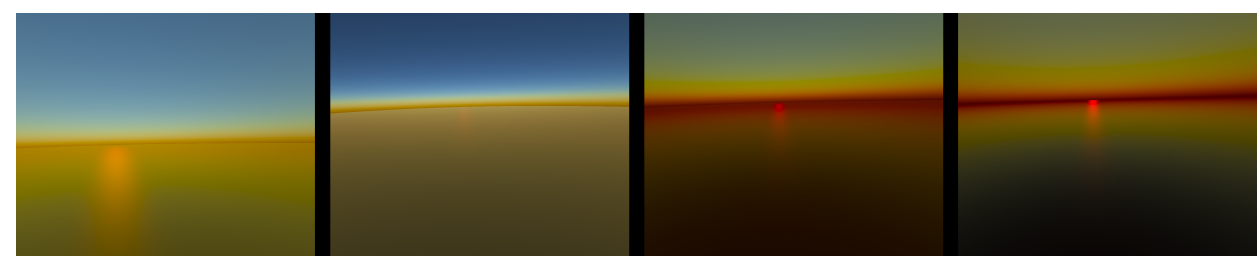

Figura 6.13: Ponto de vista (ao entrar/dentro) da atmosfera

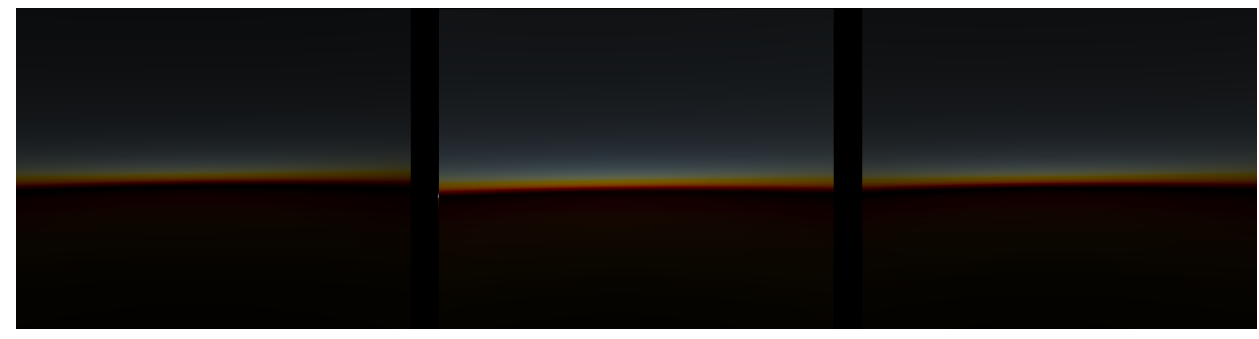

Figura 6.14: Pôr-do-Sol

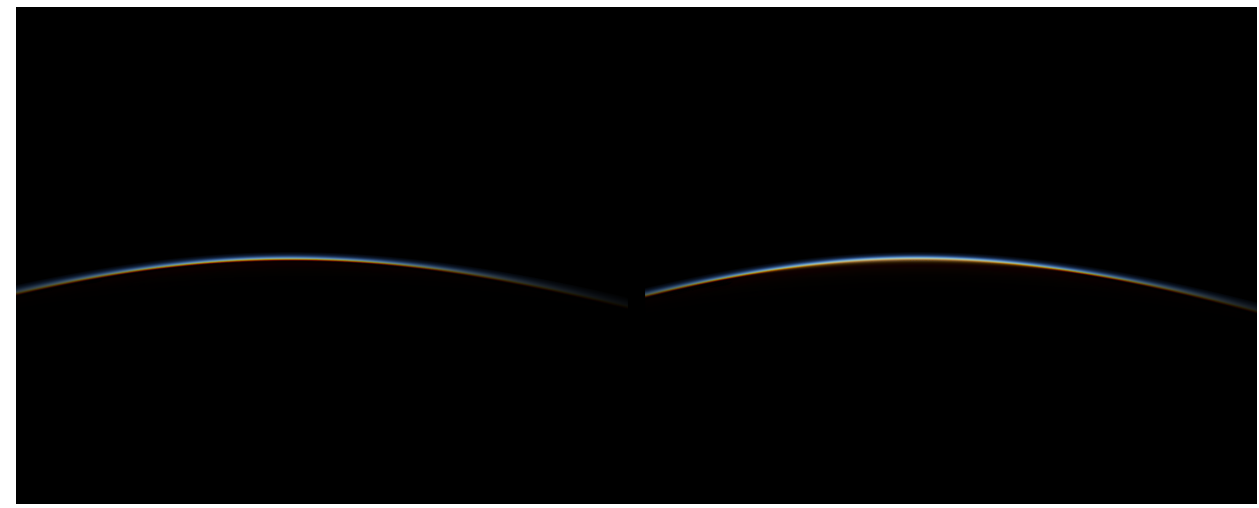

Figura 6.15: Contorno da atmosfera vista da parte oculta do planeta 


\section{7}

\section{Discussão do resultado}

- Consumo de Memória

A medição de consumo de memória não está levando em consideração o tamanho físico dos arquivos, em disco, que contém o código-fonte. Logo, ao analisarmos a técnica proposta por Schuler (que não utiliza etapas de préprocessamento e não gera nenhuma textura), estamos assumindo que não há consumo de memória na utilização da técnica.

Ao analisarmos a Figura 6.16, podemos concluir que a técnica de Schuler é a mais econômica. Sendo assim, caso a aplicação ou dispositivo (onde será aplicada a técnica de dispersão atmosférica) tenha limitação de espaço de armazenamento essa é a técnica mais apropriada.

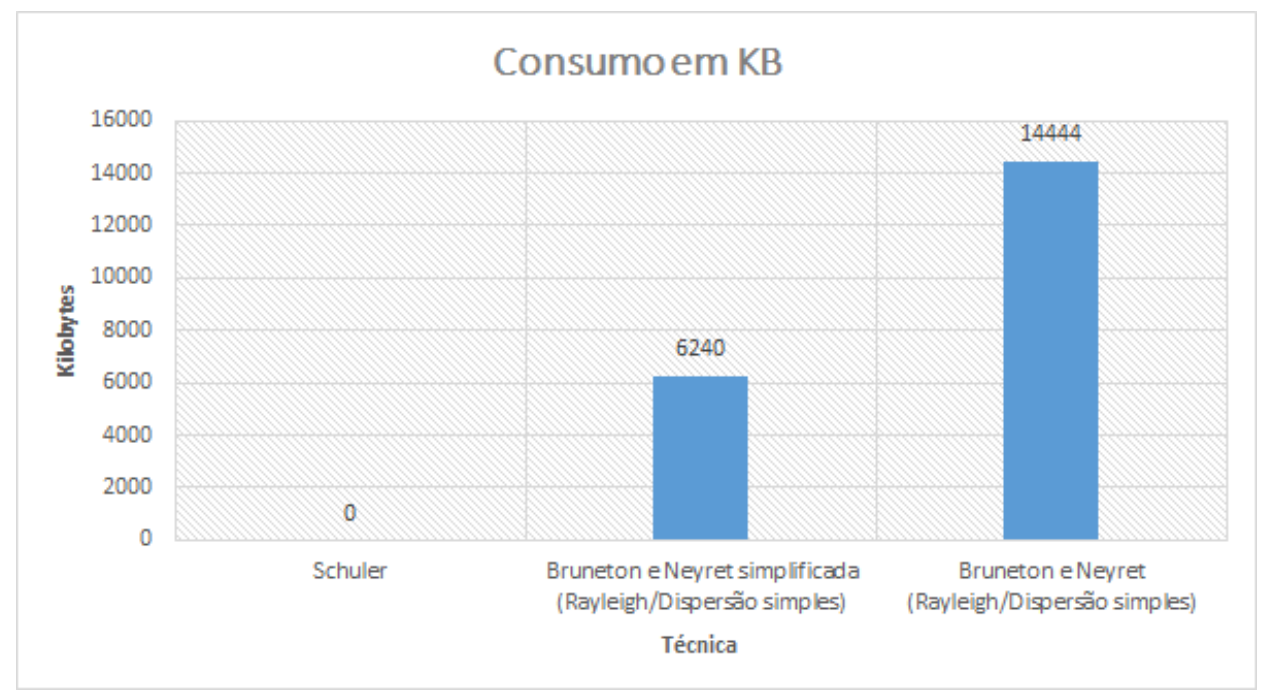

Figura 6.16: Consumo de memória (de cada técnica) em Kilobytes

Por mais que a técnica de Schuler seja mais econômica, é preciso ressaltar a significativa redução de memória promovida pela simplificação da técnica de Bruneton e Neyret. A eliminação dos resultados gerados pelos shaders que foram descartados gerou uma economia de, aproximadamente, $57 \%$ em relação ao valor de memória consumida pela técnica original de Bruneton e Neyret.

- Tempo de execução

As Figuras 6.17 e 6.18 ilustram o tempo total de execução das técnicas durante a etapa de pré-processamento e durante a etapa de renderização.

Ao considerar o tempo de execução da etapa de pré-processamento mais o tempo de renderização em um cenário de uma única dispersão e com apenas o regime de Rayleigh pode-se concluir que não há diferença significativa entre 


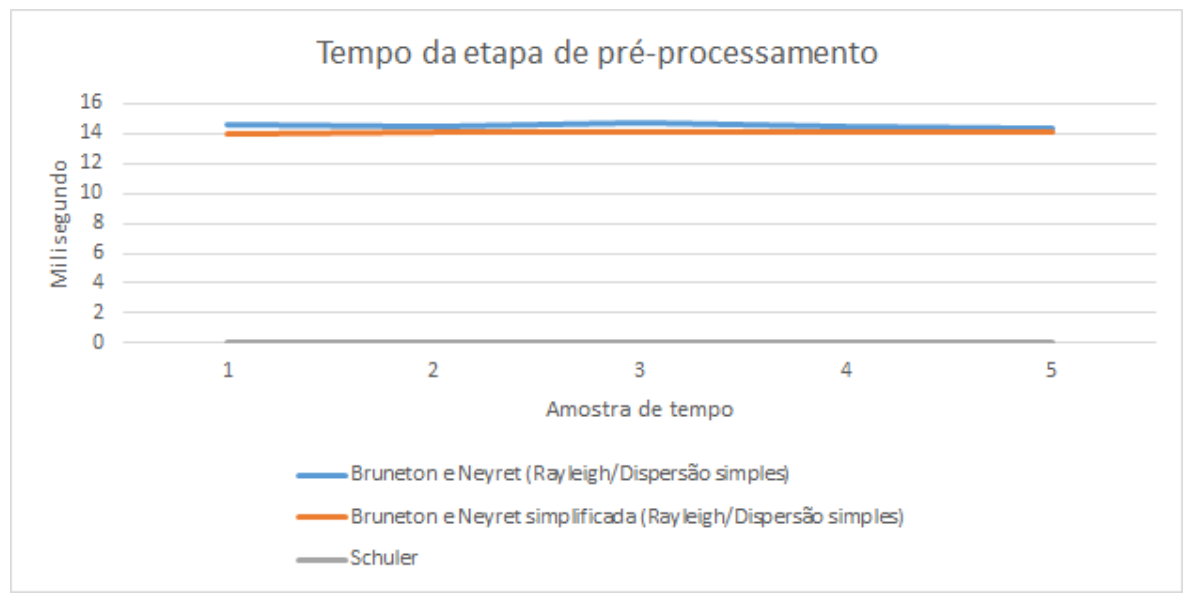

Figura 6.17: Tempo de pré-processamento (de cada técnica) em microsegundos

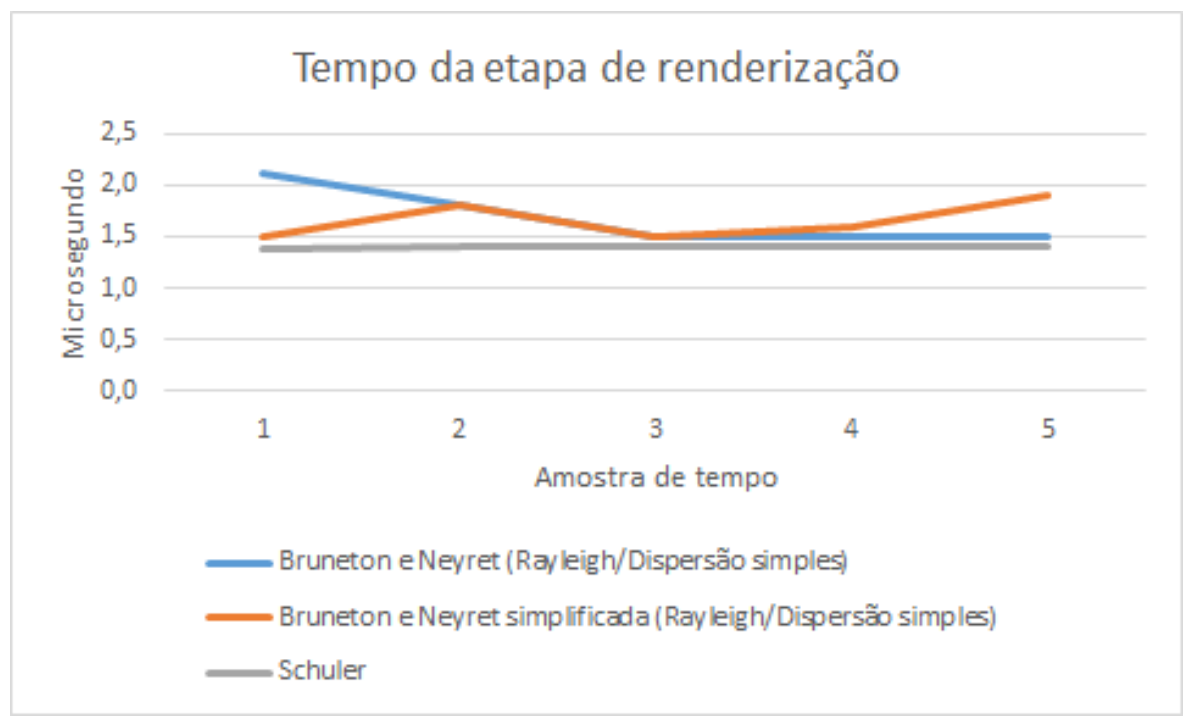

Figura 6.18: Tempo de renderização (de cada técnica) em microsegundos

a técnica de Bruneton e Neyret e técnica de Schuler. O tempo de renderização das técnicas é praticamente idêntico, o que diferencia é o tempo de préprocessamento. Porém, o tempo de pré-processamento da técnica de Bruneton e Neyret para este cenário poderia ser facilmente incorporado ao processo de tempo real, pois consome apenas 14 milisegundos. Sendo assim, a técnica de Bruneton e Neyret pode ser considerada uma melhor escolha para um cenário de uma única dispersão e com apenas o regime de Rayleigh.

No entanto, deve-se ficar atento que ao considerar a etapa de cópia da dispersão, etapa de cálculo de radiância e, posteriormente, etapa do cálculo de Mie e múltiplas dispersões o tempo de pré-processamento da técnica de Bruneton e Neyret irá aumentar consideravelmente podendo tornar-se desinteressante para determinados tipos de aplicação.

- Resultado da renderização 
Um estudo sobre técnicas de renderização do fenômeno de dispersão atmosférica

Para avaliar o resultado da renderização, adicionou-se também os resultados obtidos pela técnica de Bruneton e Neyret utilizando os regimes de Rayleigh e Mie e apenas uma única dispersão. Por mais que este o regime de Mie não tenha sido aprofundado neste estudo, vale ser apresentado como forma de validar os resultados. Todas as figuras representam uma única dispersão e são apresentadas da seguinte ordem: técnica de Bruneton e Neyret com regime de Rayleigh e Mie (esquerda), técnica de Bruneton e Neyret com regime de Rayleigh (meio) e técnica de Schuler com regime de Rayleigh (direita).

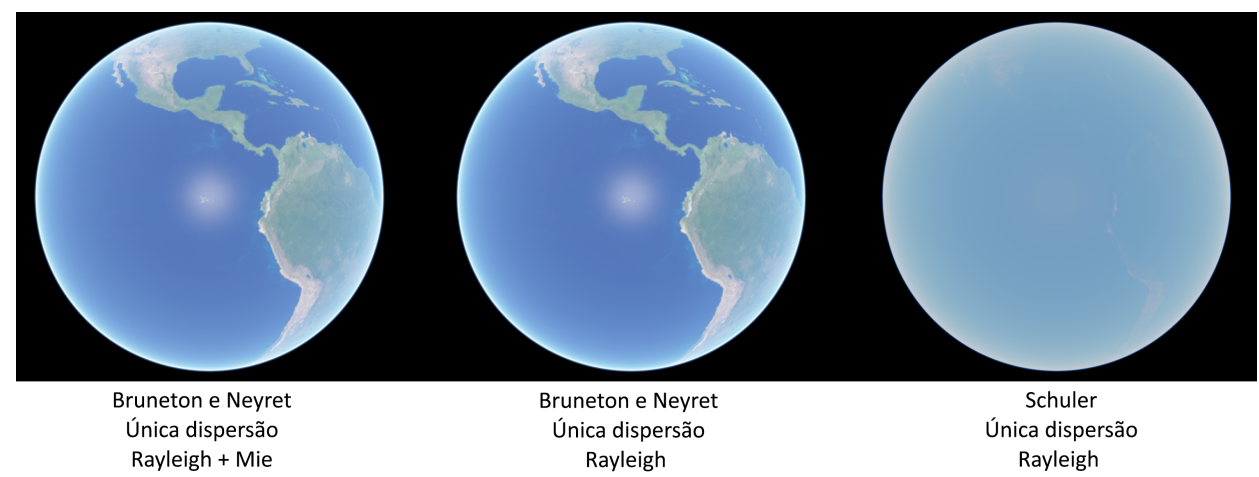

Figura 6.19: Atmosfera observada do espaço (mais distante da superfície do planeta)

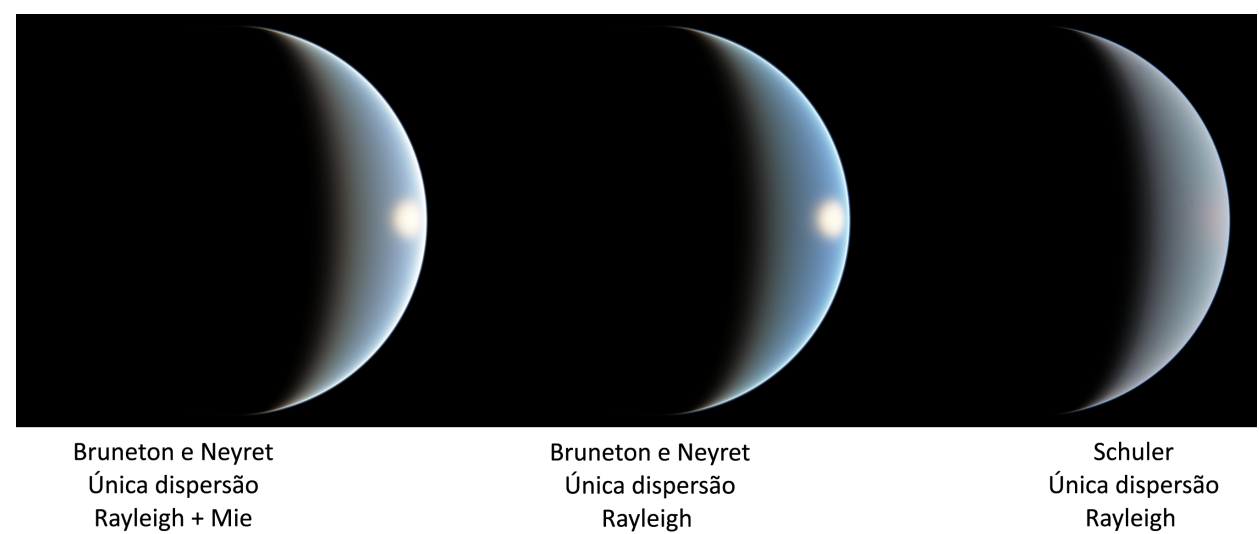

Figura 6.20: Atmosfera observada do espaço (mais distante da superfície do planeta)

Ao observar a distribuição da densidade atmosférica, concluímos que a técnica de Bruneton e Neyret representa melhor a densidade em qualquer ponto de vista; ao contrário da técnica de Schuler que, dependendo do ponto de vista, apresenta uma qualidade melhor quando o está no espaço ou quando está ao nível do mar. 
Um estudo sobre técnicas de renderização do fenômeno de dispersão atmosférica

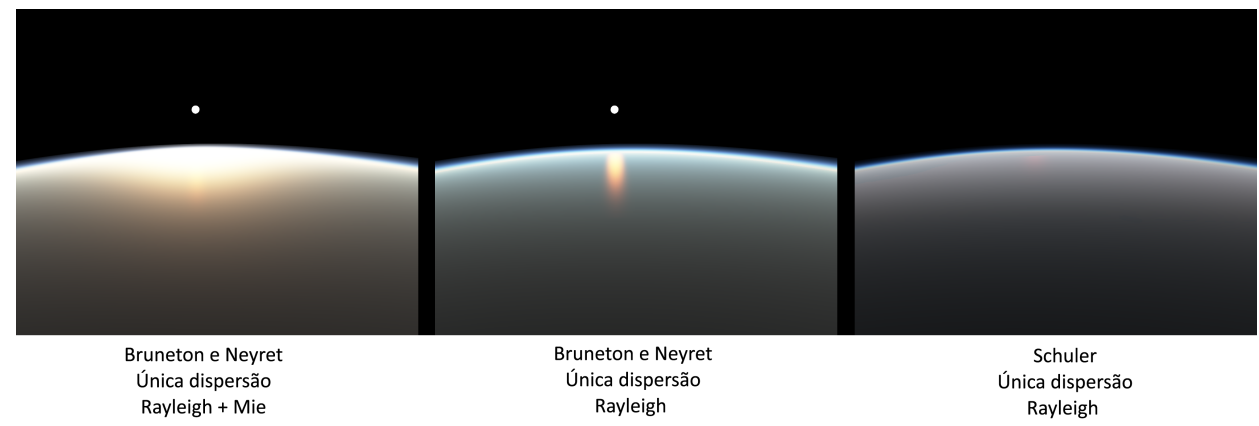

Figura 6.21: Atmosfera observada do espaço (mais próximo da superfície do planeta)

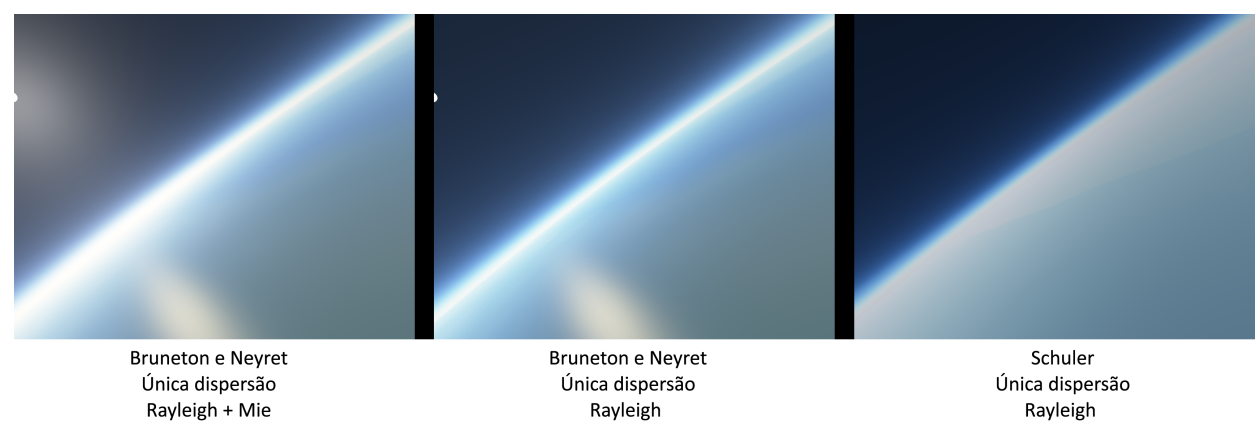

Figura 6.22: Ponto de vista ao entrar na atmosfera

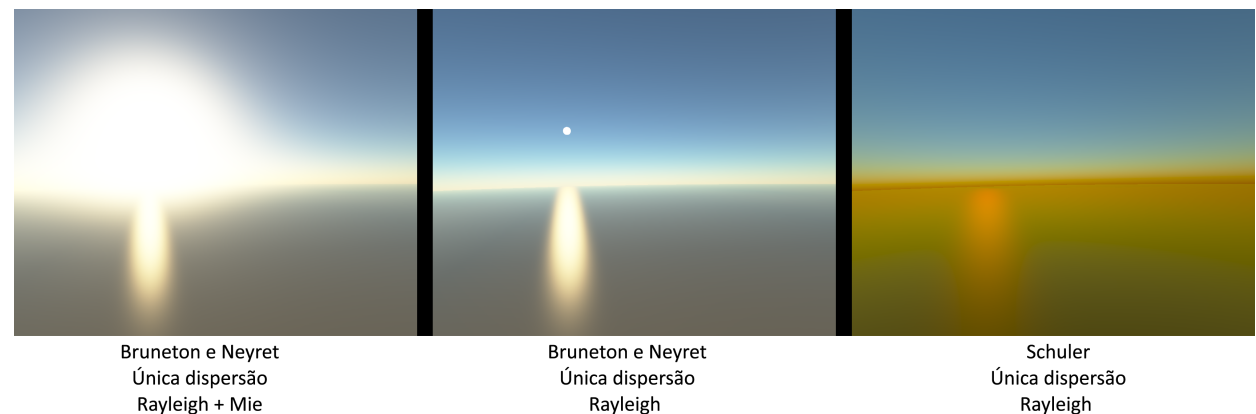

Figura 6.23: Ponto de vista dentro da atmosfera

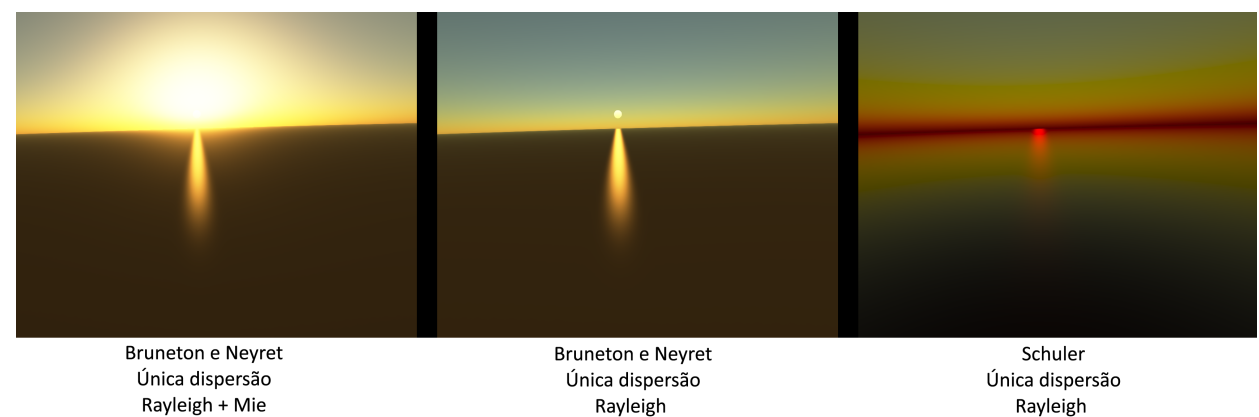

Figura 6.24: Pôr-do-Sol 


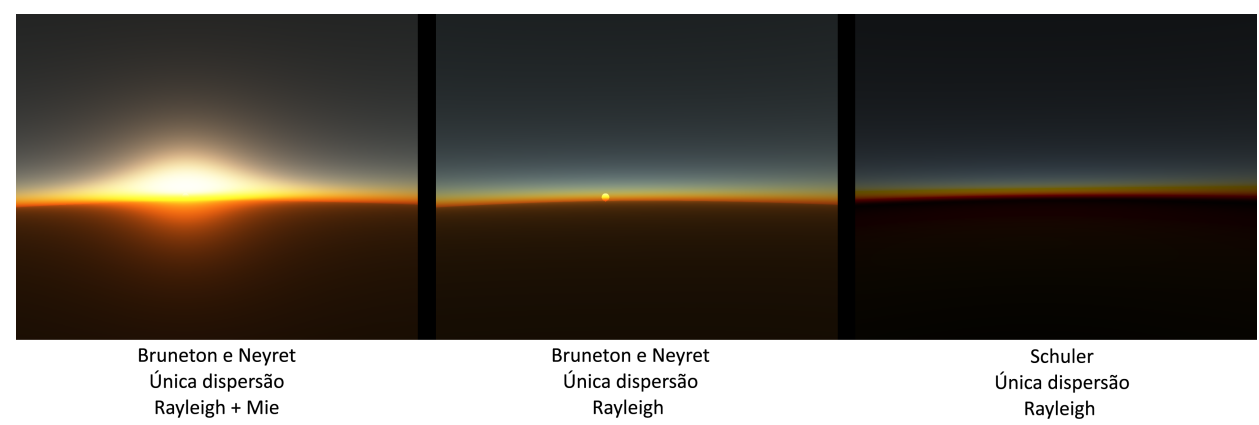

Figura 6.25: Pôr-do-Sol

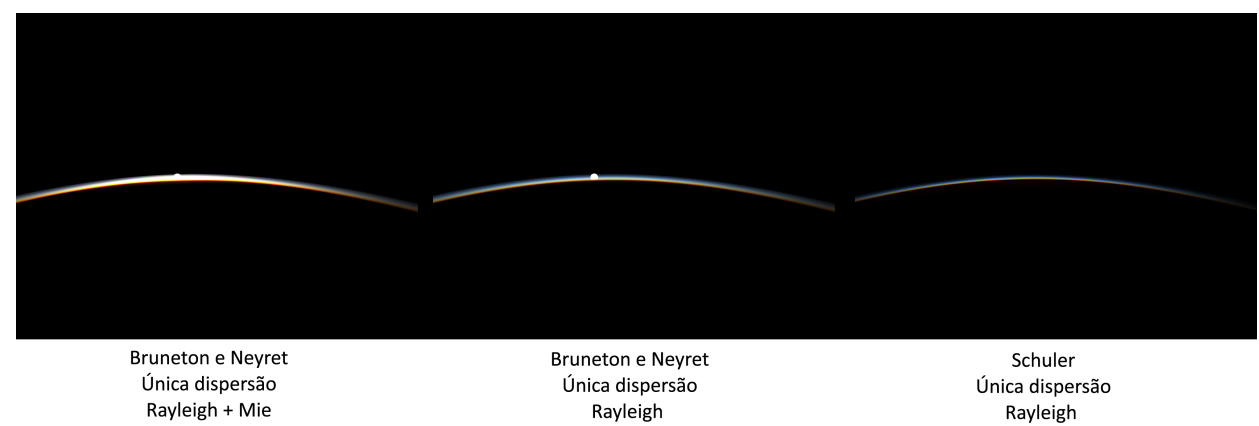

Figura 6.26: Contorno da atmosfera vista da parte oculta do planeta

Ao observar o serrilhamento, concluímos que - em todos os casos - o serrilhamento não foi um fator influente logo foi descartado como critério de seleção da técnica.

Ao comparar esses resultados com imagens reais disponibilizadas pela NASA [21] [20] [19], ficou evidente, na opinião do autor, que a técnica de Bruneton e Neyret representa melhor a realidade.

Outro fator importante é que a qualidade visual da técnica de Bruneton e Neyret ainda pode ser melhorada caso a técnica seja evoluída para a versão que considera o regime de Mie. Com o regime de Mie, é possível observar a influência que ele exerce quando o observador está próximo da superfície do planeta. Por mais que haja uma melhora notável, também é possível perceber um aspecto estourado da luz, ou seja, a luz está excessivamente forte. Caso tivesse sido considerado múltiplas dispersões, os resultados seriam ainda melhores, pois a intensidade da luz dispersada seria atenuada pelas múltiplas dispersões diminuindo, assim, o excesso de luz.

De um modo geral, concluí-se que a técnica de Bruneton e Neyret apresenta uma qualidade visual superior a da técnica de Schuler. Ou seja, caso a sua aplicação necessite representar o fenômeno de dispersão atmosférica com mais fidelidade com a realidade essa é a melhor técnica a ser utilizada. 


\subsection{1}

\section{Limitações e Melhorias}

Após analisar as técnicas, concluímos que existem dois fatores importantes que influenciam na decisão da escolha da técnica: limitações e possibilidade de melhorias.

A técnica de Schuler está limitada ao regime de Rayleigh e a uma única dispersão. Para que seja possível expandir a técnica é preciso, primeiramente, incluir o regime de Mie e depois conseguir calcular o processo de múltiplas dispersões em tempo-real. Após algumas pesquisas, não conseguimos encontrar na literatura uma forma eficiente de calcular esse processo em tempo real. Sendo assim, consideramos que é uma técnica mais difícil de evoluir.

A técnica de Bruneton e Neyret abordada nesse estudo considera somente o regime de Rayleigh e uma única dispersão. Porém, a técnica orignal utiliza o regime de Rayleigh e o de Mie considerando múltiplas dispersões. Logo, é possível expandir a técnica descrita nesse estudo para a técnica completa. Sendo assim, é uma técnica mais fácil de evoluir. 


\section{Conclusão e trabalhos futuros}

Neste capítulo será apresentada a conclusão desse estudo e os trabalhos futuros a serem realizados.

\section{1}

\section{Conclusão}

Esse estudo propôs entender o fenômeno de dispersão atmosférica e apresentar duas técnicas distintas que visam renderizá-lo. Para alcançar esses objetivos foram realizadas as seguintes etapas:

Primeiramente, foram apresentados os conceitos físico-matemáticos responsáveis por representar o fenômeno de dispersão atmosférica. Esses conceitos foram apresentados desde a classificação do campo da Física na qual o fenômeno se enquadra passando por diversas outras definições físicas, como por exemplo, radiação eletromagnética, densidade atmosférica, como a luz interage com a matéria, processo de polarização, como é dado o processo de dispersão da luz, quais os regimes atmosféricos que definem o tipo de dispersão da luz, os conceitos de transmitância, profundidade óptica, irradiância e radiância até chegar finalmente a explicação do fenômeno de dispersão atmosférica e seus efeitos.

Em seguida, foram apresentados os trabalhos mais pertinentes relacionados ao processo de renderização do fenômeno de dispersão atmosférica. Esses trabalhos foram organizados de forma cronológica a fim de facilitar o acompanhamento da evolução das técnicas ao longo dos anos. Além disso, foi apresentado um infográfico que ilustrou a evolução das técnicas de acordo com o tipo de modelo matemático e o recurso utilizado para renderizar o fenômeno.

Uma vez definidos os conceitos físicos e os trabalhos existentes, foram apresentadas as equações matemáticas que definem os conceitos citados anteriormente. As equações apresentadas nesse estudo fazem parte de um conjunto mínimo de equações (na opinião do autor) necessárias para o entendimento matemático do fenômeno. Além disso, foram adicionadas diversas figuras a fim de auxiliar o entendimento do fenômeno.

Através dessas etapas anteriores, o leitor já é capaz de entender, minimamente, o modelo físico-matemático que representa o fenômeno de dispersão atmosférica cumprindo parcialmente a proposta desse estudo. No 
entanto, ainda é necessário explicar o processo de renderização do fenômeno segundo a técnica de Bruneton e Neyret e a técnica de Schuler.

Para compreender as técnicas criou-se um capítulo de estudo das técnicas onde são abordados os pontos em comum entre as técnicas, os detalhes de implementação e as etapas de renderização de cada técnica. É possível encontrar nesse capítulo o número de shaders utilizados, o número de texturas geradas, se existem etapas de pré-processamento e até mesmo uma simplificação da técnica de Bruneton e Neyret. Sendo assim, através desse capítulo é o leitor é capaz de entender, minimamente, o processo de renderização do fenômeno de dispersão atmosférica cumprindo completamente a proposta desse estudo.

Para finalizar, foram apresentados os resultados obtidos após a renderização de cada uma das técnicas. A partir desses resultados, foram criados gráficos que ilustram a diferença entre as técnicas segundo o ponto de vista de consumo de memória, tempo de execução e qualidade visual. Os resultados apresentados são utéis para ajudar na escolha de qual técnica é melhor de ser implementada dependendo do tipo de aplicação.

Em termos gerais, concluí-se que a criação de um referência unificada e compacta, de fato, auxilia na rapidez do entendimento do fenômeno e das técnicas relacionadas ao fenômeno de dispersão atmosférica. Embora esse estudo não vise reproduzir as técnicas descritas por ele; a sua utilização, em conjunto com os artigos das técnicas, permitem que o processo de implementação seja mais fácil e intuitivo.

Em termos técnicos, concluí-se que a qualidade final da representação do fenômeno de dispersão atmosférica está associada, principalmente, aos regimes atmosféricos e ao número de dispersões utilizados do que o cálculo do fenômeno em si. A utilização do regime de Rayleigh em um cenário de única dispersão é suficiente e satisfatório para representar a atmosfera vista desde um ponto qualquer no espaço até um ponto próximo da calota atmosférica. Porém, quando estamos entre a calota atmosférica e a superfície do planeta, o regime de Mie passa a fazer diferença no realismo, pois ele trata outros tipos de partículas presentes especificamente em camadas mais baixas da atmosfera. Uma vez considerando o regime de Mie, o número de dispersões começa a fazer a diferença, pois essas dispersões atenuam a intensidade da luz dispersada tornando o resultado mais suave e realístico. Resumindo, para cenários com visualização planetária é suficiente a utilização da técnica de Bruneton e Neyret, a técnica de Schuler ou qualquer outra que possua apenas o regime de Rayleigh e apenas uma dispersão. Já para cenários onde o observador está dentro da atmosfera, é necessário utilizar Bruneton e Neyret ou qualquer 
outra técnica que possua o regime de Rayleigh e Mie e uma dispersão ou mais.

\section{2}

\section{Trabalhos futuros}

As técnicas utilizadas para a renderização do fenômeno de dispersão atmosférica possuem diversas possibilidades de evolução, pois podem sofrer melhorias desde uma mudança no cálculo de uma equação físico-matemática até a forma de uso dos recursos da placa gráfica. Durante a realização desse estudo identificamos alguns pontos que poderão ser abordados no futuro, são eles:

Para ambas as técnicas, pretende-se incluir efeitos derivados da renderização do Sol (raios solares, auréola solar, etc), renderizar o universo ao redor do planeta, renderizar o planeta com texturas diferentes para o hemisfério iluminado e não-iluminado e verificar a interação da atmosfera com outros elementos que compõem o ambiente como oceano e nuvens, por exemplo.

Para a técnica de Bruneton e Neyret pretende-se testar a solução analítica do cálculo da transmitância proposta por Bruneton e Neyret (não abordada nesse estudo).

Para a técnica de Schuler pretende-se incluir a renderização do Sol, incluir o regime de Mie e pesquisar um modelo analítico que seja capaz de calcular as múliplas dispersões atmosféricas. 


\section{Referências Bibliográficas}

[1] (2014). "Beer-Lambert Law".

http://en.wikipedia.org/wiki/Beer-Lambert_law. 4.5

[2] (2014). "Color Vision". http://en.wikipedia.org/wiki/Color_vision. 2.11 .1

[3] (2014). "Crytek: CryEngine 2". http://pt.wikipedia.org/wiki/CryEngine_2. 3

[4] (2014a). "Curtis Mobley: The Volume Scattering Function". http://www .oceanopticsbook.info/view/overview_of_optical_ oceanography/the_volume_scattering_function. 4.4.1

[5] (2014a). "E.P. Dolzhenko: Rational Function". http: //www . encyclopediaofmath.org/index.php?title=Rational_ function\&oldid=17805. 5.2.1

[6] (2014a). "George Gabriel Stokes". http://pt.wikipedia.org/wiki/George_Gabriel_Stokes. 4.2

[7] (2014b). "Irina A. Telyukova: Function Approximation Methods". http://econweb.ucsd.edu/ itelyukova/teaching/computation216/ 3approx.pdf. 5.2 .1

[8] (2014). "Isaac Newton's second law". http://en.wikipedia.org/wiki/ Newton's_laws_of_motion\#Newton.27s_second_law. 4.1

[9] (2014a). "James Clerk Maxwell". http://en.wikipedia.org/wiki/James_Clerk_Maxwell. 4.4.2

[10] (2014c). "Joe Mahaffy: Rational Function Approximation". http://www-rohan.sdsu.edu/ jmahaffy/courses/s10/math541/ lectures/pdf/week13/lecture.pdf. 5.2.1

[11] (2014a). "Kshitij School: Polarization of Light Waves". http://www.kshitij-school.com/Study-Material/Class-12/Physics/ Diffraction-and-polarization/Polarization-of-light-waves . aspx. 2.5

[12] (2014). "Lei dos Gases". http://pt.wikipedia.org/wiki/Lei_dos_gases_ideais. 4.1 
Um estudo sobre técnicas de renderização do fenômeno de dispersão atmosférica

[13] (2014). "Leonardo da Vinci". http://pt.wikipedia.org/wiki/Leonardo_da_Vinci. 3

[14] (2014). "LorentzLorenz equation". http://en.wikipedia.org/wiki/Lorentz-Lorenz_equation. 4.2

[15] (2014). "Martina Schmeling: Atmospheric Particles (Aerosols) - Handout4". http://homepages.luc.edu/ mschmel/Handout4.pdf. 2.7

[16] (2014b). "Maxwell's Equations". http://www.maxwells-equations.com/. 4.4.2

[17] (2014). "Michelangelo". http://pt.wikipedia.org/wiki/Michelangelo. 3

[18] (2014). "Mie". http://en.wikipedia.org/wiki/Gustav_Mie. 3, 4.4.2

[19] (2014a). "NASA: NASA2Explore". http://www.flickr.com/photos/nasa2explore. 6.7

[20] (2014b). "NASA: Space Station Gallery". http://spaceflight.nasa.gov/gallery/images/station/. 6.7

[21] (2014c). "NASA: Visible Earth". http://visibleearth.nasa.gov/. 6.7

[22] (2014). "O'Neil: Real-time atmospheric scattering". http://www.gamedev.net/page/resources/_/technical/ graphics-programming-and-theory/ real-time-atmospheric-scattering-r2093. 3

[23] (2014b). "The Physics Classroom: Polarization". http://www.physicsclassroom. com/class/light/u12l1e.cfm\#scat. 2.5

[24] (2014c). "Polarizability". http://en.wikipedia.org/wiki/Polarizability. 4.2

[25] (2014d). "Rational Function". http://en.wikipedia.org/wiki/Rational_function. 5.2.1

[26] (2014). "Rayleigh". http://pt.wikipedia.org/wiki/John_William_Strutt. 3

[27] (2014). "Refractive index". http://en.wikipedia.org/wiki/Refractive_index. 1 
Um estudo sobre técnicas de renderização do fenômeno de dispersão atmosférica

[28] (2014b). "Scattering cross-section".

http://en.wikipedia.org/wiki/Scattering_cross-section. 4.4.1

[29] (2014). "Simon Stevin".

http://en.wikipedia.org/wiki/Simon_Stevin. 4.1

[30] (2014b). "Stokes parameters".

http://en.wikipedia.org/wiki/Stokes_parameters. 4.2

[31] Bonin, K. and Kresin, V. (1997). Electric-dipole Polarizabilities of Atoms, Molecules, and Clusters. World Scientific. 4.2

[32] Bruneton, E. and Neyret, F. (2008). "Precomputed atmospheric scattering". In Proceedings of the Nineteenth Eurographics conference on Rendering, EGSR'08, pages 1079-1086, Aire-la-Ville, Switzerland, Switzerland. Eurographics Association. 1.2, 3, 5, 5.1, 3

[33] Chapman, S. (1931). "The absorption and dissociative or ionizing effect of monochromatic radiation in an atmosphere on a rotating earth". Proceedings of the Physical Society, 43(1), pp. 26. 5.2.3

[34] Cornette, W. M. and Shanks, J. G. (1992). "Physically reasonable analytic expression for the single-scattering phase function". Appl. Opt., 31(16), pp. 3152-3160. 4.4.2

[35] Dowling, J. E. (1987). The Retina: An Approachable Part of the Brain. Belknap Press of Harvard University Press. 2.11.1

[36] Elek, O. and Kmoch, P. (2010). "Real-time spectral scattering in large-scale natural participating media". In Proceedings of the 26th Spring Conference on Computer Graphics, SCCG '10, pages 77-84, New York, NY, USA. ACM. 1.2, 3

[37] Engel, W. (2012). GPU PRO 3: Advanced Rendering Techniques, Volume 3. CRC Press. (document), 5.13

[38] Evans, F. (2012). "Atmospheric Radiative Transfer and Remote Sensing". Technical report, University of Colorado. 2.7

[39] Frenkel, J. (1996). Princípios de Eletrodinâmica Clássica. EdUSP. 2.6

[40] Henyey, L. G. and Greenstein, J. L. (1941). "Diffuse radiation in the Galaxy". The Astrophysical Journal, 93, pp. 70-83. 4.4.2

[41] Hergert, Wolfram; Wriedt, T. (2012). The Mie Theory. Springer Series in Optical Sciences, Vol. 169. Springer. 4.4.2 
Um estudo sobre técnicas de renderização do fenômeno de dispersão atmosférica

[42] Hoffman, N. and Preetham, A. J. (2003). "Graphics programming methods". chapter Real-time light-atmosphere interactions for outdoor scenes, pages 337-352. Charles River Media, Inc., Rockland, MA, USA. 3

[43] J.J. Vos, P. W. (1971). On the derivation of the foveal receptor primaries. Elsevier. 2.11.1

[44] Kaneda, K.; Okamoto, T.; Nakamae, E.; and Nishita, T. (1991). "Photorealistic image synthesis for outdoor scenery under various atmospheric conditions.". The Visual Computer, 7(56), pp. 247-258. 3

[45] Klassen, R. V. (1987). "Modeling the Effect of the Atmosphere on Light". ACM Trans. Graph., 6(3), pp. 215-237. 3

[46] Kocifaj, M. (1996). "Optical air mass and refraction in a Rayleigh atmosphere". Contributions of the Astronomical Observatory Skalnate Pleso, 26, pp. 23-30. 5.2.3, 5.2.4

[47] Kunzi, K. (2003). "Environmental Physics I:The Atmosphereg". Technical report, University of Bremen. 2.7

[48] Laboratory, O. (2007). "Rayleigh scattering by gas molecules: Why is the Sky blue". Technical report, Condensed Matter Physics - University of Birmingham. 4.4.1

[49] Mead, C. A. (1960). "Theory of the Complex Refractive Index". Phys. Rev., 120, pp. 854-859. 1

[50] Michaelsen, J. (2010). "Scattering and Absorption". Technical report, University of California, Santa Barbara. 2.7

[51] Mishchenko, M.; Travis, L.; and Lacis, A. (2002). Scattering, Absorption, and Emission of Light by Small Particles. Cambridge University Press. 2.4, 4.4 .2

[52] N. Cézard, C. Besson, A. D.-B. L. L. (2009). "Airflow Characterization by Rayleigh-Mie Lidars". Journal Aerospace Lab. Onera - Optical Diagnostics of Flows. 2.7

[53] Nishita, Dobashi, K. Y. (1996). "Display method of the sky color taking into account multiple scattering". In Proceedings of Pacific Graphics, pages 117-132. 3

[54] Nishita, T.; Sirai, T.; Tadamura, K.; and Nakamae, E. (1993). "Display of the earth taking into account atmospheric scattering". In Proceedings of the 
Um estudo sobre técnicas de renderização do fenômeno de dispersão atmosférica

20th annual conference on Computer graphics and interactive techniques, SIGGRAPH '93, pages 175-182, New York, NY, USA. ACM. 3, 3

[55] O'Neil (2005). Accurate atmospheric scattering. GPU Gems 2. Addison-Wesley Professional. 3

[56] Oughstun, K. E. and Cartwright, N. A. (2003). "On the Lorentz-Lorenz formula and the Lorentz model of dielectric dispersion". Technical report, College of Engineering Mathematics, University of Vermont, Burlington. 4.2, 4.4 .2

[57] Piskozub, J. and McKee, D. (2011). "Effective scattering phase functions for the multiple scattering regime". Technical report, Institute of Oceanology, Polish Academy of Sciences and Physics Department, University of Strathclyde. 4.4.1

[58] Preetham, A. J.; Shirley, P.; and Smits, B. (1999). "A practical analytic model for daylight". In Proceedings of the 26th annual conference on Computer graphics and interactive techniques, SIGGRAPH '99, pages 91-100, New York, NY, USA. ACM Press/Addison-Wesley Publishing Co. 3, 3

[59] Ryder, C. L. (2011). "Summary of Phase Function from scatter90 and for RFM-DISORT". Technical report, University of Reading. 4.4.1

[60] Schafhitzel, T.; Falk, M.; and Ertl, T. (2007). "Real-time rendering of planets with atmospheres". In In WSCG International Conference in Central Europe on Computer Graphics, Visualization and Computer Vision. 3

[61] Schüler, C. (2012). "An Approximation to the Chapman Grazing-Incidence Function for Atmospheric Scattering". In Engel, W., editor, GPU Pro 3, pages 105-118. A K Peters. 1.2, 3, 5, 5.2

[62] Sengupta, D. and Sarkar, T. (2003). "Maxwell, Hertz, the Maxwellians, and the early history of electromagnetic waves". Antennas and Propagation Magazine, IEEE, 45(2), pp. 13-19. 4.4.2

[63] Sherman, W. and Craig, A. (2002). Understanding Virtual Reality: Interface, Application, and Design. The Morgan Kaufmann Series in Computer Graphics. Elsevier Science. 1.1

[64] Steven L. Jacques, S. A. P. (1998). "Definition and units of scattering coefficient". Technical report, Biomedical Optics - Oregon Graduate Institute. 4.4 .1 
Um estudo sobre técnicas de renderização do fenômeno de dispersão atmosférica

[65] Strutt, J. W. (1871a). "On the light from the sky, its polarization and colour". Philosophical Magazine Series 4, 41(271), pp. 107-120. 4.4.1

[66] Strutt, J. W. (1871b). "On the scattering of light by small particles". Philosophical Magazine, 41, pp. 447-454. 4.4.1

[67] Strutt, J. W. (2009). On the Transmission of Light through an Atmosphere containing Small Particles in Suspension, and on the Origin of the Blue of the Sky. Cambridge University Press. 4.4.1

[68] Thomas Kment, M. R. and Zotti, G. (2006). "Modelling of Daylight for Computer Graphics". Technical report, Institute of Computer Graphics Algorithms. 3

[69] Tilstra, L.; KNMI.; Schutgens, N.; Stammes, P.; and Instituut, K. N. M. (2003). Analytical Calculation of Stokes Parameters $Q$ and $U$ of Atmospheric Radiation. Scientific report. Koninklijk Nederlands Meteorologisch Instituut. 4.2

[70] W. Hahn, D. (2009). "Light Scattering Theory". Technical report. 2.6, 4.4.1

[71] Wallace, J. M. and Hobbs, P. V. (1977). Atmospheric Science: An Introductory Survey. Academic Press. 2.7

[72] Wenzel, C. (2006). "Real-time atmospheric effects in games". In ACM SIGGRAPH 2006 Courses, SIGGRAPH '06, pages 113-128, New York, NY, USA. ACM. 3

[73] Zotti, G.; Wilkie, A.; and Purgathofer, W. (2007). "A Critical Review of the Preetham Skylight Model". In Skala, V., editor, WSCG ' 2007 Short Communications Proceedings I, pages 23-30. University of West Bohemia. 3 


\section{Apêndices}

\section{Apêndice A: Calculo da transmitância na técnica de Bruneton e Neyret}

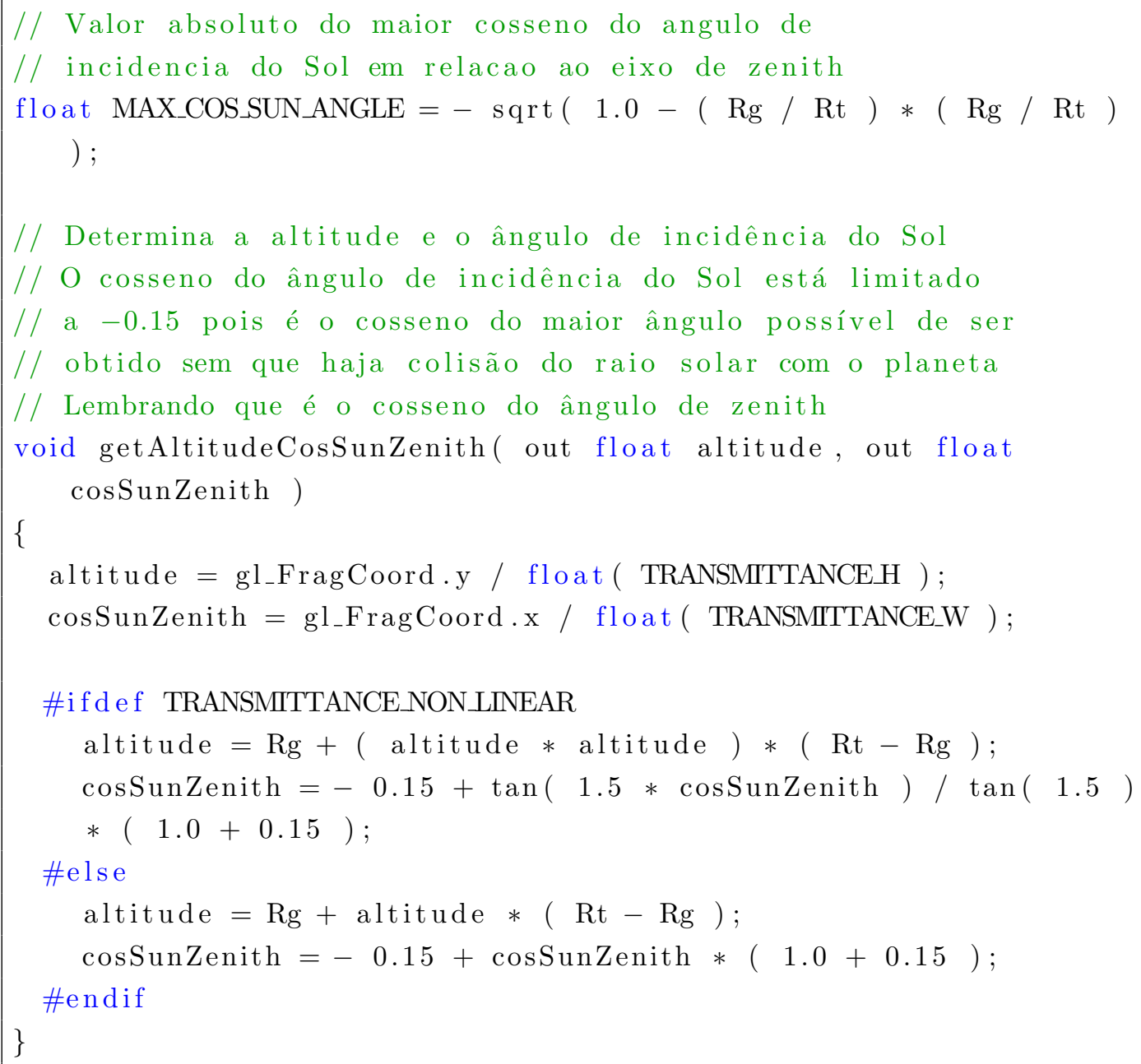

Código-fonte : Cálculo da altitude e o ângulo de incidência do Sol

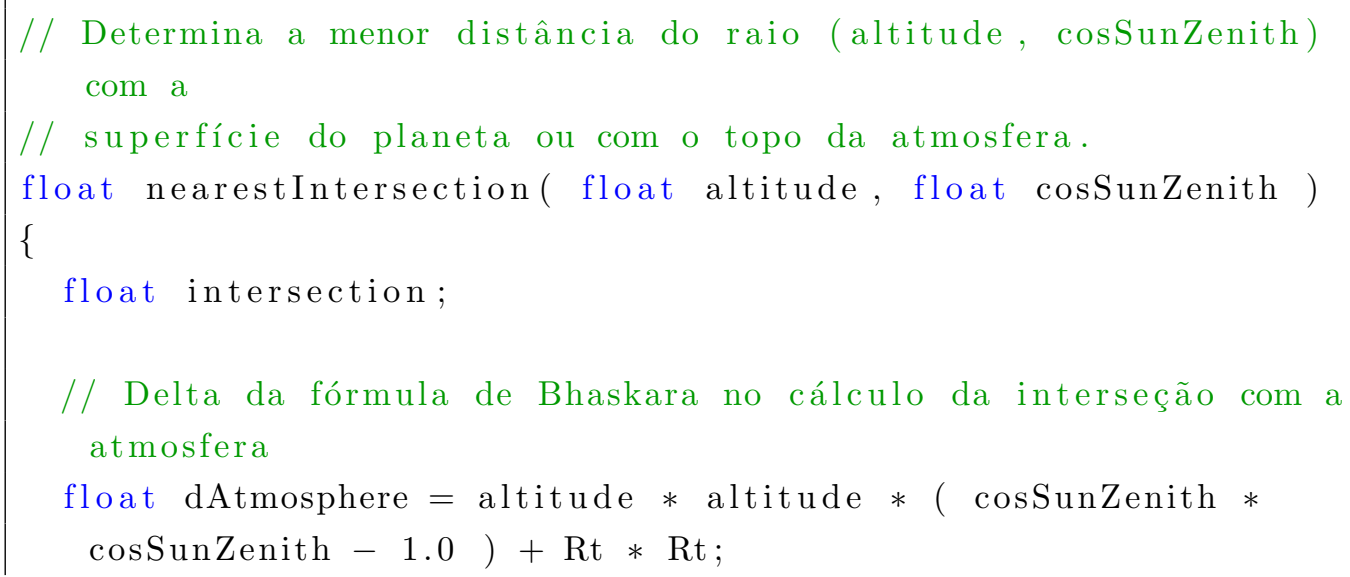


float intersectionAtmosphere $=-$ altitude $* \cos$ SunZenith + sqrt ( dAtmosphere );

intersection $=$ intersection Atmosphere;

// Delta da fórmula de Bhaskara no cálculo da interseção com o planeta

float dPlanet $=$ altitude $*$ altitude $*(\cos S u n Z e n i t h *$ cosSunZenith -1.0$)+\operatorname{Rg} * \mathrm{Rg}$;

if $($ dPlanet $>=0.0)$

\{

float intersectionPlanet $=-$ altitude $*$ cosSunZenith sqrt (dPlanet);

if ( intersectionPlanet $>=0.0$ )

\{

intersection $=\min$ ( intersectionAtmosphere, intersection Planet );

$$
\text { \} }
$$

\}

return intersection;

\}

Código-fonte : Cálculo da menor distância

float opticalDepth ( float H, float altitude, float cosSunZenith ) \{

float result $=0.0$

// Divide o menor caminho em "TRANSMITTANCEINTEGRAL_SAMPLES" pedaços

float $\mathrm{dx}=$ nearestIntersection ( altitude , cosSunZenith ) / flo a t ( TRANSMITTANCE_INTEGRAL_SAMPLES ) ;

float $\mathrm{xi}=0.0$;

float $\mathrm{yi}=\exp (-($ altitude $-\mathrm{Rg}) / \mathrm{H}) ; / /$ Densidade atmosférica no altitude do observador

for $($ int $\mathrm{i}=1 ; \mathrm{i}<=$ TRANSMITTANCEINTEGRALSAMPLES; $+\mathrm{i}$ ) \{

// Seleciona o pedaço

float $\mathrm{xj}=$ float $(\mathrm{i}) * \mathrm{dx}$;

// Calcula a densidade atmosférica no pedaço selecionado

float alt $=\exp (-(\operatorname{sqrt}($ altitude $*$ altitude $+x j * x j+$ $2.0 * \mathrm{xj} *$ altitude $* \cos$ SunZenith ) $-\mathrm{Rg}) / \mathrm{H})$; 


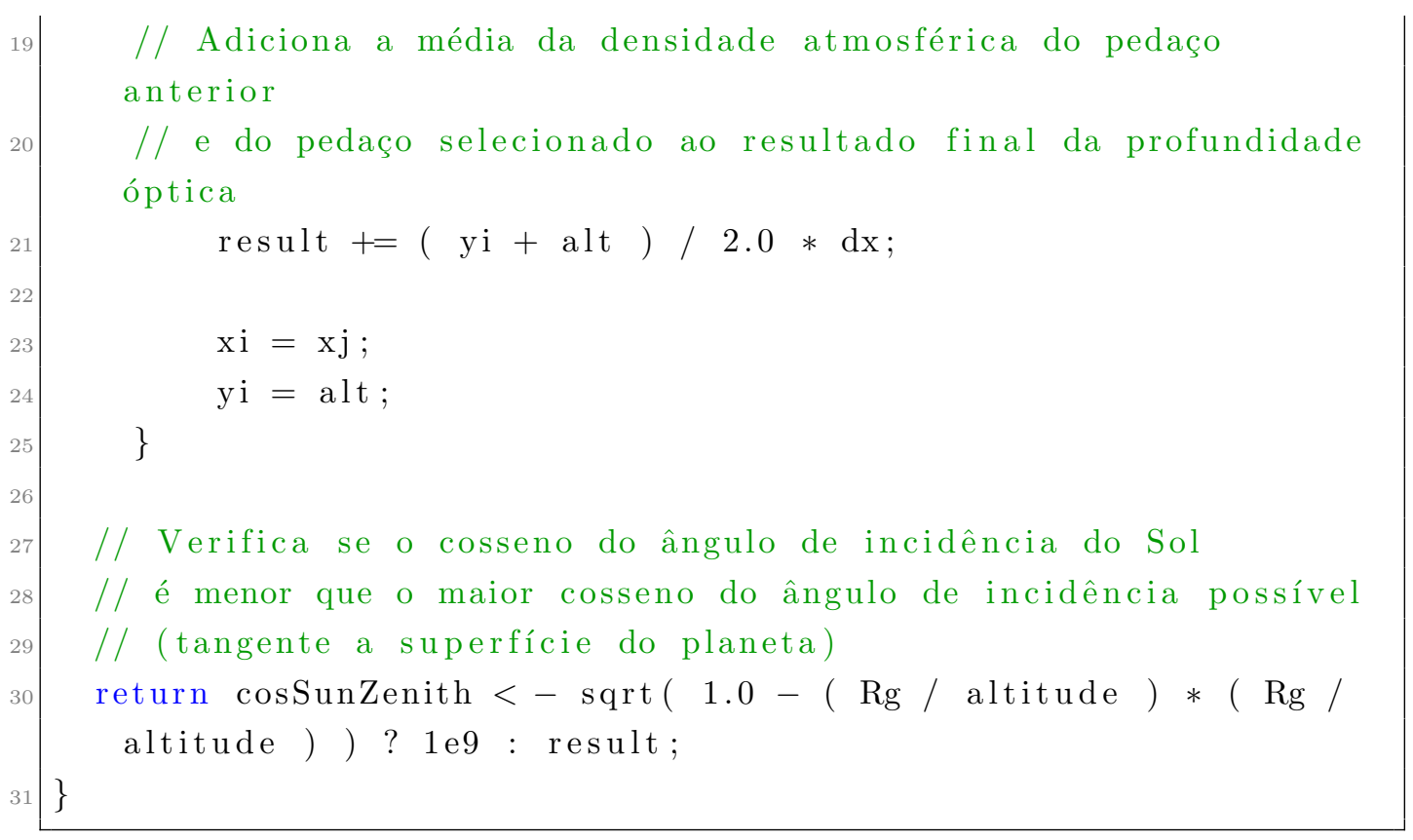

Código-fonte : Cálculo da profundidade óptica

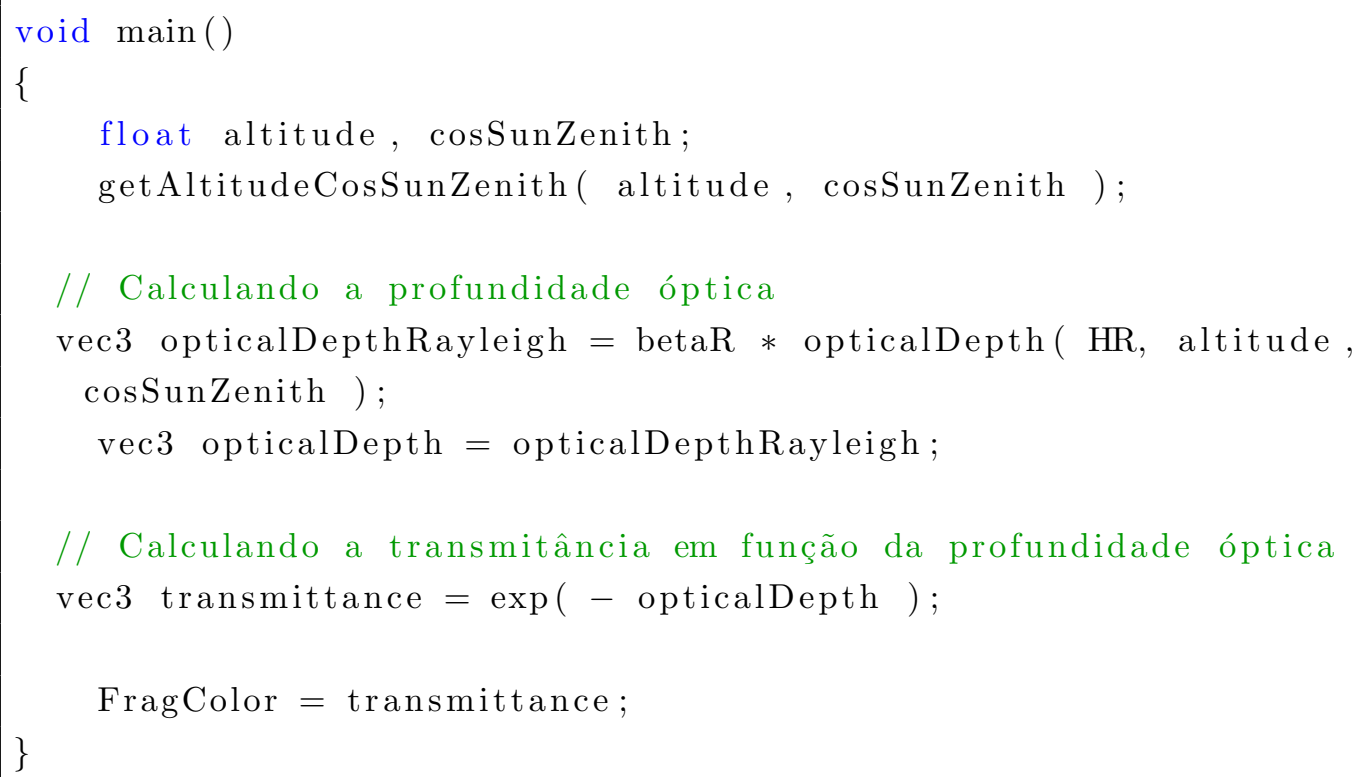

Código-fonte : Cálculo geral da transmitância 
Um estudo sobre técnicas de renderização do fenômeno de dispersão atmosférica

\section{Apêndice B: Calculo da função de Chapman na técnica de Schuler}

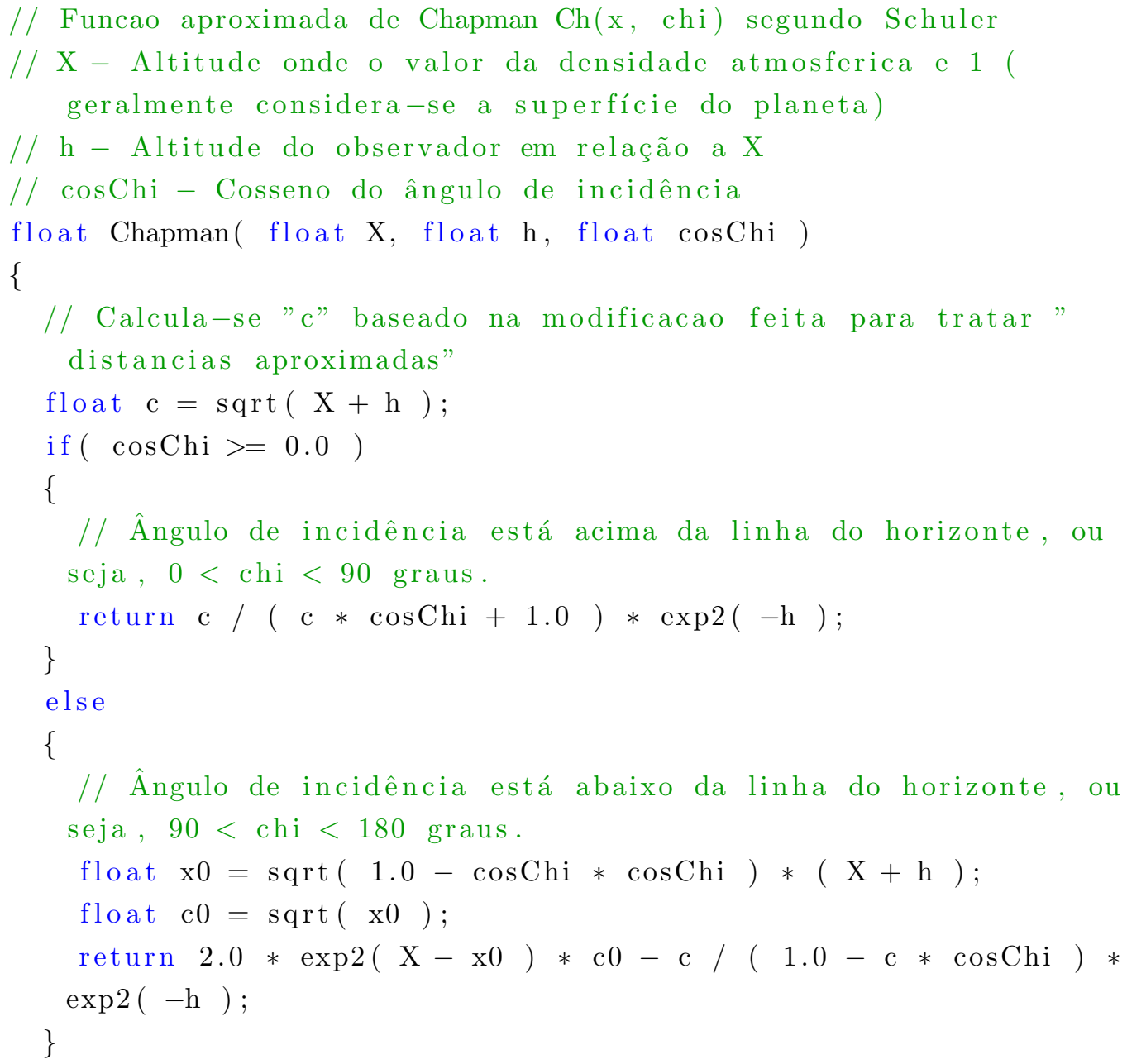

Código-fonte : Cálculo da função de Chapman 